\title{
Optimism, the natural placebo : cognitive, behavioural and motivational mechanisms of resilience towards pain
}

\author{
Citation for published version (APA):
}

Hanssen, M. M. (2014). Optimism, the natural placebo : cognitive, behavioural and motivational mechanisms of resilience towards pain. [Doctoral Thesis, Maastricht University]. Maastricht University. https://doi.org/10.26481/dis.20141205mh

Document status and date:

Published: 01/01/2014

DOI:

10.26481/dis.20141205mh

Document Version:

Publisher's PDF, also known as Version of record

\section{Please check the document version of this publication:}

- A submitted manuscript is the version of the article upon submission and before peer-review. There can be important differences between the submitted version and the official published version of record. People interested in the research are advised to contact the author for the final version of the publication, or visit the DOI to the publisher's website.

- The final author version and the galley proof are versions of the publication after peer review.

- The final published version features the final layout of the paper including the volume, issue and page numbers.

Link to publication

\footnotetext{
General rights rights.

- You may freely distribute the URL identifying the publication in the public portal. please follow below link for the End User Agreement:

www.umlib.nl/taverne-license

Take down policy

If you believe that this document breaches copyright please contact us at:

repository@maastrichtuniversity.nl

providing details and we will investigate your claim.
}

Copyright and moral rights for the publications made accessible in the public portal are retained by the authors and/or other copyright owners and it is a condition of accessing publications that users recognise and abide by the legal requirements associated with these

- Users may download and print one copy of any publication from the public portal for the purpose of private study or research.

- You may not further distribute the material or use it for any profit-making activity or commercial gain

If the publication is distributed under the terms of Article $25 \mathrm{fa}$ of the Dutch Copyright Act, indicated by the "Taverne" license above, 


\section{OPTIMISM, THE NATURAL PLACEBO}

COGNITIVE, BEHAVIOURAL AND MOTIVATIONAL MECHANISMS

OF RESILIENCE TOWARDS PAIN 
Copyright @ Marjolein Marie-Paule Hanssen, Maastricht 2014

Layout, typesetting and printing: Michał Sławiński, thesisprint.eu

Cover Design: Els Gielen \& Marjolein Hanssen

Photo Pills @ Els Gielen

Photo Dandelion @ Eric Sefton 


\title{
OPTIMISM, \\ THE NATURAL PLACEBO
}

COGNITIVE, BEHAVIOURAL AND MOTIVATIONAL MECHANISMS OF RESILIENCE TOWARDS PAIN

\author{
PROEFSCHRIFT \\ ter verkrijging van de graad van doctor aan de Universiteit Maastricht, \\ op gezag van de Rector Magnificus, Prof. Dr. L. L. G. Soete, \\ volgens het besluit van het College van Decanen, \\ in het openbaar te verdedigen \\ op vrijdag 5 december 2014 om 16:00 uur
}

door

Marjolein Marie-PAule Hanssen 
PROMOTOR

Prof. Dr. M. L. Peters

\section{COPROMOTOR}

Dr. L. M. G. Vancleef

\section{BEOORDELINGSCOMMISSIE}

Prof. Dr. P. Muris (voorzitter)

Prof Dr. Geert Crombez, Universiteit Gent, België

Dr. M. Dewitte

Prof. Dr. A. W. M. Evers, Universiteit Leiden, Nederland

Dr. C. Martijn

The research presented in this dissertation was performed at the department of Clinical Psychological Science (CPS) of Maastricht University.

This dissertation was financially supported by NWO (grant nr. 453-07-005), Maastricht University. 


\section{TABLE OF CONTENTS}

$\begin{array}{lll}\text { CHAPTER } 1 & \text { Introduction } & 7\end{array}$

CHAPTER 2 What does it mean to be an optimist in an ambiguous world? 29 Investigating positive versus negative interpretation patterns of optimists

CHAPTER 3 More optimism, less pain!

The influence of generalized and pain-specific expectations on experienced cold-pressor pain

CHAPTER 4 Optimism lowers pain:

Evidence of the causal status and underlying mechanism(s)

CHAPTER 5 Optimism, motivational coping and well-being: evidence supporting the importance of flexible goal adjustment

ChAPTER 6 General discussion

Valorisation Addendum

Summary

Samenvatting

Dankwoord 

Introduction

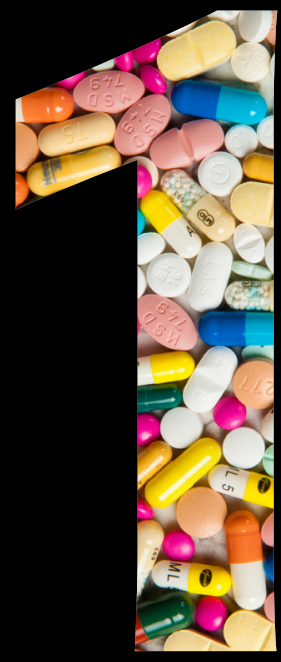



Chronic pain is a major health problem, impacting heavily on people's lives. Not only does it interfere with individuals' daily activities, but also with important goals in their lives. Worries about not being able to be a good parent, colleague or musician because of pain complaints are exemplary for the tough reality of chronic pain.

The statistics do not lie either. A large-scale survey revealed that approximately 19\% of the European population suffers from chronic pain. The lion share of this group has had pain complaints for several consecutive years. Osteoarthritis, rheumatoid arthritis, herniated or deteriorated discs, trauma or surgery and migraine headaches were reported among the causes of pain, although one out of ten of the participants could not report the cause of their pain. In $25 \%$ of the chronic pain population, the pain had impacted on their employment status and in $21 \%$ the pain had led to the diagnosis of depression at a certain point in time (Breivik, Collett, Ventafridda, Cohen, \& Gallacher, 2006). Considering the serious consequences of chronic pain, it is important to know what constitutes the syndrome of chronic pain and what contributes to its enormous impact.

The International Association for the Study of Pain (1986) has defined pain as 'an unpleasant sensory and emotional experience associated with actual or potential tissue damage, or described in terms of such damage.' Chronic pain has been defined as 'pain which persists beyond normal tissue healing' or pain that exceeds a duration of three months. Following IASP recommendations, it becomes clear that tissue damage is not a prerequisite for chronic pain. This means that pain can exist without tissue damage or that pain can persist long after it has lost its adaptive function of signalling danger.

Descartes' legacy of mind-body dualism makes it difficult to understand that pain can exist without or beyond tissue damage. Unfortunately however, it is a fact that biomedical science largely fails at providing a satisfactory solution to the problem of chronic pain. Regardless of the cause of pain, effects of medical treatments are insufficient in a significant subset of chronic pain sufferers (Breivik, et al., 2006). In the last decades, a biopsychosocial vision on pain has been adopted (Engel, 1997; Gatchel, Peng, Peters, Fuchs, \& Turk, 2007; Turk \& Okifuji, 2002; Waddell, 2004). In this conception, pain is the result of the complex interplay of biological, psychological and social factors.

The psychology of pain proved to be a fruitful area of research. Originally, psychological research focussed mainly on discovering risk factors for the onset and maintenance of persistent pain. The identification of psychological risk factors, such as pain catastrophizing, fear of pain and pain coping contributed to the understanding of the subjective experience of pain (Keefe, Rumble, Scipio, Giordano, \& Perri, 2004). This focus on 'fixing what's wrong' led to the development of the cognitive-behavioural fear-avoidance model of pain, which remains to date the leading model in pain psychology (Crombez, Eccleston, Van Damme, Vlaeyen, \& Karoly, 2012; Vlaeyen \& Linton, 2000, 2012).

In pain research, like in other areas of psychology, the exclusive focus on 'fixing what's wrong' was extended with an interest in 'building what's strong' (Karoly \& RuehIman, 2006; Luthar, Cicchetti, \& Becker, 2000; Masten \& Reed, 2002; Olsson, Bond, Burns, Vella-Brodrick, \& Sawyer, 
2003). Protective factors such as self-efficacy, readiness to change and acceptance have been associated with higher adjustment to pain (Keefe, et al., 2004). Dispositional optimism has been depicted as an important resilience factor leading to less pain sensitivity (Costello, et al., 2002; Geers, Wellman, Helfer, Fowler, \& France, 2008) and higher well-being despite pain (Allison, Guichard, \& Gilain, 2000; Novy, Nelson, Hetzel, Squitieri, \& Kennington, 1998). Nevertheless, questions regarding the causal status of optimism and the underlying mechanisms of the optimism-pain link remained largely unanswered. This dissertation aims at addressing the main remaining questions regarding optimism as a resilience factor towards pain and (pain-related) well-being.

\section{DISPOSITIONAL OPTIMISM}

The term optimism emerges recurrently in both folk wisdom and in several distinct theoretical frameworks. Therefore a definition/conceptualisation addressing key topics of the optimism construct that is the subject of this dissertation, i. e. dispositional optimism, will be provided first.

\section{A definition}

Dispositional optimism is a stable personality trait characterized by a generalized and global positive outcome expectancy (Carver \& Scheier, 2002; Scheier \& Carver, 1985). In other words, optimists generally expect good things to happen to them, while pessimists expect bad thing to happen to them. Dispositional optimism is a future-oriented construct, as it reflects positive future expectations across a wide range of outcomes. The source of these positive outcomes can be either internal (due to the self) or external (caused by for instance others or luck). Dispositional optimism is not to be mistaken from other conceptualisations of optimism, such as an optimistic attributional style and unrealistic optimism.

An optimistic attributional style is characterized by external, temporal and local attributions of negative events and internal, stable and global attributions of positive events. The opposite of this pattern has been related to depression. The optimistic attributional style differs from dispositional optimism in the sense that it is past-oriented (events that (will) occur are explained by the attributions made about events in the past). Moreover, in contrast to dispositional optimism, an optimistic attributional style includes causal attributions of success or failure (Peterson \& Seligman, 1984).

Unrealistic optimism describes a specific form of optimistic expectations about the future (Radcliffe \& Klein, 2002; Weinstein, 1980, 1989). It refers to the expectancy that negative events are more likely to happen to others then to oneself. Weinstein (1980) postulates that unrealistic optimism goes beyond a positive outlook, but rather describes an error in judgment. Unrealistic optimism has therefore been related to an optimistic bias as an underestimation of personal risk. According to Radcliffe and Klein (2002), dispositional optimism can be differentiated from unrealistic optimism with regard to 3 characteristics: specificity, social comparison and accuracy. In 
contrast to dispositional optimism, unrealistic optimism concerns specific expectations regarding ones' own risk in comparison to others'. The lack of accuracy inherent to the underestimating personal risks seems to be exemplary for unrealistic but not dispositional optimism (Radcliffe \& Klein, 2002).

\section{The expectancy-value model of motivation}

The definition of dispositional optimism is grounded in the expectancy-value model of motivation (Carver \& Scheier, 1998). The basic assumption of this self-regulation model is that all human behaviour is organised around goals, which are defined as internal representations of a desired state (Austin \& Vancouver, 1996). The expectancy-value model proposes two factors that determine goal-directed behaviour. First, the value or importance of a goal is a key motivator. The higher a goal is valued, the more action it will provoke. Second, motivation is determined by the expectation of attainability of a goal. While a sense of doubt impairs effort, confidence leads to continued effort even in the face of difficulty.

Both goals and expectations vary from very broad and abstract to very specific and concrete (Armor \& Taylor, 1998; Carver \& Scheier, 1998). Carver and Scheier (1998) describe a goal hierarchy that consists of goals at several levels of concreteness. On top of the hierarchy are 'be' goals or principles one needs to follow to accomplish ones'ideal self. On the next level are activities or programs that people engage in to meet these principles, called 'do' goals. The lowest level in the hierarchy describes the motor sequences necessary for the execution of these programs, referred to as 'motor control' goals.

In a comparable manner, dispositional optimism as a global generalized positive outcome expectancy forms the highest level in a comparable hierarchy of outcome expectancies. Optimists generally expect more positive than negative outcomes in life. Specific outcome expectancies describe positive or negative expectations towards specific events (Armor \& Taylor, 1998).

It has been argued that the predictive value of expectations towards goal-directed actions is probably the highest when their specificity levels match. However, dispositional optimism as a generalized outcome expectation might guide specific expectations concerning new, uncertain and challenging situations (Scheier \& Carver, 1985). It is suggested that optimists' general sense of confidence leads them to continued pursuit of goals, even in the face of adversity. In contrast, pessimism leads to doubt and this might encourage disengagement from goals (Carver \& Scheier, 2002; Carver, Scheier, \& Segerstrom, 2010).

\section{The source of optimism}

While some people have an extremely positive outlook on life, others might be referred to as 'true pessimists.' Interindividual differences in optimism led researchers to study which factors contribute to a person's level of optimism. 
It seems that dispositional optimism partially is the result of nature. Functional analyses suggest a genetic base of optimism, which is linked to the oxytocin receptor gene (OXTR) (Saphire-Bernstein, Way, Kim, Sherman, \& Taylor, 2011). The heritability of optimism has been supported by twin studies (Alessandri, et al., 2010; Mosing, Zietsch, Shekar, Wright, \& Martin, 2009; Plomin, et al., 1992). In a large-scale twin-study (Plomin, et al., 1992), the genetic contribution to the level of dispositional optimism was estimated at approximately 25 percent.

On the other hand, the level of optimism also seems to be influenced by nurture. Optimists have been ascribed a history of positive events (Scheier \& Carver, 1985). Scheier, Carver and Bridges (1994) assume that success- and fail experiences, as well as the subsequent reactions of caregivers during childhood impact on the development of dispositional optimism. Secure attachment and long-lasting affective relationships have been associated with higher levels of optimism in children (Carver \& Scheier, 2002).

\section{The changeability of optimism}

Although dispositional optimism is conceptualized as a stable personality trait, researchers discovered it is changeable in adult life (Atienza, Stephens, \& Townsend, 2004; Segerstrom, 2007). Atienza, Stephens and Townsend (2004) found that stressors negatively impacted on optimistic expectations in women over a period of one year. Segerstrom (2007) reported on the mutual influence of optimism and life experiences. She followed university students for a period of 10 years and established a bidirectional relation between growth of resources and increases in the level of optimism.

The relative changeability of dispositional optimism inspired researchers to work on interventions aimed at changing the level of optimism. One of the interventions that was developed for this purpose is the Best Possible Self(=BPS) writing and visualization exercise (Peters, Flink, Boersma, \& Linton, 2010), based on the work of King (2001). King discovered that subjects who wrote about their best possible self in the future on 4 consecutive days reported higher levels of subjective well-being. Other researchers demonstrated the Best Possible Self exercise induces positive emotion and leads to higher levels of both psychological and physical well-being (Austenfeld, Paolo, \& Stanton, 2006; Sheldon \& Lyubomirsky, 2006). Peters and colleagues (Meevissen, Peters, \& Alberts, 2011; Peters, et al., 2010; Peters, Meevissen, \& Hanssen, 2013) added an imagery component to the Best Possible Self intervention and used it successfully to increase individual's level of optimism. The changeability of optimism might not only offer possibilities for experimental work, but might also have clinical implications.

\section{Measuring optimism}

Scheier and Carver (1985) developed the Life Orientation Test as a trait measure for dispositional optimism. The Life Orientation Test consists of items such as such 'In uncertain times, I usually expect the best' or 'If anything can go wrong for me, it will' to measure global outcome expectations. A total score of the Life Orientation Test can be obtained by summing up the scores of the 
positively framed items and the reversed scores of the negatively framed items. A higher total score indicates a higher level of dispositional optimism. Scores for the optimism and pessimism subscale can be calculated by summing up positive and negative items.

The Life Orientation Test was developed to measure dispositional optimism as a unipolar construct with optimism and pessimism as opposite ends of a continuum. However, the dimensionality of the Life Orientation Test has been questioned (Chang, D'Zurilla, \& Maydeu-Olivares, 2004; Kubzansky, Kubzansky, \& Maselko, 2004; Marshall, Wortman, Kusulas, Hervig, \& Vickers, 1992). It has been advised to stay attentive to the possibility of discriminant predictive value of the optimism and pessimism subscales (Hanssen \& Peters, 2009; Vinck, Wels, Arickx, \& Vinck, 1998). Not only the optimism continuum, but also the specificity of optimism was subject to criticism. While certain authors ascribe the effect of optimism to overlap with constructs such as self-mastery (Marshall \& Lang, 1990) or negative affectivity/neuroticism (Robbins, Spence, \& Clark, 1991; Smith, Pope, Rhodewalt, \& Poulton, 1989), others reported on the discriminant validity of the Life Orientation Test (Hanssen \& Peters, 2009).

In 1994, the Life Orientation Test was superseded by the Life Orientation Test Revised. The Life Orientation Test Revised (Scheier, et al., 1994) is briefer than the original, including only 3 positive and 3 negative items instead of 4 items on each subscale. Certain items were omitted or rephrased in the revised version, leading to higher correlations between the subscales of the LOT-R and less overlap with constructs such as coping. Both versions include the same 4 filler items that were added to conceal measurement purposes. The LOT-R showed good internal consistency, stability over time and unique predictive value over trait anxiety, self-mastery and self-esteem (Scheier, et al., 1994).

For research purposes, not only a trait but also a state measure of optimism was developed. A momentary state of optimism is assessed by means of instruments measuring several specific outcome expectancies. The Subjective Probability Task (SPT; MacLeod, 1996) consists of 20 negative and 10 positive future expectations, such a 'You will have health problems' or 'You will make good and lasting friendships.' This measure provided a good basis for the Future Expectations Scale (=FEX) that was developed by our group and can be used as a manipulation check for measuring a state level of optimism in the lab. This measure consists of 10 positive and 10 negative possible future events for which participants provide probability ratings. It is presumed that total scores of probability ratings for positive and negative future events provide a sound measure for momentary optimistic/pessimistic state. Further details about the Future Expectations Scale will be reported in chapter 4.

\section{DisPositTIONAL OPTIMISM AS A NATURAL PLACEBO}

In 1811, the term placebo was defined as 'an epithet given to any medicine adapted more to please than to benefit the patient' in a medical dictionary (Hooper, 1811). Not only a placebo but also optimism has long been considered a characteristic that merely pleases the one harbouring 
it instead of making a real difference in individuals' well-being. It has become difficult to ignore the amalgam of positive outcomes that dispositional optimism has been related to. However, questions can be raised pertaining to the risks of optimism and the causality of the associations.

\section{Optimism and positive outcomes}

In general, optimists seem to lead longer (Chida \& Steptoe, 2008; Giltay, Geleijnse, Zitman, Hoekstra, \& Schouten, 2004) and more successful lives (Segerstrom, 2007; Solberg Nes, Evans, \& Segerstrom, 2009).

In the social domain, optimists have broader social networks (MacLeod \& Conway, 2005), more stable friendships (Geers, Reilly, \& Dember, 1998) and higher levels of perceived social support and relationship satisfaction (Brisette, Scheier, \& Carver, 2002; Srivastava, McGonigal, Richards, Butler, \& Gross, 2006).

Optimism also shows a significant association with general psychological well-being, as becomes clear from review articles based on a vast amount of evidence (Carver, et al., 2010; Scheier \& Carver, 1992). Especially in times of adversity, optimists seem to cope better with difficulties (Scheier \& Carver, 1985; Scheier, et al., 1994). For instance, optimism protects women from distress or depressive feelings postpartum (Carver \& Gaines, 1987), following unsuccessful attempts of in vitro fertilisation (Litt, Tennen, Affleck, \& Klock, 1992) or during midlife (Bromberger \& Matthews, 1996).

Evidence for better physical health of optimists is substantiated in an extensive review by Rasmussen, Scheier and Greenhouse (2009). Optimism has been related to less physical symptoms and better physical functioning in patients with chronic diseases (de Ridder, Fournier, \& Bensing, 2004; Fournier, De Ridder, \& Bensing, 2002), during cardiac rehabilitation (Glazer, Emery, Frid, \& Banyasz, 2002) and recovering from surgery (Peters, et al., 2007; Scheier, et al., 1989).

Dispositional optimism has been linked to pain in two ways. First, optimists seem to adjust better to acute (Wright, Zautra, \& Going, 2008) and chronic pain (Mangelli, Gribbin, Buchi, Allard, \& Sensky, 2002; Novy, et al., 1998; Ramirez-Maestre \& Esteve, 2013; Sturgeon \& Zautra, 2010). Optimists show higher levels of quality of life and well-being in response to pain-related conditions such as fibromyalgia (Affleck, et al., 2001) or cancer (Allison, et al., 2000; Wong \& Fielding, 2007). Second, optimists also seem to be less sensitive to pain (Allison, et al., 2000; Costello, et al., 2002; Geers, et al., 2008; Kurtz, Kurtz, Given, \& Given, 2008). Moreover, optimism enhances the placebo effect, while pessimism has been linked to stronger nocebo effects (Geers, Kosbab, Helfer, Weiland, \& Wellman, 2007; Geers, Weiland, Kosbab, Landry, \& Helfer, 2005; Geers, Wellman, Fowler, Helfer, \& France, 2010; Morton, Watson, El-Deredy, \& Jones, 2009).

\section{The risks of optimism}

It has been argued that an optimist's perception of life might also hold risks to health and wellbeing. Optimists have been found to show less self-protective behaviour due to an underestimation of risks in relation to for instance health (Weinstein, 1989; Weinstein \& Lyon, 1999) or gam- 
bling (Gibson \& Sanbonmatsu, 2004). The tendency of optimists to continue the pursuit of goals might lead to higher levels of experienced goals conflict (Segerstrom \& Nes, 2006) and lower immune responses in case of difficult challenges (Segerstrom, 2005). However, reports on the benefits of optimism largely outweigh the ones pointing out the risks.

\section{The causality issue}

Although several studies have linked optimism to pain and (pain-related) well-being, it remains unclear whether this relationship is a causal one. It has been found that distressing life circumstances impact on people's level of optimism (Atienza, et al., 2004). It is not unthinkable that experiencing pain on a daily basis reduces optimism in pain patients.

Longitudinal (Allison, et al., 2000; Luger, Cotter, \& Sherman, 2009; Mahler \& Kulik, 2000; Peters, et al., 2007) and experimental studies (Geers, et al., 2008) suggest that optimism may be causally related to pain. However, experimentally inducing optimism could provide additional evidence for the 'natural placebo effect' of optimism on pain and/or (pain-related) well-being.

\section{THE OPTIMISM EFFECT ON PAIN: IN SEARCH FOR UNDERLYING MECHANISMS}

Although systematic research on optimism has gradually expanded during the last decades, not only the causality issue, but also questions regarding the underlying mechanisms of the optimism effect still remain. In search for possible protective processes underlying the optimism-pain association, we can benefit from what is already known in the field of pain.

Two research foci have yielded useful insights into the psychology of pain. The focus on 'fixing what's wrong' led to the detection of highly influential risk factors for pain, as depicted in the fear-avoidance model of pain (Vlaeyen \& Linton, 2000). Research aimed at 'building-what'sstrong' identified important processes of resilience for pain. Following an introduction to these approaches, candidate mechanisms for the explanation of the optimism effect on pain and wellbeing are proposed.

\section{Fixing what's wrong}

So far, the lion share of knowledge on the psychology of pain originates from studying who is at risk for chronic pain and disability. The leading paradigm in the understanding of pain disability is the fear-avoidance model of pain (Lethem, Slade, Troup, \& Bentley, 1983; Vlaeyen, Haazen, Schuerman, Kole-Snijders, \& van Eek, 1995; Vlaeyen, Kole-Snijders, Boeren, \& van Eek, 1995; Vlaeyen \& Linton, 2000). The fear-avoidance model is depicted in Figure 1.

Central in the fear-avoidance model is the cognitive appraisal or interpretation of pain. A catastrophic interpretation of pain is considered a precursor of pain-related fear, which in turn 


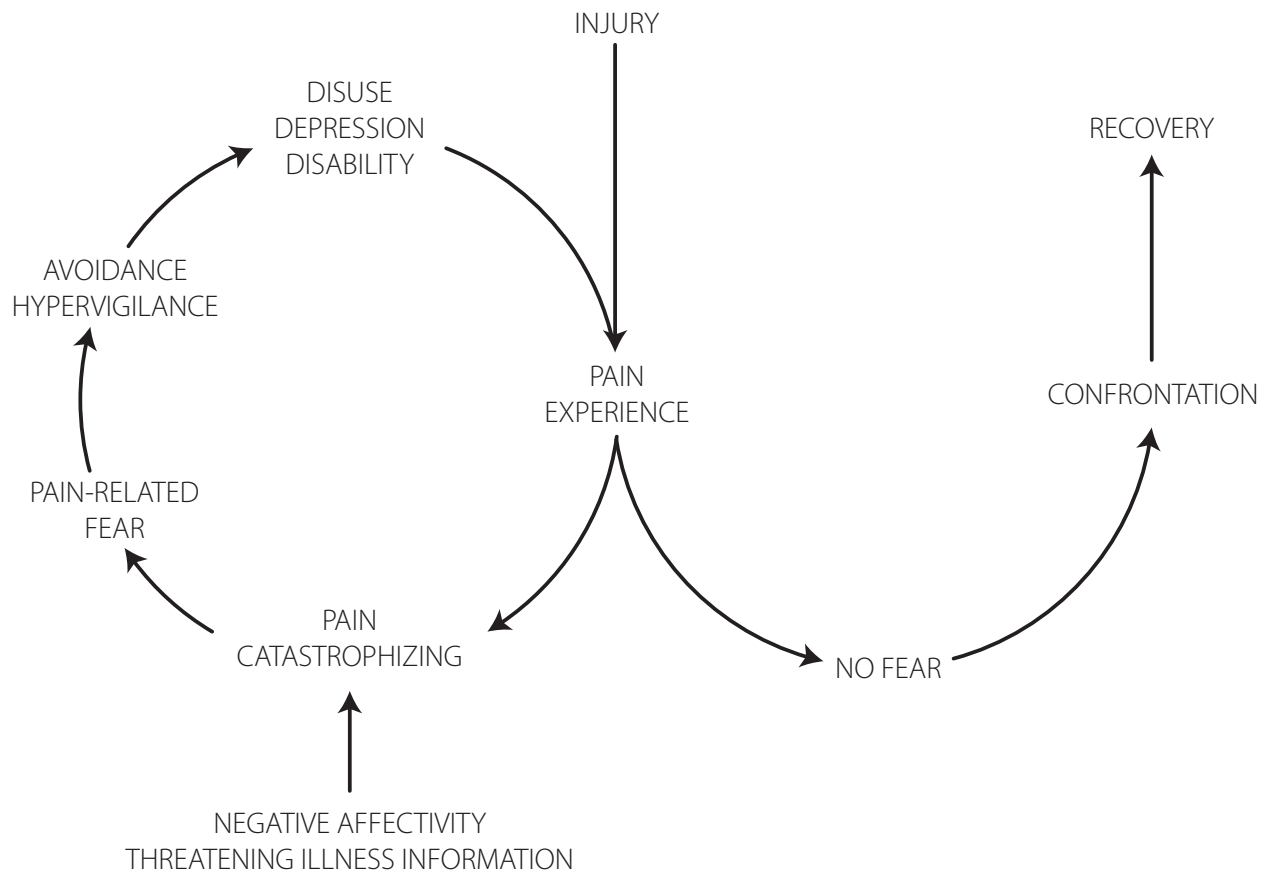

Fig. 1. Graphical display of the fear-avoidance model, reproduced with permission from Vlaeyen and Linton (2000).

might lead to defensive behaviours. The fear-avoidance model specifies two types of defensive behaviours. First, escape and avoidant behaviours affecting daily activities are aimed at preventing pain and reinjury. Second, hypervigilance or heightened attention for signals of threat serves the same purpose. In the short term, these protective behaviours might offer benefits, but in the long run they might lead to disability. Moreover, they do not offer opportunity for correcting catastrophic expectancies and beliefs (Leeuw, et al., 2007; Lethem, et al., 1983; Vlaeyen, Haazen, et al., 1995; Vlaeyen, Kole-Snijders, et al., 1995; Vlaeyen \& Linton, 2000).

The fear-avoidance model does not only stipulate a negative downward spiral, but also a positive upward spiral. The fear-avoidance model specifies that when pain is appraised in a non-threatening way, it promotes maintained engagement in daily activities, leading to functional recovery. Unfortunately, this pathway is based on rather minimal theoretical underpinning.

The basic Fear-Avoidance (FA) idea that 'fear of pain might be more disabling than the pain itself' (Crombez, Vlaeyen, Heuts, \& Lysens, 1999; Waddell, Newton, Henderson, Somerville, \& Main, 1993) fostered a true advancement in the study of pain and it received substantial support in the literature. It was shown repeatedly that when the meaning of pain is manipulated by means of direct or indirect threat instructions, this alters the experience of pain (Arntz \& Claassens, 2004; Moseley \& Arntz, 2007; Vlaeyen, et al., 2009). Negative affect and personality factors such as anxiety sensitivity facilitate negative appraisals (Asmundson, Norton, \& Vlaeyen, 2004; 
Ramirez-Maestre \& Esteve, 2013). Not only negative pain-specific appraisals, but also negative pain-specific expectations (called nocebo expectations when induced by negative information) can produce processes typical for the downward spiral of pain. Placebo/nocebo research teaches us that the expectation of pain not only impacts on the subjective pain experience, but even on the underlying neural processes (Colloca, Sigaudo, \& Benedetti, 2008; Keltner, et al., 2006; Lorenz, et al., 2005; Mirsky, 2007). In an extensive review, Pincus and Morley (2001) provide evidence for the relation between biased cognitive orientation towards pain-related information and pain. They also report that higher frequencies of attention, interpretation and memory biases for pain-related threatening information have been found in chronic pain patients. Evidence for pain avoidance as an extremely disadvantageous pain coping strategy and for the effectiveness of exposure techniques aimed at countering this avoidance tendency is convincing (Leeuw, et al., 2007). However, effect sizes for exposure interventions are modest (Eccleston, Morley, \&Williams, 2013).

In recent years, several changes to the FA model have been proposed. Some of them are highlighted below: First, including not only fear but also anxiety as a as a future-oriented affective state would add the anticipation of pain in the model (Asmundson, et al., 2004; Norton \& Asmundson, 2003). Second, the sequential nature of the relationships in the model is questioned. Recent findings support cumulative interactions (Vlaeyen \& Linton, 2012; Wideman, et al., 2013). Third, it has been argued that a shift towards a motivational perspective on pain is quintessential. The conviction has grown that fear and avoidance operate in a context of multiple competing goals (Crombez, et al., 2012). Fourth, it has been argued that the fear-avoidance model lacks information on how individuals try to function despite pain or how they attempt to recover. More insight in this pathway of confrontation is essential to develop optimal interventions for individuals with acute or chronic pain (Crombez, et al., 2012). A more dynamic conceptualisation of both disability and functional recovery views pain as an obstacle that has to be coped with in the daily pursuit of valued activities (Aldrich, Eccleston, \& Crombez, 2000; Crombez, et al., 2012; Eccleston \& Crombez, 2007; Van Damme, Crombez, \& Eccleston, 2008). Wideman and colleagues (2013) put forward that the fear-avoidance model cannot account for a certain cohort of chronic pain patients without high levels of pain catastrophizing or fear of pain. They suggest that research exploring resilience factors might help to understand the existence of chronic pain or recovery beyond what can be explained by risk factors.

\section{Building what's strong}

After decades of investigating factors that put people at risk for pain, researchers gained interest in studying factors that protect them. The observation that certain children at risk develop successfully in the most challenging circumstances inspired a new research perspective focussed on resilience or 'health-despite-adversity' since the 1970's (Masten \& Reed, 2002). Resilience refers to a process in which one shows positive adaptation to apparently adverse circumstances (Karoly \& Ruehlman, 2006; Luthar, et al., 2000; Masten \& Reed, 2002; Olsson, et al., 2003). This conceptuali- 
sation of resilience comprises of two essential elements. First, one is exposed to significant threat or adversity. Second, one adapts successfully despite the assaults the threat or adversity places on development/functioning.

Chronic pain is a stressor that seriously impacts on physical/psychological functioning and challenges individuals'adaptive abilities. However, research on resilience in the area of pain is limited. Over the years, dispositional optimism, self-efficacy, readiness to change and acceptance have been related to higher adjustment to pain (Keefe, et al., 2004; Novy, et al., 1998; RamirezMaestre \& Esteve, 2013). Research on risk factors however clearly outweighs research on protective factors in quantity as well as in degree to which systematic research is used to identify specific outcomes in the context of pain.

Karoly and RuehIman (2006) conducted a study in a large US community sample of individuals with chronic pain. In this sample they identified resilient individuals as individuals high in pain severity, low in functional interference and low in emotional burdening. Subsequently they studied the sample to find correlates of resilience in the context of pain. Among a myriad of outcomes, they found lower levels of pain catastrophizing, fear of pain and protective pain behaviours (e.g. guarding), as well as a diminished belief in a medical solution in the resilient subset. Moreover, resilient individuals showed high levels of positive self-talk, task persistence and perceived control.

Although still largely understudied, certain mechanisms of resilience are stressed in the pain literature. While negative attitudes and beliefs have generally been related to avoidance tendencies, positive attitudes and beliefs have been related to active coping and engagement (Jensen \& Karoly, 1991). In general, it has been argued that optimists differ from pessimists in the way they approach problems and challenges and in the way they cope with adversity (Carver \& Scheier, 2002). Not only do optimists prefer an active problem-solving approach to a diversity of adversity, they are also able to flexibly adjust their coping effects to demands of the situation (Nes \& Segerstrom, 2006). Recently, the importance of applying a motivational perspective on pain has been put forward (Van Damme, et al., 2008). Not only goal persistence, but also flexibility in relation to blocked goals is important to ensure quality of life (Brandstädter \& Renner, 1990), also in relation to pain (Schmitz, Saile, \& Nilges, 1996).

Alex Zautra, one of the pioneers of resilience research in pain, found that positive affect can attenuate the negative effects of pain/stress in women with osteoarthritis and fibromyalgia (Zautra, Johnson, \& Davis, 2005). His belief that positive emotions protect against the narrowing effects of negative emotions (Zautra, Smith, Affleck, \& Tennen, 2001) correspond to the basic postulates of the broaden-and-build model of Fredrickson (Fredrickson, 1998, 2001; Fredrickson \& Branigan, 2005). The broaden-and-build model describes how positive emotions broaden people's attention and momentary thought-action repertoires. In the long run, this builds enduring physical, cognitive and social resources.

Sturgeon and Zautra (Sturgeon \& Zautra, 2010) express the need for systematic research examining resilience/vulnerability resources and mechanisms leading to outcomes of recovery (return to homeostasis), sustainability (enduring engagement in valued activities) 
and growth (benefit finding/post traumatic growth) in the field of pain. Systematic research could lead to development and refinement of positive psychology interventions for chronic pain patients. First experiences with for instance acceptance-based treatments (McCracken, Vowles, \& Eccleston, 2005) and loving kindness meditation (Carson, et al., 2005) for chronic pain patients seem promising.

\section{Possible mechanisms underlying the optimism effect}

Based on what is already known about the optimism construct and on the advances in the field of pain, certain candidate mechanisms were identified to explain the relationship between optimism and pain/well-being.

The definition and conceptualization of dispositional optimism (Carver \& Scheier, 1998; Carver \& Scheier, 2002; Carver, et al., 2010; Scheier \& Carver, 1985) lead to the proposition of expectancy as a first tentative candidate. It has been argued that a generalized expectation determines specific expectations in new and ambiguous situations (Carver \& Scheier, 2002; Scheier \& Carver, 1985). Therefore the tendency of optimists to generally expect positive instead of negative experiences might translate to expectations specific to pain (i. e. lower expected pain intensity). The role of pain-specific expectations towards the pain experience is well-established (Arntz \& Claassens, 2004; Vlaeyen \& Linton, 2000). Placebo/nocebo expectations lead to less/more intense pain (Colloca, et al., 2008). Pain-specific expectations might mediate the relation between optimism and pain sensitivity/tolerance.

Another mechanism that might underlie the relation between optimism and pain/ (pain-related) well-being might be sought in interpretation tendencies of optimists. Hence the tendency to make less exaggerated negative interpretations of pain-related situations (i. e. pain catastrophizing), as well as the general tendency to interpret ambiguity in a benign manner might explain the effect of optimism on well-being.

One of the basic postulates of the fear avoidance model is that the meaning of pain determines pain-related outcomes (Vlaeyen \& Linton, 2000). While a catastrophic interpretation of pain leads to heightened fear for pain, avoidant behaviours and eventually disability, a non-threatening interpretation leads to less fear, confrontation and functional recovery. Optimism might impact on this initial point leading to a negative downward spiral versus a positive upward spiral in the fear-avoidance model through its influence on interpretation of ambiguity. There is reason to believe that optimism is related to a non-threatening interpretation of pain-related stimuli. Optimism was associated with lower levels of pain catastrophizing (BargielMatusiewicz \& Krzyszkowska, 2009; Sinclair, 2001), a mechanisms that often leads to heightened pain sensitivity (Keefe, et al., 2001; Keefe, et al., 2004; Vlaeyen, et al., 2009). Pain catastrophizing might explain the relation between optimism and diminished pain sensitivity.

Possibly optimism is related to a less catastrophic interpretation of ambiguity in general. Negative interpretation biases have been related to the development and maintenance of emotional disorders (MacLeod \& Mathews, 2012). Vancleef and Peters (2008) reported that optimists 
make less negative or catastrophic interpretations of ambiguous information in different domains (pain-related sensations, other bodily sensations, social and general situations). Research indicates that optimists are reluctant to process negative information in favour of positive aspects of a situation (Karademas, Argyropoulou, \& Karvelis, 2007; Segerstrom, 2001). General interpretation patterns of optimists might lead to higher well-being (despite pain).

A last mechanism that repeatedly has been related to optimism and well-being is coping. Optimism has been shown to lead to higher well-being due to the employment of active problem-focused coping strategies (Nes \& Segerstrom, 2006; Scheier \& Carver, 1985). Following the expectancy-value conceptualization of motivation, optimistic expectations lead to continued engagement towards goals (Carver \& Scheier, 2002; Carver, et al., 2010). However, the ability to flexibly adjust goals when goals have become unattainable has been found to be extremely important for chronic pain patients' well-being (Eccleston \& Crombez, 2007; Van Damme, et al., 2008). Motivational coping is proposed as a mediator in the relation between optimism and well-being. In the literature, optimism has not only been related to goal engagement, but also to goal dis- en reengagement (Brandstädter \& Renner, 1990; Wrosch \& Scheier, 2003). Especially flexible goal adjustment might be an important mediator in the relation between optimism and well-being despite adversities, such as pain.

\section{OUTLINE OF THIS DISSERTATION}

The aim of this thesis is to investigate the relation between dispositional optimism and pain and (pain-related) well-being. Specifically, 7 empirical studies described in 4 chapters of this dissertation aim at answering two central research questions:'Is optimism causally related to pain?'and 'What are the underlying mechanisms in the relation between optimism and pain/(pain-related) well-being?'

Chapter $\mathbf{2}$ presents three consecutive studies in which interpretation patterns of optimists are investigated in relation to pain-related and non-pain-related ambiguous situations by means of the Body Sensations Interpretations Questionnaire (BSIQ; Clark, et al., 1997). In this chapter, it is examined whether the earlier finding that optimists make less negative interpretations of ambiguity in several domains could be replicated (Vancleef \& Peters, 2008). In addition, this chapter investigates whether optimists are inclined to make more positive in addition to less negative interpretations. For this purpose, the BSIQ was adapted and a positive interpretation category was added. Two studies using the adapted BSIQ with answer categories and one study using an open version of the adapted BSIQ were conducted in the general population. It was expected that results of all three studies would show that dispositional optimism is significantly related to less negative and possibly also more positive interpretations of ambiguity.

Chapter $\mathbf{3}$ focuses on pain-specific expectations as an important mechanism in the relation between optimism and pain. Two studies were conducted to investigate whether optimism relates to or interacts with less negative pain-specific expectations leading to higher pain tol- 
erance and/or lower pain reports. In a first study, optimism and expected pain intensity were measured prior to the induction of cold pressor pain in university students. It was hypothesized that higher levels of dispositional optimism would lead to lower expected pain intensity and therefore less cold pressor pain (mediation hypothesis). In a second study, expected pain intensity was manipulated by means of verbal instructions about the temperature of the water in the cold pressor bath. Again, dispositional optimism and expected pain intensity were measured before the cold pressor task. It was expected that the interaction between a generalized outcome expectancy (dispositional optimism) and specific outcome expectancies ('low pain expectancy' versus 'high pain expectancy' condition) would influence verbal pain reports during the cold pressor task (moderation hypothesis).

Chapter 4 describes an experimental study in which the causal status of optimism towards pain was investigated in healthy participants. Moreover, pain-specific expectations and pain catastrophizing were studied as possible underlying mechanisms in the relation between optimism and induced pain. In this experiment, a temporary optimistic state was induced in half of the participants using the Best Possible Self writing and visualisation exercise using the procedure of Peters and colleagues (2010). The other half of the participants wrote and visualised about a Typical Day (control condition). Subsequently, participants were asked to conduct a cold pressor task. Again, expected pain intensity was measured prior to immersion to investigate whether previous findings could be replicated with an optimism induction. In addition, situational pain catastrophizing during the cold pressor task was measured immediately after the CPT immersion. It was hypothesized that induced optimism would lead to lower pain intensity ratings during a cold pressor task via lower expected pain and lower levels of pain catastrophizing during the CPT.

Chapter $\mathbf{5}$ reports on a study that was conducted to investigate the role of motivational coping as a mechanism in the relation between dispositional optimism and (pain-related) wellbeing. As a first step in studying motivational coping as an underlying mechanism in the association between optimism and (pain-related) well-being, a questionnaire study in the general population was conducted. A mediation model was tested with anxiety, depression, physical complaints and general well-being as four indices of subjective well-being. It was expected that motivational coping (specifically flexible goal adjustment) would be a significant mediator in the relationships between optimism and all four indices of subjective well-being.

Chapter $\mathbf{6}$ will provide a general overview and discussion of results of the studies that were conducted for the purpose of answering the two main research questions that are subject to this dissertation: 'Is optimism causally related to pain?' and 'What are the underlying mechanisms in the relation between optimism and pain/(pain-related) well-being?'. Since all the data was collected in a healthy or in the general populations, predictions on how current findings can be translated to the situation of chronic pain will be made. Methodological limitations as well as theoretical and clinical implications will be discussed, followed by recommendations for future research on optimism and resilience in the context of chronic pain. 


\section{REFERENCES}

Affleck, G., Tennen, H., Zautra, A., Urrows, S., Abeles, M., \& Karoly, P. (2001). Women's pursuit of personal goals in daily life with fibromyalgia: a value-expectancy analysis. Journal of consulting and clinical psychology, 69, 587-596.

Aldrich, S., Eccleston, C., \& Crombez, G. (2000). Worrying about chronic pain: vigilance to threat and misdirected problem solving. Behaviour research and therapy, 38, 457-470.

Alessandri, G., Vecchione, M., Corrado, F., Bentier, P. M., Barbaranelli, C., Meddi, E., Nistico, L., Stazi, M. A., \& Caprara, G. V. (2010). Much More Than Model Fitting? Evidence for the Heritability of Method Effect Associated With Positively Worded Items of the Life Orientation Test Revised. Structural Equation Modelling: A Multidisciplinary Journal, 17, 642-653.

Allison, P. J., Guichard, C., \& Gilain, L. (2000). A prospective investigation of dispositional optimism as a predictor of health-related quality of life in head and neck cancer patients. Quality of life research: an international journal of quality of life aspects of treatment, care and rehabilitation, 9, 951-960.

Armor, D. A., \& Taylor, S. E. (1998). Situated optimism: Specific outcome expectancies and self-regulation. In M. P. Zanna (Ed.), Advances in experimental social psychology. (Vol. 30, pp. 309-379). New York: Academic Press.

Arntz, A., \& Claassens, L. (2004). The meaning of pain influences its experienced intensity. Pain, 109, $20-25$.

Asmundson, G. J., Norton, P. J., \& Vlaeyen, J. W. S. (2004). Fear-avoidance models of chronic pain: An overview. In G. J. Asmundson, J. W. S. Vlaeyen \& G. Crombez (Eds.), Understanding and treating fear of pain (pp. 3-24). Oxford: Oxford University Press.

Atienza, A., Stephens, M., \& Townsend, A. (2004). Role stressors as predictors of changes in women's optimistic expectations. Personality and Individual Differences, 37, 471-484.

Austenfeld, J. L., Paolo, A. M., \& Stanton, A. L. (2006). Effects of writing about emotions versus goals on psychological and physical health among third-year medical students. Journal of personality, 74, 267-286.

Austin, J. T., \& Vancouver, J. B. (1996). Goal Constructs in Psychology: Structure, Process, and Content. Psychological Bulletin, 120, 338-375.

Bargiel-Matusiewicz, K., \& Krzyszkowska, A. (2009). Dispositional optimism and coping with pain. European journal of medical research, 14 Supp/ 4, 271-274.

Brandstädter, J., \& Renner, G. (1990). Tenacious goal pusuit and flexible goal adjustment: Explication and age-related analysis of assimilative and accommodative strategies of coping. Psychology and aging, 5, 58-67.

Breivik, H., Collett, B., Ventafridda, V., Cohen, R., \& Gallacher, D. (2006). Survey of chronic pain in Europe: prevalence, impact on daily life, and treatment. European Journal of Pain, 10, 287-333.

Brisette, I., Scheier, M. F., \& Carver, C. S. (2002). The role of optimism in social network development, coping, and psychological adjustment during a life transition. Journal of Personality and Social Psychology, 82, 102-111.

Bromberger, J.T., \& Matthews, K. A. (1996). A longitudinal study of the effects of pessimism, trait anxiety, and life stress on depressive symptoms in middle-aged women. Psychology and aging, 11, 207-213.

Carson, J. W., Keefe, F. J., Lynch, T. R., Carson, K. M., Goli, V., Fras, A. M., \& Thorp, S. R. (2005). Loving-kindness meditation for chronic low back pain: results from a pilot trial. Journal of holistic nursing : official journal of the American Holistic Nurses' Association, 23, 287-304.

Carver, C. S., \& Gaines, J. G. (1987). Optimism, pessimism, and postpartum depression. Cognitive Therapy and Research, $11,449-462$. 
Carver, C. S., \& Scheier, M. (1998). On the Self-Regulation of Behavior. New York: Cambridge University Press.

Carver, C. S., \& Scheier, M. F. (2002). Optimism. In S. J. Lopez \& C. R. Snyder (Eds.), The handbook of positive psychology (pp. 231-243). New York: Oxford University Press.

Carver, C. S., Scheier, M. F., \& Segerstrom, S. C. (2010). Optimism. Clinical Psychological Review, 30.

Chang, E. C., D'Zurilla, T. J., \& Maydeu-Olivares, A. (2004). Assessing the dimensionality of optimism and pessimism using a multi-measure approach. Cognitive Therapy and Research, 18, 143-161.

Chida, Y., \& Steptoe, A. (2008). Positive psychological well-being and mortality: a quantitative review of prospective observational studies. Psychosomatic medicine, 70, 741-756.

Clark, D. M., Salkovskis, P. M., Ost, L. G., Breitholtz, E., Koehler, K. A., Westling, B. E., Jeavons, A., \& Gelder, M. (1997). Misinterpretation of body sensations in panic disorder. Journal of consulting and clinical psychology, 65, 203-213.

Colloca, L., Sigaudo, M., \& Benedetti, F. (2008). The role of learning in nocebo and placebo effects. Pain, 136, $211-218$.

Costello, N. L., Bragdon, E. E., Light, K. C., Sigurdsson, A., Bunting, S., Grewen, K., \& Maixner, W. (2002). Temporomandibular disorder and optimism: relationships to ischemic pain sensitivity and interleukin-6. Pain, 100, 99-110.

Crombez, G., Eccleston, C., Van Damme, S., Vlaeyen, J. W., \& Karoly, P. (2012). Fear-avoidance model of chronic pain: the next generation. The Clinical Journal of Pain, 28, 475-483.

Crombez, G., Vlaeyen, J. W., Heuts, P. H., \& Lysens, R. (1999). Pain-related fear is more disabling than pain itself: evidence on the role of pain-related fear in chronic back pain disability. Pain, 80, 329-339.

de Ridder, D., Fournier, M., \& Bensing, J. (2004). Does optimism affect symptom report in chronic disease? What are its consequences for self-care behaviour and physical functioning? Journal of psychosomatic research, 56, 341-350.

Eccleston, C., \& Crombez, G. (2007). Worry and chronic pain: a misdirected problem solving model. Pain, 132, $233-236$.

Eccleston, C., Morley, S. J., \& Williams, A. C. (2013). Psychological approaches to chronic pain management: evidence and challenges. British journal of anaesthesia, 111, 59-63.

Engel, G. L. (1997). From biomedical to biopsychosocial. Being scientific in the human domain. Psychosomatics, 38, 521-528.

Fournier, M., De Ridder, D., \& Bensing, J. (2002). Optimism and adaptation to chronic disease: The role of optimism in relation to self-care options of type 1 diabetes mellitus, rheumatoid arthritis and multiple sclerosis. British journal of health psychology, 7, 409-432.

Fredrickson, B. L. (1998). What Good Are Positive Emotions? Review of general psychology: journal of Division 1, of the American Psychological Association, 2, 300-319.

Fredrickson, B. L. (2001). The role of positive emotions in positive psychology. The broaden-and-build theory of positive emotions. The American psychologist, 56, 218-226.

Fredrickson, B. L., \& Branigan, C. (2005). Positive emotions broaden the scope of attention and thought-action repertoires. Cognition \& emotion, 19, 313-332.

Gatchel, R. J., Peng, Y. B., Peters, M. L., Fuchs, P. N., \& Turk, D. C. (2007). The biopsychosocial approach to chronic pain: scientific advances and future directions. Psychological Bulletin, 133, 581-624.

Geers, A. L., Kosbab, K., Helfer, S. G., Weiland, P. E., \&Wellman, J. A. (2007). Further evidence for individual differences in placebo responding: an interactionist perspective. Journal of psychosomatic research, 62, 563-570.

Geers, A. L., Reilly, S. P., \& Dember, W. N. (1998). Optimism, pessimism and friendship. Current psychology: Developmental, Learning, Personality, Social, 17. 
Geers, A. L., Weiland, P. E., Kosbab, K., Landry, S. J., \& Helfer, S. G. (2005). Goal activation, expectations, and the placebo effect. Journal of Personality and Social Psychology, 89, 143-159.

Geers, A. L., Wellman, J. A., Fowler, S. L., Helfer, S. G., \& France, C. R. (2010). Dispositional optimism predicts placebo analgesia. The Journal of Pain, 11, 1165-1171.

Geers, A. L., Wellman, J. A., Helfer, S. G., Fowler, S. L., \& France, C. R. (2008). Dispositional optimism and thoughts of wellbeing determine sensitivity to an experimental pain task. Annals of Behavioral Medicine, 36, 304-313.

Gibson, B., \& Sanbonmatsu, D. M. (2004). Optimism, pessimism, and gambling: the downside of optimism. Personality \& social psychology bulletin, 30, 149-160.

Giltay, E. J., Geleijnse, J. M., Zitman, F. G., Hoekstra, T., \& Schouten, E. G. (2004). Dispositional optimism and all-cause and cardiovascular mortality in a prospective cohort of elderly dutch men and women. Archives of General Psychiatry, 61, 1126-1135.

Glazer, K. M., Emery, C. F., Frid, D. J., \& Banyasz, R. E. (2002). Psychological predictors of adherence and outcomes among patients in cardiac rehabilitation. Journal of cardiopulmonary rehabilitation, 22, 40-46.

Hanssen, M. M., \& Peters, M. L. (2009). Is optimism healthy and pessimism unhealthy? About the unique predictive value of the Life Orientation Test towards stress-related complaints. Psychologie en Gezondheid, 37, 298-307.

Hooper, R. (1811). Quincy's Lexicon-Medicum. London.

IASP. (1986). Pain terms: A Current List with Definitions and Notes of Usage. Pain, Supplement 3, S215-S221.

Jensen, M. P., \& Karoly, P. (1991). Control beliefs, coping efforts, and adjustment to chronic pain. Journal of consulting and clinical psychology, 59, 431-438.

Karademas, E. C., Argyropoulou, K., \& Karvelis, S. (2007). Psychological symptoms of breast cancer survivors: a comparison with matched healthy controls and the association with cancer-related stress and coping. Journal of psychosocial oncology, 25, 59-74.

Karoly, P., \& Ruehlman, L. S. (2006). Psychological "resilience" and its correlates in chronic pain: findings from a national community sample. Pain, 123, 90-97.

Keefe, F. J., Lumley, M., Anderson, T., Lynch, T., Studts, J. L., \& Carson, K. L. (2001). Pain and emotion: new research directions. Journal of clinical psychology, 57, 587-607.

Keefe, F. J., Rumble, M. E., Scipio, C. D., Giordano, L. A., \& Perri, L. M. (2004). Psychological aspects of persistent pain: current state of the science. The Journal of Pain, 5, 195-211.

Keltner, J. R., Furst, A., Fan, C., Redfern, R., Inglis, B., \& Fields, H. L. (2006). Isolating the modulatory effect of expectation on pain transmission: a functional magnetic resonance imaging study. The Journal of neuroscience: the official journal of the Society for Neuroscience, 26, 4437-4443.

King, L. A. (2001). The health benefits of writing about life goals. Personality \& social psychology bulletin, 27, 798-807.

Kubzansky, L. D., Kubzansky, P. E., \& Maselko, J. (2004). Optimism and pessimism in the context of health: bipolar opposites or separate constructs? Personality \& social psychology bulletin, 30, 943-956.

Kurtz, M. E., Kurtz, J. C., Given, C. W., \& Given, B. A. (2008). Patient optimism and mastery-do they play a role in cancer patients' management of pain and fatigue? Journal of pain and symptom management, 36, 1-10.

Leeuw, M., Goossens, M. E., Linton, S. J., Crombez, G., Boersma, K., \& Vlaeyen, J. W. (2007). The fear-avoidance model of musculoskeletal pain: current state of scientific evidence. Journal of behavioral medicine, 30, 77-94.

Lethem, J., Slade, P. D., Troup, J. D., \& Bentley, G. (1983). Outline of a Fear-Avoidance Model of exaggerated pain perception--I. Behaviour research and therapy, 21, 401-408. 
Litt, M. D., Tennen, H., Affleck, G., \& Klock, S. (1992). Coping and Cognitive factors in adaption to in vitro fertilization failure. Journal of behavioral medicine, 15, 171-187.

Lorenz, J., Hauck, M., Paur, R. C., Nakamura, Y., Zimmermann, R., Bromm, B., \& Engel, A. K. (2005). Cortical correlates of false expectations during pain intensity judgments--a possible manifestation of placebo/nocebo cognitions. Brain, behavior, and immunity, 19, 283-295.

Luger, T., Cotter, K. A., \& Sherman, A. M. (2009). It's all in how you view it: pessimism, social relations, and life satisfaction in older adults with osteoarthritis. Aging \& Mental Health, 13, 635-647.

Luthar, S. S., Cicchetti, D., \& Becker, B. (2000). The construct of resilience: a critical evaluation and guidelines for future work. Child development, 71, 543-562.

MacLeod, A. K. (1996). Affect, Emotional Disorder, and Future-directed Thinking. Cognition and Emotion, 10, 69-86.

MacLeod, A. K., \& Conway, C. (2005). Well-being and the anticipation of future positive experiences: The role of income, social networks, and planning ability. Cognition and Emotion, 19, 357-374.

MacLeod, C., \& Mathews, A. (2012). Cognitive bias modification approaches to anxiety. Annual review of clinical psychology, 8, 189-217.

Mahler, H. I. M., \& Kulik, J. Q. (2000). Optimism, pessimism and recovery from coronary bypass surgery: prediction of affect, pain and functional status. Psychology, Health \& Medicine, 5, 347-358.

Mangelli, L., Gribbin, N., Buchi, S., Allard, S., \& Sensky, T. (2002). Psychological well-being in rheumatoid arthritis: relationship to 'disease' variables and affective disturbance. Psychotherapy and psychosomatics, 71, 112-116.

Marshall, G. N., \& Lang, E. L. (1990). Optimism, self-mastery, and symptoms of depression in women professionals. Journal of Personality and Social Psychology, 59, 132-139.

Marshall, G. N., Wortman, C. B., Kusulas, J. W., Hervig, L. K., \& Vickers, R. R. (1992). Distinguishing optimism from pessimism: Relations to fundamental dimensions of mood and personality. Journal of Personality and Social Psychology, 62, 1067-1074.

Masten, A. S., \& Reed, M. J. (2002). Resilience in development. In C. R. Snyder \& S. J. Lopez (Eds.), The handbook of positive psychology. New York, NY: Oxford University Press.

McCracken, L. M., Vowles, K. E., \& Eccleston, C. (2005). Acceptance-based treatment for persons with complex, long standing chronic pain: a preliminary analysis of treatment outcome in comparison to a waiting phase. Behaviour research and therapy, 43, 1335-1346.

Meevissen, Y. M., Peters, M. L., \& Alberts, H. J. (2011). Become more optimistic by imagining a best possible self: effects of a two week intervention. Journal of behavior therapy and experimental psychiatry, 42, 371-378.

Mirsky, J. B. (2007). Expectancy and the placebo effect: How cognitive processing utilizes the rACC to alter the perception of pain. . Mind Matters: The Wesleyan Journal of Psychology, 2, 19-28.

Morton, D. L., Watson, A., El-Deredy, W., \& Jones, A. K. (2009). Reproducibility of placebo analgesia: Effect of dispositional optimism. Pain, 146, 194-198.

Moseley, G. L., \& Arntz, A. (2007). The context of a noxious stimulus affects the pain it evokes. Pain, 133, 64-71.

Mosing, M. A., Zietsch, B. P., Shekar, S. N., Wright, M. J., \& Martin, N. G. (2009). Genetic and environmental influences on optimism and its relationship to mental and self-rated health: a study of aging twins. Behavior genetics, 39, 597-604.

Nes, L. S., \& Segerstrom, S. C. (2006). Dispositional optimism and coping: a meta-analytic review. Personality and social psychology review: an official journal of the Society for Personality and Social Psychology, Inc, 10, 235-251. 
Norton, P. J., \& Asmundson, G. J. G. (2003). Amending the Fear-Avoidance Model of Chronic Pain: What is the Role of Physicalogical Arousal? Behavior Therapy, 34, 17-30.

Novy, D. M., Nelson, D. V., Hetzel, R. D., Squitieri, P., \& Kennington, M. (1998). Coping with chronic pain: sources of intrinsic and contextual variability. Journal of behavioral medicine, 21, 19-34.

Olsson, C. A., Bond, L., Burns, J. M., Vella-Brodrick, D. A., \& Sawyer, S. M. (2003). Adolescent resilience: a concept analysis. Journal of adolescence, 26, 1-11.

Peters, M. L., Flink, I., Boersma, K., \& Linton, S. (2010). Manipulating optimism: Can imagining a best possible self be used to increase positive future expectancies? Journal of Positive Psychology, 5, 204-211.

Peters, M. L., Meevissen, Y. M., \& Hanssen, M. M. (2013). Specificity of the Best Possible Self intervention for increasing optimism: Comparison with a gratitude intervention. Terapia Psicologica, 31, 93-100.

Peters, M. L., Sommer, M., Rijke, J. M. d., Kessels, A. G. H., Heineman, E., Patijn, J., Marcus, M. A., Vlaeyen, J. W. S., \& Kleef, M. v. (2007). Somatic and psychological predictors of long-term unfavorable outcome after surgical intervention. annals of Surgery, 245, 487-494.

Peterson, C., \& Seligman, M. E. (1984). Causal explanations as a risk factor for depression: theory and evidence. Psychological review, 91, 347-374.

Pincus, T., \& Morley, S. (2001). Cognitive-processing bias in chronic pain: a review and integration. Psychological Bulletin, 127, 599-617.

Plomin, R., Scheier, M., Bergeman, C., Pedersen, N., Nesselroade, J., \& McClearn, G. (1992). Optimism, pessimism and mental health: A twin/adoption analysis. Personality and Individual Differences, 13, 921-930.

Radcliffe, N. M., \& Klein, W. M. P. (2002). Dispositional, Unrealistic, and Comparative Optimism: Differential Relations with the Knowledge and Processing of Risk Information and Beliefs about Personal Risk. Personality and Social Psychology Bulletin, 28, 836-846.

Ramirez-Maestre, C., \& Esteve, R. (2013). Disposition and adjustment to chronic pain. Current pain and headache reports, 17, 312 .

Rasmussen, H. N., Scheier, M. F., \& Greenhouse, J. B. (2009). Optimism and physical health: a meta-analytic review. Annals of behavioral medicine: a publication of the Society of Behavioral Medicine, 37, 239-256.

Robbins, A. S., Spence, J. T., \& Clark, H. (1991). Psychological determinants of health and performance: the tangled web of desirable and undesirable characteristics. Journal of Personality and Social Psychology, 61, 755-765.

Saphire-Bernstein, S., Way, B. M., Kim, H. S., Sherman, D. K., \& Taylor, S. E. (2011). Oxytocin receptor gene (OXTR) is related to psychological resources. Proceedings of the National Academy of Sciences of the United States of America, 108, 15118-15122.

Scheier, M. F., \& Carver, C. S. (1985). Optimism, coping, and health: assessment and implications of generalized outcome expectancies. Health Psychology, 4, 219-247.

Scheier, M. F., \& Carver, C. S. (1992). Effects of optimism on psychological and physical well-being: Theoretical overview and empirical update. Cognitive Therapy and Research, 16, 201-228.

Scheier, M. F., Carver, C. S., \& Bridges, M. W. (1994). Distinguishing optimism from neuroticism (and trait anxiety, selfmastery, and self-esteem): a reevaluation of the Life Orientation Test. Journal of Personality and Social Psychology, 67, 1063-1078. 
Scheier, M. F., Matthews, K. A., Owens, J. F., Magovern, G. J. S., Lefebvre, R. C., Abbott, R. A., \& Carver, C. S. (1989). Dispositional optimism and recovery from coronary artery bypass surgery: The beneficial effects on physical and psychological well-being. Journal of Personality and Social Psychology, 57, 1024-1040.

Schmitz, U., Saile, H., \& Nilges, P. (1996). Coping with chronic pain: flexible goal adjustment as an interactive buffer against pain-related distress. Pain, 67, 41-51.

Segerstrom, S. C. (2001). Optimism, goal conflict, and stressor-related immune change. Journal of behavioral medicine, 24, 441-467.

Segerstrom, S. C. (2005). Optimism and immunity: do positive thoughts always lead to positive effects? Brain, behavior, and immunity, 19, 195-200.

Segerstrom, S. C. (2007). Optimism and resources: Effects on each other and on health over 10 years. Journal of research in personality, 41, 772-786.

Segerstrom, S. C., \& Nes, L. S. (2006). When Goals Conflict But People Prosper: The Case of Dispositional Optimism. Journal of research in personality, 40, 675-693.

Sheldon, K. M., \& Lyubomirsky, S. (2006). How to increase and sustain positive emotion: The effects of expressing grattitude and visualizing best possible selves. The Journal of Positive Psychology, 1.

Sinclair, V. G. (2001). Predictors of pain catastrophizing in women with rheumatoid arthritis. Archives of psychiatric nursing, 15, 279-288.

Smith, T. W., Pope, M. K., Rhodewalt, F., \& Poulton, J. L. (1989). Optimism, neuroticism, coping, and symptom reports: an alternative interpretation of the Life Orientation Test. Journal of Personality and Social Psychology, 56, 640648.

Solberg Nes, L., Evans, D. R., \& Segerstrom, S. C. (2009). Optimism and college retention: mediation by motivation, performance and adjustment. Journal of Applied Social Psychology, 39, 1887-1912.

Srivastava, S., McGonigal, K. M., Richards, J. M., Butler, E. A., \& Gross, J. J. (2006). Optimism in close relationships: How seeing things in a positive light makes them so. Journal of Personality and Social Psychology, 91, 143-153.

Sturgeon, J. A., \& Zautra, A. J. (2010). Resilience: A New Paradigm for Adaptation to Chronic Pain. Current pain and headache reports, 14, 105-112.

Turk, D. C., \& Okifuji, A. (2002). Psychological factors in chronic pain: evolution and revolution. Journal of consulting and clinical psychology, 70, 678-690.

Van Damme, S., Crombez, G., \& Eccleston, C. (2008). Coping with pain: a motivational perspective. Pain, 139, 1-4.

Vancleef, L. M., \& Peters, M. L. (2008). Examining content specificity of negative interpretation biases with the Body Sensations Interpretation Questionnaire (BSIQ). Journal of anxiety disorders, 22, 401-415.

Vinck, J., Wels, G., Arickx, M., \& Vinck, S. (1998). Optimisme gemeten. Validatie van een Nederlandstalige Levensorientatietest bij jongeren. Gedrag en Gezondheid, 26.

Vlaeyen, J. W., Haazen, I. W., Schuerman, J. A., Kole-Snijders, A. M., \& van Eek, H. (1995). Behavioural rehabilitation of chronic low back pain: comparison of an operant treatment, an operant-cognitive treatment and an operantrespondent treatment. The British journal of clinical psychology, 34 (Pt 1), 95-118.

Vlaeyen, J. W., Hanssen, M., Goubert, L., Vervoort, T., Peters, M., van Breukelen, G., Sullivan, M. J., \& Morley, S. (2009). Threat of pain influences social context effects on verbal pain report and facial expression. Behaviour research and therapy, 47, 774-782. 
Vlaeyen, J. W., Kole-Snijders, A. M., Boeren, R. G., \& van Eek, H. (1995). Fear of movement/(re)injury in chronic low back pain and its relation to behavioral performance. Pain, 62, 363-372.

Vlaeyen, J. W., \& Linton, S. J. (2000). Fear-avoidance and its consequences in chronic musculoskeletal pain: a state of the art. Pain, 85, 317-332.

Vlaeyen, J. W., \& Linton, S. J. (2012). Fear-avoidance model of chronic musculoskeletal pain: 12 years on. Pain, in press. Waddell, G. (2004). The biopsychosocial model. In G. Waddell (Ed.), The Back Pain Revolution (Vol. 265-282). Edinburgh: Churchill Livingston.

Waddell, G., Newton, M., Henderson, I., Somerville, D., \& Main, C. J. (1993). A Fear-Avoidance Beliefs Questionnaire (FABQ) and the role of fear-avoidance beliefs in chronic low back pain and disability. Pain, 52, 157-168.

Weinstein, N. D. (1980). Unrealistic Optimism About Future Life Events. Journal of Personality and Social Psychology, $39,806-820$.

Weinstein, N. D. (1989). Optimistic biases about personal risks. Science, 246, 1232-1233.

Weinstein, N. D., \& Lyon, J. E. (1999). Mindset, optimistic bias about personal risk and health-protective behaviour. Britisch Journal of Health Psychology, 4, 289-300.

Wideman, T. H., Asmundson, G. G., Smeets, R. J., Zautra, A. J., Simmonds, M. J., Sullivan, M. J., Haythornthwaite, J. A., \& Edwards, R. R. (2013). Rethinking the fear avoidance model: Toward a multidimensional framework of painrelated disability. Pain, 154, 2262-2265.

Wong, W. S., \& Fielding, R. (2007). Quality of life and pain in Chinese lung cancer patients: is optimism a moderator or mediator? Quality of Life Research, 16, 53-63.

Wright, L. J., Zautra, A. J., \& Going, S. (2008). Adaptation to early knee osteoarthritis: the role of risk, resilience, and disease severity on pain and physical functioning. Annals of behavioral medicine : a publication of the Society of Behavioral Medicine, 36, 70-80.

Wrosch, C., \& Scheier, M. F. (2003). Personality and quality of life: the importance of optimism and goal adjustment. Quality of life research : an international journal of quality of life aspects of treatment, care and rehabilitation, 12 Suppl 1, 59-72.

Zautra, A., Smith, B., Affleck, G., \& Tennen, H. (2001). Examinations of chronic pain and affect relationships: applications of a dynamic model of affect. Journal of consulting and clinical psychology, 69, 786-795.

Zautra, A. J., Johnson, L. M., \& Davis, M. C. (2005). Positive affect as a source of resilience for women in chronic pain. Journal of consulting and clinical psychology, 73, 212-220. 


\section{What does it mean to be an optimist in an ambiguous world? Investigating positive versus negative interpretation patterns of optimists}

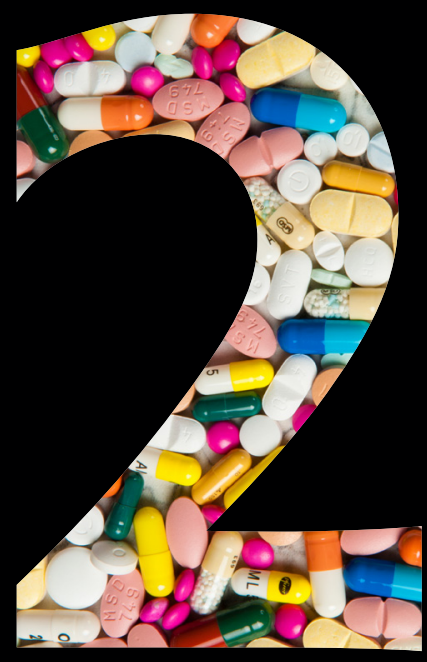

This chapter is submitted for publication as: Hanssen, M. M., Vancleef, L. M. G. \& Peters, M. L. What does it mean to be an optimist in an ambiguous world? Investigating positive versus negative interpretation patterns of optimists. 



\section{ABSTRACT}

Optimism has been associated with better general well-being and less psychopathology. The pathways through which optimism enhances well-being and protects against psychopathology are yet unclear. Previous research indicates that optimists make less negative interpretations. The aim of the present studies is to replicate and extend this finding by means of investigating both negative and positive interpretation patterns of optimists. In three studies, positive and negative interpretations were measured with an adapted version of the Body Sensations Interpretation Questionnaire (= BSIQ). In study 1 and 2, participants were asked to rank and rate positive, neutral and negative explanations of ambiguous situations in several domains (somatic sensations, social situations and general situations). In study 3, participants generated their own explanations to the ambiguous situations in an open-answer format of the BSIQ. Both the participants and independent coders provided valence ratings of these participant-generated explanations. Dispositional optimism was significantly related to less negative interpretations and (to a lesser degree) to more positive interpretations in all three studies. In study 3, optimism was particularly related to participants'valence ratings of their own responses to the open BSIQ. Limitations: Subtle differences between the studies complicate comparing the findings and conducting the study in a patient population could have added clinical relevance. Interpretation patterns might be an important pathway through with optimism impacts on well-being and protects against psychological complaints. 



\section{INTRODUCTION}

'Optimism is a moral duty', Popper proclaimed (Popper, 1994, p. xiii). In his conviction, not the prediction of bad outcomes, but the active support of good ones leads humans to create a better future. A plunge in the health science literature gives the impression that, at least on a personal level, optimism might indeed support a better life.

A global tendency to expect positive future outcomes, called dispositional optimism (Scheier \& Carver, 1985), has been linked to a myriad of benefits (Carver, Scheier, \& Segerstrom, 2010; Rasmussen, Scheier, \& Greenhouse, 2009; Scheier \& Carver, 1992). In the social domain, the optimism advantage translates into broader social networks (Macleod \& Conway, 2005), higher perceived social support (Brissette, Scheier, \& Carver, 2002; Srivastava, McGonigal, Richards, Butler, \& Gross, 2006) and higher relationship satisfaction (Srivastava, et al., 2006). Additionally optimists seem to be more successful than pessimists in their academic and professional undertakings (Segerstrom, 2007; Solberg Nes, Evans, \& Segerstrom, 2009). In the domain of physical and mental health, optimists experience higher levels of well-being and quality of life in response to for instance acute or chronic pain (Ramirez-Maestre, Esteve, \& Lopez, 2012; Wright, Zautra, \& Going, 2008), cancer treatment (Allison, Guichard, \& Gilain, 2000; Carver, et al., 1994), psychological trauma or stress (Jaksic, Brajkovic, Ivezic, Topic, \& Jakovljevic, 2012; Scheier, Weintraub, \& Carver, 1986) and surgical interventions (Mahler \& Kulik, 2000; Peters, et al., 2007). Furthermore, optimism seems to protect against psychopathology. It was found that optimism buffers anxiety symptoms following for instance illness burden (Hirsch, Walker, Chang, \& Lyness, 2012) and war zone stress (Thomas, Britt, Odle-Dusseau, \& Bliese, 2011). Moreover, less depressive symptoms including suicidal ideation have been found in optimists in adverse or challenging times (Litt, Tennen, Affleck, \& Klock, 1992; Rasmussen \& Wingate, 2011).

It is still unclear what leads optimists to this 'better life' or what protects them from the physical and psychological difficulties that pessimists are more inclined to experience. One potential mechanism may be that optimists interpret ambiguous and potentially threatening situations in a more benign way, i.e. that they are less prone to catastrophic misinterpretations (Vancleef \& Peters, 2008). The role of interpretation biases has so far mostly been investigated in the domain of affective disorders, where it has typically been found that anxious participants overestimate the threat value of certain sensations and events (Butler \& Mathews, 1983). These exaggerated negative or catastrophic interpretations of ambiguous cues might be domain specific: individuals with heightened levels of social anxiety overestimate the threat value of ambiguous social cues (Hirsch \& Mathews, 1997; Lucock \& Salkovskis, 1988), whereas panic disorder patients interpret bodily sensations in a catastrophic manner (Clark, et al., 1997; Salkovskis, Clark, \& Gelder, 1996). Similarly, chronic pain patients display negative interpretation biases towards pain-related stimuli (Pincus \& Morley, 2001; Pincus, Pearce, McClelland, Farley, \& Vogel, 1994; Pincus, Pearce, \& Perrott, 1996). That interpretation biases are not just a by-product of the emotional disorder, but may play a role in the onset or maintenance of these conditions is suggested by 
the fact that cognitive bias modification procedures that aim to establish more benign interpretations have positive effects on emotion and behaviour (MacLeod \& Mathews, 2012; Salemink, van den Hout, \& Kindt, 2007).

Interpretation biases can be measured with the Body Sensations Interpretation Questionnaire (BSIQ; Clark, et al., 1997). The BSIQ, based on the work of Butler and Matthews (1983) and McNally and Foa (1987), consists of several descriptions of ambiguous situations in several domains, prompting participants to make inferences about 'what's going on'. Studies that have used the BSIQ - either with a fixed multiple choice or with an open response format - report moderate to high correlations between measures of anxiety and negative interpretations (Austin \& Kiropoulos, 2008; Austin, Richards, \& Klein, 2006; Clark, et al., 1997; Keogh, Hamid, Hamid, \& Ellery, 2004; Teachman, 2005; Vancleef \& Peters, 2008). Moreover, these associations appear to be content specific with individual differences in anxiety sensitivity being most predictive of negative interpretations of panic-related sensations, injury/illness sensitivity of other bodily sensations and fear of negative evaluations of social situations (Vancleef \& Peters, 2008).

This latter study is as far as we know also the only study to date that has examined interpretation biases using the BSIQ in relation to optimism. Optimism was found to be inversely related to likelihood ratings of negative interpretations across all domains (panic-related sensations, other bodily sensations, social situations and general situations). Moreover, this effect was independent from the influence of the other included measures of anxiety and fear (Vancleef \& Peters, 2008). These findings suggest that a more benign interpretation style could underlie the protective function of optimism in the development of emotional disorders and its association to higher levels of wellbeing. However, the association between optimism and more benign interpretations is in need of replication.

The previous study has used a multiple choice format that only allowed examining the degree to which people endorsed negative explanations. Results from attention research provide evidence for optimists' preference of processing positive as opposed to negative stimuli (Karademas, Kafetsios, \& Sideridis, 2007; Segerstrom, 2001). Conform to the hypothesis of a bidirectional relation between fear and a negative interpretation bias (Mathews \& MacLeod, 1994), the processing of positive information might elicit underlying positive feelings. In turn this might activate related schemas, possibly leading to maintained or elevated levels of optimism and subjective well-being. Whether optimism is only related to less negative interpretations or whether optimists are also inclined to make explicit positive interpretations in ambiguous situations has so far not been examined.

Three studies were set up to investigate interpretation tendencies as a function of dispositional optimism more in depth. In addition to the aim of replicating the finding that optimists make less negative interpretations of ambiguity (Vancleef \& Peters, 2008), we examined whether optimism is associated with a positive interpretation bias. For this purpose, we adapted the BSIQ (Clark, et al., 1997) in study 1 and study 2, such that it contained a positive explanation for each 
ambiguous situation, in addition to the negative and neutral explanations as already provided in the original BSIQ. In study 3, we administered an open ended version of an adapted BSIQ in order to examine spontaneous interpretations as given in response to the diverse BSIQ items in relation to optimism levels.

\section{STUDY 1}

\section{METHODS}

\section{Participants}

Participants were recruited at Maastricht University. The recruitment addressed University students between the age of 18 and 35 years old with Dutch as their native language. Prior to participation, inclusion criteria were verbally checked. 82 subjects participated in this study. Three of them were excluded because they did not meet the inclusion criteria and two participants could not complete the study due to technical problems. The final sample consisted of 77 students (15 men and 62 women) with a mean age of 21.83 ( $s d=2.90)$.

\section{Measures}

\section{Dispositional Optimism}

The Dutch version of the revised Life Orientation Test (Carver, et al., 1994) was used to measure dispositional optimism. This questionnaire consists of 10 items of which 3 are positively framed, 3 are negatively framed, and 4 serve as filler items. Participants indicate to which extent they agree with the statements on a scale ranging from $1=$ strongly disagree to $5=$ strongly agree. Consistent with previous findings (Carver, et al., 1994) the internal consistency of the questionnaire is satisfactory with a Cronbach's alpha of .71.

\section{Adapted Body Sensations Interpretation Questionnaire}

To measure both negative and positive explicit interpretations of ambiguous situations, an adapted version of the Body Sensations Interpretation Questionnaire (Clark et al., 1997) was created ${ }^{1}$. This adapted version consists of 27 ambiguous descriptions of situations, followed by the question 'Why?' and three alternative explanations. Participants are asked to indicate which explanation they consider to be the most probable (ranking score). Additionally, participants are asked to provide probability scores (rating score) for each of these explanations on a scale ranging from 0 (= not probable at all) to 100 (= extremely probable).

1 The adapted version of the BSIQ can be obtained by the author on request. 
The adaptation of the BSIQ in this study consists of the followings aspects: First, positive explanations were added. Whereas the original version provided one threatening and two non-threatening explanations, the adapted version specifies one negative (= threatening), one neutral and one positive explanation for each ambiguous situation. Second, reworded and new descriptions of ambiguous situations were included to enable these positive explanations. Third, the categories 'panic-related sensations' and 'other bodily sensations' (Vancleef \& Peters, 2008) were combined to the category'somatic sensations'. Inclusion of positive explanations resulted in a less clear distinction between both categories. The adapted version therefore consisted of ambiguous descriptions of situations in the following domains: (1) somatic sensations, consisting of panic-related and other bodily sensations (13 items - E.g.' 'You are short of breath') (2) social events (8 items - E.g. 'You notice that some people you know are looking at you') and (3) general events (6 items - E.g. 'You smell smoke).

Psychometric qualities of the BSIQ have been referred to as satisfactory (Clark, et al., 1997). The internal consistency of the adapted version used in this study was satisfactory. Cronbach's Alpha's based on the probability ratings of negative explanations of all the situations, somatic sensations, social events and general events were respectively $.92, .84,85$ and .69. Cronbach's alpha's that were calculated based on probability ratings of the positive explanations of each of these categories were $.89, .79, .76$ and .69. In this study, mean proportion scores for rankings (calculated as ranking score / amount of situations) and mean rating scores (likelihood percentage between 0-100) of negative and positive explanations are studied in relation to dispositional optimism. Ranking and rating scores are calculated for total BSIQ and the four domains separately (somatic sensations, social events, general events).

\section{Procedure}

Students were recruited at Maastricht University and invited to participate in a study on information processing. On arrival at the lab, participants received additional information about the study and provided informed consent. Several students (with a maximum of 5 at each time) participated simultaneously in one lab session. Partition walls provided participants with a personal space in the computer lab. During the lab session, participants completed several questionnaires and computer tasks, some of them beyond the scope of this article. For this study, participants completed the Life Orientation Test Revised and subsequently a computerized version of the Adapted BSIQ. After presentation of each BSIQ situation, the question 'Why?' appeared on the computer screen for a fixed duration of 4 seconds. Hereafter the participants were prompted to provide one ranking and three rating scores based on the three alternative explanations that were provided. At the end of the study, participants received a gift coupon and they were thanked for their participation. 


\section{RESULTS}

\section{Descriptives and correlations}

In this sample, the mean score for dispositional optimism, as measured with the Life Orientation Test Revised was 22.60 ( $s d=2.98$ ). Table 1 shows the descriptive statistics for proportion scores of rankings and probability ratings of negative and positive explanations of the ambiguous BSIQ situations. Values are provided for rankings and ratings in total and for rankings and ratings divided over the subcategories (somatic sensations, social events and general events). Paired samples ttests showed that on average positive explanations were judged as significantly more likely than negative for all type of situations, except for rankings of social events.

Table 1. Descriptive statistics and Pearson correlation coefficients of dispositional optimism with BSIQ ranking (proportion) scores and rating scores.

\begin{tabular}{|c|c|c|c|c|c|}
\hline & \multicolumn{4}{|c|}{ Descriptives } & \multirow{2}{*}{$\frac{\text { Correlations }}{\text { Lot-R }}$} \\
\hline & Min & Max & M & sd & \\
\hline Total Ranking Negative Explanations & .00 & .30 & .09 & .08 & $-.39 * *$ \\
\hline Ranking Negative Explanations Somatic Sensations & .00 & .23 & .03 & .05 & $-.26^{*}$ \\
\hline Ranking Negative Explanations Social Events & .00 & .75 & .21 & .19 & $-.31^{* *}$ \\
\hline Ranking Negative Explanations General Events & .00 & .33 & .05 & .10 & $-.30^{* *}$ \\
\hline Total Ranking Positive Explanations & .04 & .48 & .25 & .09 & $.31^{* *}$ \\
\hline Ranking Positive Explanations Somatic Sensations & .08 & .54 & .30 & .12 & $.25^{*}$ \\
\hline Ranking Positive Explanations Social Events & .00 & .63 & .21 & .13 & $.27^{*}$ \\
\hline Ranking Positive Explanations General Events & .00 & .67 & .20 & .16 & .07 \\
\hline Total Probability Negative Explanations & 2.04 & 50.19 & 20.21 & 10.37 & $-.44^{* *}$ \\
\hline Probability Negative Explanations Somatic Sensations & .00 & 41.54 & 13.42 & 8.52 & $-.44^{* *}$ \\
\hline Probability Negative Explanations Social Events & 3.75 & 74.38 & 31.34 & 15.79 & $-.31^{* *}$ \\
\hline Probability Negative Explanations General Events & .83 & 60.00 & 20.10 & 11.71 & $-.51 * *$ \\
\hline Total Probability Positive Explanations & 16.85 & 77.59 & 46.21 & 11.49 & .21 \\
\hline Probability Positive Explanations Somatic Sensations & 17.08 & 80.38 & 47.92 & 12.62 & .14 \\
\hline Probability Positive Explanations Social Events & 18.13 & 78.63 & 42.64 & 13.70 & .17 \\
\hline Probability Positive Explanations General Events & 11.67 & 80.83 & 47.26 & 14.21 & $.26^{*}$ \\
\hline
\end{tabular}

Lot- $\mathrm{R}$, revised Life Orientation Test. * $p<.05 ;{ }^{* *} p<.01$ 
To investigate whether dispositional optimism is significantly related to positive and negative interpretation patterns, bivariate Pearson correlation analyses were performed. Table 1 displays correlations for dispositional optimism with rankings and probability ratings of positive and negative BSIQ explanations. The level of optimism is significantly related to lower rankings of all negative explanations and higher rankings of positive explanations in all domains except general events. Correlation analyses with rating scores demonstrate that optimism is negatively related to probability ratings of negative explanations in all BSIQ domains. Optimism is (only) positively related to probability ratings of positive explanations of general events. Steiger $\mathrm{z}$ transformations were used to test if the correlations between optimism and negative explanations differ significantly from the correlations between optimism and positive explanations. The only significant difference was found for ratings in the domain of somatic sensations $(z=2.28 ; p(2$-tailed $)=.02)$. A borderline significant difference was found for ratings in the domain of general events $(z=1.84$; $\mathrm{p}(2$-tailed $)=.07)$ and for total probability ratings $(\mathrm{z}=1.74 ; \mathrm{p}(2$-tailed $)=.08)$.

\section{Discussion}

It was expected that optimism would be related to less negative interpretations, as reported by Vancleef \& Peters (2008). Results of both ranking and rating scores confirmed this expectation, hereby replicating previous findings. Using an adapted BSIQ, we wanted to extend these findings by exploring relations between optimism and positive interpretations. Although optimists were more inclined to prefer the positive explanation (ranking response) in most domains, they only rated positive explanations of general events as more probable.

A second study was set up to replicate/extend the findings with the adapted version of the Body Sensations Interpretation Questionnaire. Completion of the LOT-R prior to filling out the BSIQ could have led to more positive ranking choices due to activation of the positive mind set or to demand effects in study 1. Therefore, we chose to administer the LOT-R after the assessment of the BSIQ in study 2. Furthermore, a broader age range was allowed for the second study. 


\section{STUDY 2}

\section{METHODS}

\section{Participants}

53 participants between the age of 18 and 58 participated in this study. The final sample consisted out of 20 men and 33 women, with a mean age of 21.92 ( $\mathrm{sd}=3.90)$. Not having Dutch as mother tongue was an exclusion criterion. People were invited to participate in exchange for course credits or a gift coupon of 5 euro.

\section{Measures}

\section{Dispositional Optimism}

Consistent with the previous study, the Dutch version of the revised Life Orientation Test (Carver, et al., 1994) was used to measure dispositional optimism. Internal reliability was again satisfactory with a Cronbach's alpha of .76.

\section{Adapted Body Sensations Interpretation Questionnaire}

In line with study 1, the Adapted Body Sensations Interpretation Questionnaire was used in this study. Again, the internal consistency of all of the subscales proved to be satisfactory based on probability ratings. Cronbach's alpha values for the probability ratings of negative explanations of all situations, somatic sensations, social events and general events were respectively $.84, .87$, 83 and .66. Cronbach's alpha values for probability ratings of positive explanations were $.88, .78$, 70 and .61 respectively.

\section{Procedure}

Students participated in groups of maximum 5 in this study. Prior to participation, students received detailed information about the study procedure and they were asked to sign an informed consent form. Participants were placed at separate computer desks and they were asked to complete several computer tasks and questionnaires (some of which are beyond the scope of this article). Participants completed the Adapted Body Sensations Interpretation Task and subsequently the Life Orientation Test Revised. 


\section{REsUlts}

\section{Descriptives and correlations}

In this study, the mean score of dispositional optimism was $21.96(\mathrm{sd}=3.66)$. Table 2 shows the descriptives of the Adapted Body Sensations Interpretation Questionnaire. Again, positive explanations were chosen significantly more often (ranking score) in all domains except social events and they were considered to be more likely (rating score) than the negative explanations.

Table 2. Descriptive statistics and Pearson correlation coefficients of dispositional optimism with BSIQ ranking (proportion) scores and rating scores.

\begin{tabular}{|c|c|c|c|c|c|}
\hline & \multicolumn{4}{|c|}{ Descriptives } & \multirow{2}{*}{$\frac{\text { Correlations }}{\text { Lot-R }}$} \\
\hline & Min & Max & M & sd & \\
\hline Total Ranking Negative Explanations & .00 & .52 & .10 & .11 & $-.36^{* *}$ \\
\hline Ranking Negative Explanations Somatic Sensations & .00 & .38 & .06 & .09 & -.23 \\
\hline Ranking Negative Explanations Social Events & .00 & .88 & .20 & .21 & $-.33^{*}$ \\
\hline Ranking Negative Explanations General Events & .00 & .67 & .07 & .14 & $-.29^{*}$ \\
\hline Total Ranking Positive Explanations & .07 & .41 & .26 & .09 & .04 \\
\hline Ranking Positive Explanations Somatic Sensations & .00 & .54 & .29 & .12 & .08 \\
\hline Ranking Positive Explanations Social Events & .00 & .75 & .23 & .17 & .01 \\
\hline Ranking Positive Explanations General Events & .00 & .50 & .24 & .14 & -.05 \\
\hline Total Probability Negative Explanations & 3.41 & 42.04 & 18.76 & 9.13 & -.21 \\
\hline Probability Negative Explanations Somatic Sensations & .38 & 43.46 & 13.51 & 9.97 & -.08 \\
\hline Probability Negative Explanations Social Events & 5.00 & 70.63 & 27.41 & 14.00 & -.26 \\
\hline Probability Negative Explanations General Events & .83 & 52.50 & 18.58 & 10.39 & -.21 \\
\hline Total Probability Positive Explanations & 15.56 & 64.81 & 42.96 & 11.16 & $.28^{*}$ \\
\hline Probability Positive Explanations Somatic Sensations & 12.31 & 68.46 & 42.83 & 12.82 & .21 \\
\hline Probability Positive Explanations Social Events & 15.63 & 70.00 & 41.32 & 11.97 & .21 \\
\hline Probability Positive Explanations General Events & 20.00 & 70.00 & 45.45 & 12.78 & $.39^{* *}$ \\
\hline
\end{tabular}

Lot-R, revised Life Orientation Test. * $p<.05 ;{ }^{* *} p<.01$ 
Table 2 also includes correlations between optimism and ranking/rating scores of the Adapted BSIQ. Optimism is significantly correlated with negative interpretations of the BSIQ situations, but only with most ranking scores and not the rating scores. In contrast, with regard to the positive explanations of BSIQ situations, optimism did not correlate with any of the ranking scores but was significantly related to probability ratings and more specifically to the ratings of positive explanations of general events. No significant differences in correlations of optimism with positive versus negative explanations were found in this study.

\section{Discussion}

In this second study, it was again expected that optimism would correlate significantly with negative interpretations of the ambiguous BSIQ situations. This hypothesis was confirmed for all but one ranking scores in this study. In contrast to the results of study 1, higher levels of optimism were not significantly related to lower probability ratings of negative explanations. With regard to positive explanations, optimism was - in line with study 1 - significantly correlated with probability ratings of positive explanations of general events. Optimism was not significantly related to a preference (ranking) for positive explanations in this study.

Although results from study 2 are less convincing than the results from study 1, combined results from both studies do indicate that optimists make less negative interpretations in several domains and more positive interpretations of general events.

A third study was designed as an extension of prior studies, using an open-ended version of the adapted Body Sensations Interpretation Questionnaire. While open-ended versions of the BSIQ have been used before (Austin \& Kiropoulos, 2008; Austin, et al., 2006; Clark, et al., 1997), none of these studies specifically coded positive explanations. The BSIQ was therefore further adapted to allow investigation of spontaneous negative, neutral and positive interpretations.

We collected both coders' and participants' ratings of the open BSIQ responses because it has previously been argued that coders might be unable to rate the degree of catastrophe in participant-generated responses on the BSIQ. Indeed, every anxiety-related response might (or might not) represent a catastrophe or a specific harm-related outcome (Clark, et al., 1997). In an attempt to circumvent this problem, Richards and Klein (2006) added the follow up question 'And what might happen then?' and had participants rate the degree of catastrophe in their responses on a scale ranging from 'not bad at all' to 'extremely bad'. In line with this approach, we also asked participants themselves to rate the valence of their responses. In line with study 2, the study addressed a broader research population and dispositional optimism was measured after the completion of the Open BSIQ. 


\section{STUDY 3}

\section{METHODS}

\section{Participants}

Fifty participants between the age of 18 and 65 participated in this study. Participants who provided more than one explanation or had missing values for at least $1 / 3^{\text {rd }}$ of the Open BSIQ situations, were excluded from data analysis. This resulted in a sample consisting of 44 participants (16 men and 28 women), of which 43 participants completed the second part of the study. The mean age of the study population was 24.39 years $(s d=7.00)$. Good knowledge of the Dutch language was an inclusion criterion for this study. Gift coupons were distributed among the participants using a lottery procedure.

\section{Measures}

\section{Dispositional Optimism}

The Dutch version of the revised Life Orientation Test (Carver, et al., 1994) was used again in this study. This questionnaire yielded good internal reliability, with a Cronbach's alpha of .82.

\section{Open-ended Body Sensations Interpretation Questionnaire - Adapted version}

In this study, an open-ended version of the Adapted Body Sensations Interpretation Questionnaire was used. Some of the items of the adapted BSIQ as used in studies 1 and 2 were rephrased or omitted in this version, because they were considered to be limited in ambiguity without the predetermined answer format. This resulted in an open-ended version of the BSIQ consisting of 26 items ( 11 somatic sensations, 9 social events and 6 general events). Again, each situation was followed by the question 'Why?'. In response to this question participants formulated their own spontaneous explanation of the ambiguous situation.

Valence ratings for the participant-generated explanations were obtained in two ways: by two independent coders and by the participant him-/herself.

The valence ratings by two independent coders were obtained after a short training phase. The coders rated the valence of participants' generated explanations on the open BSIQ on a VAS scale ranging from 0 (='very negative') to 100 (='very positive'). Answers including more than one explanation for a given situation, were coded as a missing value.

Valence rating by participants occurred in the second phase of the study, as explained in the procedure section. Participants were asked to rate the valence of their own explana- 
tions on a VAS-scale ranging from 0 (= 'very negative') to 100 (= 'very positive'). One participant did not complete the second part of the study and was excluded for data analysis of participants' ranking.

Although both raters and participants were asked to code the valence of the data on a continuous scale, the continuous data was recoded to a discrete scale, with the following values: negative (0-34), neutral (35-65) and positive (66-100). This scale is comparable to the ranking scores of the previous studies. To eliminate the influence of missing values, mean proportion scores for ranking of coders and participants were calculated.

Interrater reliability was calculated based on 25 percent of the coding material that was rated by both independent coders by means of the KALPHA macro for SPSS (Hayes \& Krippendorff, 2007). This resulted in a Krippendorff's alpha of .78 as an interrater reliability estimate for the continuous valence ratings of both coders. Because interrater reliability was satisfactory, the rest of the data was coded by one of the two coders.

\section{Procedure}

The study was set up as an online questionnaire study. Individuals that verbally agreed to participation received an e-mail with additional information and an informed consent form. After receiving an autographed version of the informed consent from, online participation in the study was initiated. In the first phase of the study, participants filled in the Open-ended version of the Adapted Body Sensations Interpretation Questionnaire. Subsequently they completed the Life Orientation Test Revised.

Within 2 days, participants were invited by e-mail to participate in the second phase of the study. In the second phase of the study participants received a document containing their own responses to the ambiguous situations of the open-ended adapted BSIQ. Participants provided valence ratings of these explanations online within one week.

\section{RESULTS}

\section{Descriptives and correlations}

The level of dispositional optimism of this sample is comparable to the previous studies, with a mean value of 21.36 ( $s d=4.42$ ). Table 3 shows the proportion scores for the amount of negative and positive explanations based on valence ratings of participants and coder(s). Paired samples ttests showed that the proportion of positive explanations was significantly higher than the proportion of negative explanations in all domains, following both participants' and coders' ratings. With exception of the proportion of negative explanations of general situations, proportion scores of participants were significantly higher than proportion scores of the independent coders. 
Table 3. Descriptive statistics and Pearson correlation coefficients of dispositional optimism with Open BSIQ ranking (proportion) scores.

\begin{tabular}{|c|c|c|c|c|c|}
\hline & \multicolumn{4}{|c|}{ Descriptives } & \multirow{2}{*}{$\frac{\text { Correlations }}{\text { LOT-R }}$} \\
\hline & Min & Max & M & sd & \\
\hline Total Coders'Ranking Negative Explanations & .00 & .35 & .13 & .09 & $-.33^{*}$ \\
\hline Coders'Ranking Negative Explanations Somatic Sensations & .00 & .36 & .12 & .11 & -.23 \\
\hline Coders'Ranking Negative Explanations Social Events & .00 & .50 & .15 & .15 & -.28 \\
\hline Coders'Ranking Negative Explanations General Events & .00 & .50 & .12 & .13 & -.10 \\
\hline Total Coders' Ranking Positive Explanations & .04 & .45 & .23 & .09 & .17 \\
\hline Coders'Ranking Positive Explanations Somatic Sensations & .00 & 60 & .23 & .14 & .12 \\
\hline Coders'Ranking Positive Explanations Social Events & .00 & .56 & .22 & .14 & .15 \\
\hline Coders'Ranking Positive Explanations General Events & .00 & 60 & .26 & .16 & -.02 \\
\hline Total Participants' Ranking Negative Explanations & .00 & .73 & .21 & .17 & $-.52^{* *}$ \\
\hline $\begin{array}{l}\text { Participants' Ranking Negative Explanations Somatic } \\
\text { Sensations }\end{array}$ & .00 & .73 & .21 & .19 & $-.46^{* *}$ \\
\hline Participants'Ranking Negative Explanations Social Events & .00 & .88 & .20 & .21 & $-.40^{* *}$ \\
\hline Participants'Ranking Negative Explanations General Events & .00 & .67 & .17 & .17 & $-.37^{*}$ \\
\hline Total Participants'Ranking Positive Explanations & .00 & 1.00 & .43 & .25 & $.30^{*}$ \\
\hline $\begin{array}{l}\text { Participants' Ranking Positive Explanations Somatic } \\
\text { Sensations }\end{array}$ & .00 & 1.00 & .39 & .28 & .24 \\
\hline Participants' Ranking Positive Explanations Social Events & .00 & 1.00 & .40 & .28 & $.37^{* *}$ \\
\hline Participants'Ranking Positive Explanations General Events & .00 & 1.00 & .50 & .27 & .16 \\
\hline
\end{tabular}

Lot- $R$, revised Life Orientation Test. ${ }^{*} p<.05 ;{ }^{* *} p<.01$

Table 3 also shows correlations of dispositional optimism with the proportion of positive and negative explanations of the open-ended Adjusted BSIQ situations. Optimism is only significantly and inversely correlated with the total proportion of negative explanations following coders' assessment. However, more optimism is related to less negative explanations in all domains and more positive explanations of ambiguous social situations according to the valence ratings that participants provided for their own explanations. No significant differences were found for correlations of optimism with positive or negative explanations using Z transformations for dependent correlations. 


\section{Discussion}

Spontaneous interpretation patterns of optimists were measured using an open-ended version of the Adapted BSIQ. Following Austin and Richards (2001), respondents were given the opportunity to rate the valence of their answers on a scale ranging from very negative to very positive with the purpose to measure the degree of catastrophe (versus prosperity) attributed to the participants.

Only coders' rankings of negative explanations (total score) were significantly related to optimism. Participants' rankings were significantly related to dispositional optimism. Based on participants' valence ratings, optimism was negatively related to negative explanations of ambiguous situations in all domains. Optimism was only positively related to positive explanations, as indicated by participants'valence ratings, with regard to social situations.

\section{General Discussion}

In three studies, an adapted version of the Body Sensations Interpretation questionnaire with fixed and open answer format were used to measure not only negative, but also positive interpretation patterns in relation to the level of optimism. Overall, results underscore that dispositional optimism is related to less negative interpretations and (to a lesser degree) to more positive interpretations of ambiguous situations.

The first aim of the studies was to replicate the previous finding that optimists make generally less negative interpretations of ambiguous situations (Vancleef \& Peters, 2008). All three studies conducted with the adapted BSIQ (fixed and open answer format) support the idea that optimism might protect against a negative interpretation bias. However, there is some variation in the particular variables for which the associations reached significance. While optimism showed strong associations with both rating and ranking scores in study 1 , only the correlations with negative ranking scores of social and general situations reached significance in study 2 . An open-ended Adjusted BSIQ extended this line of findings by showing that also spontaneous selfgenerated negative explanations were inversely related to optimism, at least when participants' own valence ratings of their previous answers were examined. The correlations between optimism and coders' valence ratings were less convincing: only the associations with the total proportion negative explanations reached significance. This might underline the difficulty of coders to correctly judge the degree of catastrophe that was previously noted (Austin, et al., 2006).

Negative interpretation patterns have been proposed to play an important role in the onset and/or maintenance of psychological disorders (MacLeod \& Mathews, 2012; Mathews \& MaCLeod, 1994, 2005; Salemink, et al., 2007). Interpretation biases have been reported in relation to for instance panic disorder, (social) anxiety and chronic pain (Clark, 1999; Clark, et al., 1997; Hirsch 
\& Mathews, 1997; Lucock \& Salkovskis, 1988; Pincus \& Morley, 2001; Pincus, et al., 1994; Pincus, et al., 1996; Salkovskis, et al., 1996). Research has mainly focussed on risk factors for catastrophic interpretations and found evidence for the impact of several anxiety constructs, such as anxiety sensitivity, illness-injury sensitivity or fear of negative evaluation (Keogh, et al., 2004; Teachman, 2005; Vancleef \& Peters, 2008). Results of the present studies show that optimism might be a protective factor for negative interpretation biases.

The second aim of this study was to add to earlier research by examining not only negative but also positive interpretation patterns of optimists. Studies using implicit attention task paradigms provide evidence of optimists' distinct information processing pattern in favour of positive information (Karademas, et al., 2007; Segerstrom, 2001). To this date, it is unclear whether this finding extends to interpretation patterns of optimists. Most interpretation bias studies have mainly considered threatening (negative) versus non-threatening (neutral or positive) inferences, as exemplified by the original Body Sensations Interpretation Questionnaire (Clark, et al., 1997). Nevertheless, differentiation between non-threatening/neutral and outright positive interpretations can potentially add understanding and contribute to refining the existing interpretation training paradigms (MacLeod \& Mathews, 2012).

The results from three studies using an adapted version of the BSIQ provide preliminary evidence for the relation between dispositional optimism and positive interpretation patterns. In the first study, optimism was related to all rating scores for positive explanations and ranking scores for positive explanations of general situations. In the second and third study however, optimists only showed a preference (ranking) for positive interpretations of respectively general and social situations. Only participants' coding of the valence of their own responses led to this conclusion in the third study. Even though formal testing of the difference in magnitude of the correlations between optimism and negative interpretations compared to the magnitude of the correlations between optimism and positive interpretations did not differ significantly, the absolute value of the correlations suggest weaker correlations between optimism and positive interpretations.

Although research on positive interpretation patterns is scarce, there is however at least one line of research that has focused on this subject, namely the studies on optimistic biases. An optimistic bias refers to an overestimation of the likelihood of positive future events and an underestimation of the likelihood of negative future events. An optimistic bias is common in the general population, but absent in depressed individuals (Strunk, Lopez, \& DeRubeis, 2006). Although it has been argued an optimistic bias is adaptive (McKay \& Dennett, 2009), extreme forms of underestimation of threat might be maladaptive with regard to certain behaviours such as for instance drunk driving, safe sex and gambling (Weinstein, 1989). Radcliffe and Klein (2002) found that maladaptive processing of risk information is related to unrealistic, but not dispositional optimism. The results of our three studies demonstrate that positive explanations are preferred more and that they are considered to be more probable in general. However, inferences about the level of realism of optimistic versus pessimistic interpretations cannot be made based on these studies.

In the third study, we found a differentiation between correlations of dispositional optimism with participant-rated and with coder-rated valences of open answers. This finding seems 
to underscore the importance of participants' own interpretations of their responses, as emphasized by Austin and Richards (2001). Possibly subtle differences in coding criteria that were employed by our coders and by participants may have contributed to this differentiation. However, several other explanations may also be plausible. The (Adapted) Body Sensations Interpretations Questionnaire is designed to investigate interpretation of potentially threatening situations in several domains. However, the cognitive theory does not only include appraisals of threat, but also cognitions of coping efficacy and control. It has been argued that positive cognitions concerning coping or control might prevent the escalation of initial appraisals of threat (Casey, Oei, \& Newcombe, 2004; Casey, Oei, Newcombe, \& Kenardy, 2004). Coping efficacy and control attributions of optimists might have contributed to participants rating their own explanation of the ambiguous situation as less negative than the coders. In line with Seligman's theory on learned helplessness, one might speculate that the activation of these attributions regarding coping efficacy and control might protect optimists against feelings of depression (Seligman, 1972). It is also possible that optimists' less negative ratings represent a positive reappraisal of optimists that might be initiated by their tendency to broaden their attention (Fredrickson, 2001) and/or to generally anticipate a positive future (Scheier \& Carver, 1985).

Several shortcomings of these studies should be acknowledged. First, subtle differences in procedures between the two adapted versions of the BSIQ (open-ended and fixed answer format) and the three studies might have complicated comparing results. Second, studies were executed in a healthy population. It has been argued that interpretation biases are more common in a clinical population. Investigation of negative and positive interpretation patterns of optimists in a patient sample might produce stronger effects. We are currently investigating this research question. Third, only dispositional optimism as a resilience factor was related to threat-related cognitions. Including both resilience and risk factors in investigating interpretation in a broader sense would contribute to these findings.

Despite mixed results over the three studies, it does seem that optimism is related to negative and (to a lesser extend to) positive interpretations of ambiguous threat-related information. These findings are in line with attention research, in which evidence is found for information processing strategies of optimists that are focussed on turning away from negative information (Isaacowitz, 2005) and/or turning towards positive information (Karademas, et al., 2007; Segerstrom, 2001). Based on results of these studies, it is argued that interpretation might be one of the core processes leading to the optimists' advantage.

Future research could advance the field taking the following steps. First, research should not only focus on optimism as a resilience factor but also on risk factors, converging these two research lines and testing the unique contribution of optimism in the prediction of interpretation patterns. Second, Carr (1974) defined threat as the product of the perceived probability and subjective cost of aversive events. Our studies indicate that optimists not only rate negative events as less probable, but also as less threatening (or subjectively costly). Measuring both aspects of threat perception would add knowledge to interpretation patterns in optimists. Third, and in line with this notion, investigating cognitions in a broader sense may add understanding to how 
optimists deal with potentially threatening situations. Experimental evidence in the broad area of cognitive information processing could enhance cognitive bias modification programs focussed on (less) negative versus (more) positive interpretations (MacLeod \& Mathews, 2012; Salemink, et al., 2007), imagining positive events (Holmes, Lang, \& Shah, 2009) or even perspective broadening (Schartau, Dalgleish, \& Dunn, 2009). Last but not least, the adapted versions of the BSIQ might provide useful tools to advance this line of research in both negative and positive interpretation patterns and their role in the beneficial effects of optimism on well-being.

\section{ACKNOWLEDGMENTS}

We thank Michiel Vestjens and Charlie Bonnemayer for their technical support with the online BSIQ. Further, we thank Astrid Dello and Sita van Riet for their valuable assistance in coding the data of study 3. Kevin van Gestel, Monique Gubbels and Susan Steenhuis are thanked for their help in the data collection. This work was supported by the Netherlands Organisation for Scientific Research under Grant (number 453-07-005). The contribution of Dr. Linda Vancleef was supported by the Netherlands Organisation for Scientific Research under Grant (number 451-09-026). 


\section{REFERENCES}

Allison, P. J., Guichard, C., \& Gilain, L. (2000). A prospective investigation of dispositional optimism as a predictor of health-related quality of life in head and neck cancer patients. Quality of life research: an international journal of quality of life aspects of treatment, care and rehabilitation, 9, 951-960.

Austin, D., \& Kiropoulos, L. (2008). An internet-based investigation of the catastrophic misinterpretation model of panic disorder. Journal of anxiety disorders, 22, 233-242.

Austin, D. W., \& Richards, J. C. (2001). The catastrophic misinterpretation model of panic disorder. Behaviour research and therapy, 39, 1277-1291.

Austin, D. W., Richards, J. C., \& Klein, B. (2006). Modification of the Body Sensations Interpretation Questionnaire (BSIQM): validity and reliability. Journal of anxiety disorders, 20, 237-251.

Brissette, I., Scheier, M. F., \& Carver, C. S. (2002). The role of optimism in social network development, coping, and psychological adjustment during a life transition. Journal of Personality and Social Psychology, 82, 102-111.

Butler, G., \& Mathews, A. (1983). Cognitive processes in anxiety. Advances in Behaviour Research and Therapy, 5, 51-62.

Carr, A. T. (1974). Compulsive neurosis: a review of the literature. Psychological bulletin, 81, 311-318.

Carver, C. S., Pozo-Kaderman, C., Harris, S. D., Noriega, V., Scheier, M. F., Robinson, D. S., Ketcham, A. S., Moffat, F. L., Jr., \& Clark, K. C. (1994). Optimism versus pessimism predicts the quality of women's adjustment to early stage breast cancer. Cancer, 73, 1213-1220.

Carver, C. S., Scheier, M. F., \& Segerstrom, S. C. (2010). Optimism. Clinical Psychological Review.

Casey, L. M., Oei, T. P., \& Newcombe, P. A. (2004). An integrated cognitive model of panic disorder: the role of positive and negative cognitions. Clinical psychology review, 24, 529-555.

Casey, L. M., Oei, T. P., Newcombe, P. A., \& Kenardy, J. (2004). The role of catastrophic misinterpretation of bodily sensations and panic self-efficacy in predicting panic severity. Journal of anxiety disorders, 18, 325-340.

Clark, D. M. (1999). Anxiety disorders: why they persist and how to treat them. Behaviour research and therapy, 37 Suppl 1, S5-27.

Clark, D. M., Salkovskis, P. M., Ost, L. G., Breitholtz, E., Koehler, K. A., Westling, B. E., Jeavons, A., \& Gelder, M. (1997). Misinterpretation of body sensations in panic disorder. Journal of consulting and clinical psychology, 65, 203-213.

Fredrickson, B. L. (2001). The role of positive emotions in positive psychology. The broaden-and-build theory of positive emotions. The American psychologist, 56, 218-226.

Hayes, A. F., \& Krippendorff, K. (2007). Answering the call for a standard reliability measure for coding data. Communication Methods and Measures, 1, 77-89.

Hirsch, C., \& Mathews, A. (1997). Interpretative inferences when reading about emotional events. Behaviour research and therapy, 35, 1123-1132.

Hirsch, J. K., Walker, K. L., Chang, E. C., \& Lyness, J. M. (2012). Illness burden and symptoms of anxiety in older adults: optimism and pessimism as moderators. International Psychogeriatrics, 24, 1614-1621.

Holmes, E. A., Lang, T. J., \& Shah, D. M. (2009). Developing interpretation bias modification as a "cognitive vaccine" for depressed mood: imagining positive events makes you feel better than thinking about them verbally. Journal of abnormal psychology, 118, 76-88.

Isaacowitz, D. M. (2005). The gaze of the optimist. Personality \& social psychology bulletin, 31, 407-415. 
Jaksic, N., Brajkovic, L., Ivezic, E., Topic, R., \& Jakovljevic, M. (2012). The role of personality traits in posttraumatic stress disorder (PTSD). Psychiatria Danubina, 24, 256-266.

Karademas, E. C., Kafetsios, K., \& Sideridis, G. D. (2007). Optimism, self-efficacy and information processing of threatand well-being-related stimuli. Stress and Health, 23, 285-294.

Keogh, E., Hamid, R., Hamid, S., \& Ellery, D. (2004). Investigating the effect of anxiety sensitivity, gender and negative interpretative bias on the perception of chest pain. Pain, 111, 209-217.

Litt, M. D., Tennen, H., Affleck, G., \& Klock, S. (1992). Coping and cognitive factors in adaptation to in vitro fertilization failure. J Behav Med, 15, 171-187.

Lucock, M. P., \& Salkovskis, P. M. (1988). Cognitive factors in social anxiety and its treatment. Behaviour research and therapy, 26, 297-302.

Macleod, A. K., \& Conway, C. (2005). Well-being and the anticipation of future positive experiences: The role of income, social networks, and planning ability. Cognition \& emotion, 19, 357-374.

MacLeod, C., \& Mathews, A. (2012). Cognitive bias modification approaches to anxiety. Annual Review of Clinical Psychology, 8, 189-217.

Mahler, H. I. M., \& Kulik, J. A. (2000). Optimism, pessimism and recovery from coronary bypass surgery: Prediction of affect, pain and functional status. Psychology, Health and Medicine, 5, 347-358.

Mathews, A., \& MacLeod, C. (1994). Cognitive approaches to emotion and emotional disorders. Annual review of psychology, 45, 25-50.

Mathews, A., \& MacLeod, C. (2005). Cognitive vulnerability to emotional disorders. Annual Review of Clinical Psychology, 1, 167-195.

McKay, R. T., \& Dennett, D. C. (2009). The evolution of misbelief. The Behavioral and brain sciences, 32, 493-510; discussion 510-461.

McNally, R. J., \& Foa, E. B. (1987). Cognition and agoraphobia: Bias in the interpretation of threat. Cognitive Therapy and Research, 11, 567-581.

Peters, M. L., Sommer, M., de Rijke, J. M., Kessels, F., Heineman, E., Patijn, J., Marcus, M. A., Vlaeyen, J. W., \& van Kleef, M. (2007). Somatic and psychologic predictors of long-term unfavorable outcome after surgical intervention. Annals of Surgery, 245, 487-494.

Pincus, T., \& Morley, S. (2001). Cognitive-processing bias in chronic pain: a review and integration. Psychological bulletin, 127, 599-617.

Pincus, T., Pearce, S., McClelland, A., Farley, S., \&Vogel, S. (1994). Interpretation bias in responses to ambiguous cues in pain patients. Journal of psychosomatic research, 38, 347-353.

Pincus, T., Pearce, S., \& Perrott, A. (1996). Pain patients' bias in the interpretation of ambiguous homophones. The British journal of medical psychology, 69 (Pt 3), 259-266.

Popper, K. R. (1994). Introduction. In K. R. Popper (Ed.), The Myth of the Framework: In Defence of Science and Rationality (pp. xii-xiii). London: Routledge.

Radcliffe, N. M., \& Klein, W. M. P. (2002). Dispositional, unrealistic and comparative optimism: Differential relations with the knowledge and processing of risk information and beliefs about personal risk. . Personality \& social psychology bulletin, 28.

Ramirez-Maestre, C., Esteve, R., \& Lopez, A. E. (2012). The role of optimism and pessimism in chronic pain patients adjustment. The Spanish Journal of Psychology, 15, 286-294. 
Rasmussen, H. N., Scheier, M. F., \& Greenhouse, J. B. (2009). Optimism and physical health: a meta-analytic review. Annals of Behavioral Medicine, 37, 239-256.

Rasmussen, K. A., \& Wingate, L. R. (2011). The role of optimism in the interpersonal-psychological theory of suicidal behavior. Suicide and Life-Threatening Behavior, 41, 137-148.

Salemink, E., van den Hout, M., \& Kindt, M. (2007). Trained interpretive bias: validity and effects on anxiety. Journal of behavior therapy and experimental psychiatry, 38, 212-224.

Salkovskis, P. M., Clark, D. M., \& Gelder, M. G. (1996). Cognition-behaviour links in the persistence of panic. Behaviour research and therapy, 34, 453-458.

Schartau, P. E., Dalgleish, T., \& Dunn, B. D. (2009). Seeing the bigger picture: training in perspective broadening reduces self-reported affect and psychophysiological response to distressing films and autobiographical memories. Journal of abnormal psychology, 118, 15-27.

Scheier, M. F., \& Carver, C. S. (1985). Optimism, coping, and health: assessment and implications of generalized outcome expectancies. Health Psychology, 4, 219-247.

Scheier, M. F., \& Carver, C. S. (1992). Effects of optimism on psychological and physical well-being: Theoretical overview and empirical update. Cognitive Therapy and Research, 16, 201-228.

Scheier, M. F., Weintraub, J. K., \& Carver, C. S. (1986). Coping with stress: divergent strategies of optimists and pessimists. Journal of Personality and Social Psychology, 51, 1257-1264.

Segerstrom, S. C. (2001). Optimism and attentional bias for negative and positive stimuli. Personality and Social Psychology Bulletin, 27, 1334-1343.

Segerstrom, S. C. (2007). Optimism and resources: Effects on each other and on health over 10 years. Journal of research in personality, 41, 772-786.

Seligman, M. E. (1972). Learned helplessness. Annu Rev Med, 23, 407-412.

Solberg Nes, L., Evans, D. R., \& Segerstrom, S. C. (2009). Optimism and college retention: mediation by motivation, performance and adjustment. Journal of Applied Social Psychology, 39, 1887-1912.

Srivastava, S., McGonigal, K. M., Richards, J. M., Butler, E. A., \& Gross, J. J. (2006). Optimism in close relationships: How seeing things in a positive light makes them so. Journal of Personality and Social Psychology, 91, 143-153.

Strunk, D. R., Lopez, H., \& DeRubeis, R. J. (2006). Depressive symptoms are associated with unrealistic negative predictions of future life events. Behaviour research and therapy, 44, 861-882.

Teachman, B. A. (2005). Information Processing and Anxiety Sensitivity: Cognitive Vulnerability to Panic Reflected in Interpretation and Memory Biases. Cognitive Therapy and Research, 29, 479-499.

Thomas, J. L., Britt, T. W., Odle-Dusseau, H., \& Bliese, P. D. (2011). Dispositional optimism buffers combat veterans from the negative effects of warzone stress on mental health symptoms and work impairment. Journal of Clinical Psychology, 67, 866-880.

Vancleef, L. M., \& Peters, M. L. (2008). Examining content specificity of negative interpretation biases with the Body Sensations Interpretation Questionnaire (BSIQ). Journal of anxiety disorders, 22, 401-415.

Weinstein, N. D. (1989). Optimistic biases about personal risks. Science, 246, 1232-1233.

Wright, L. J., Zautra, A. J., \& Going, S. (2008). Adaptation to early knee osteoarthritis: the role of risk, resilience, and disease severity on pain and physical functioning. Annals of Behavioral Medicine, 36, 70-80. 



\section{More optimism, less pain! The influence of generalized and pain-specific expectations on experienced cold-pressor pain}

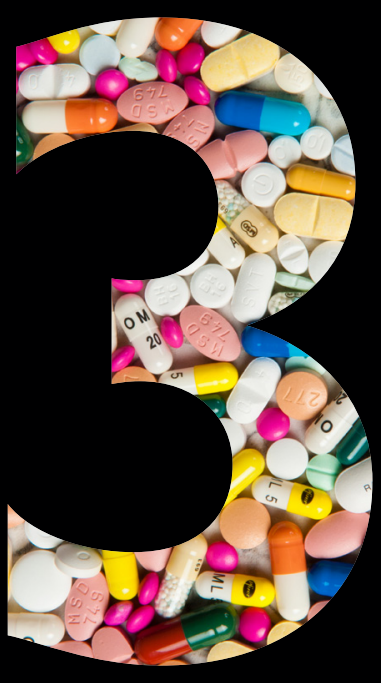

This chapter is published as: Hanssen, M. M., Vancleef, L. M. G., Vlaeyen, J. W. S. \& Peters, M. L. (2014). More optimism, less pain! The influence of generalized and pain-specific expectations on experienced cold-pressor pain. Journal of behavioral medicine, 37, 47-58. 



\section{ABSTRACT}

Accumulating evidence suggests that dispositional optimism might be a protective factor against experiencing pain. The current paper presents two studies investigating the association between dispositional optimism and experimental pain. Moreover, the influence of pain-specific expectations on this association is investigated. In Study 1, mediation of pain-specific expectations in the relation between dispositional optimism and pain was hypothesized. Expected and experienced pain ratings were obtained from 66 healthy participants undergoing a cold pressor tolerance task. In Study 2, the moderating effect of dispositional optimism on the association between induced pain expectations and pain reports was studied in 60 healthy participants undergoing a one-minute cold pressor task. Both studies controlled for individual differences in fear of pain. Significant associations between dispositional optimism and pain ratings were found in both studies, although the exact time point of these associations differed. Subscale analyses revealed that only the pessimism subscale contributed significantly to these findings. We found no evidence for hypothesized mediation and moderation effects. Alternative explanations for the optimism-pain association are discussed. 



\section{INTRODUCTION}

Chronic pain is an important health problem, profoundly impacting on millions of people's lives. In the past decades, research has successfully identified important psychological risk factors for the transition of acute to chronic pain (Linton \& Shaw, 2011). For instance the fear-avoidance model of pain, one of the most influential cognitive-behavioral models nowadays, describes how a negative spiral of catastrophic appraisals, pain-related fear and avoidance can lead to or maintain pain-related disability (Leeuw, et al., 2007; Vlaeyen \& Linton, 2000, 2012). Despite major advances in understanding and treating pain, an exclusive focus on risk factors might fail to capture the full complexity of the pain experience and its determinants.

Although the attention is growing, comparably little effort has been put into the systematic study of resilience factors for pain so far. Disentangling what protects people from getting caught up in the negative spiral towards disability can lead to new possibilities for therapeutic interventions. Several studies have already indicated that higher levels of resilience in pain patients are related to various positive outcomes, such as lower levels of daily pain catastrophizing (Ong, Zautra, \& Reid, 2010), less health care and medication use (Karoly \& Ruehlman, 2006), better adjustment to early confrontation with pain (Wright, Zautra, \& Going, 2008) and better psychological adjustment to chronic pain (Mangelli, Gribbin, Buchi, Allard, \& Sensky, 2002; Ramirez-Maestre, Esteve, \& Lopez, 2012a; Sturgeon \& Zautra, 2010). In the past decades, dispositional optimism has been proposed as one potential resilience factor for pain. However, few studies have studied its influence on pain using an experimental design or tried to unravel the underlying mechanisms.

\section{Dispositional Optimism and Pain}

There is a vast amount of research relating dispositional optimism, defined as generalized positive outcome expectancy, to increased psychological and physical well-being (Rasmussen, Scheier, \& Greenhouse, 2009; Scheier \& Carver, 1985, 1992). More recently, the role of dispositional optimism in relation to the experience of pain has been acknowledged. First, dispositional optimism may be related to better well-being despite pain. In chronic pain patients, dispositional optimism was found to be related to increased feelings of control, the use of more active coping strategies and better functional performance (Affleck, et al., 2001; Brenes, Rapp, Rejeski, \& Miller, 2002; Novy, Nelson, Hetzel, Squitieri, \& Kennington, 1998; Ramirez-Maestre, Esteve, \& Lopez, 2012b). Second, optimists may be less sensitive to the experience of pain, which may protect them from the transition of acute to chronic pain. Survey studies in community samples indicated that the prevalence of various types of pain complaints is lower in more optimistic people (Achat, Kawachi, Spiro, DeMolles, \& Sparrow, 2000; Sipila, Ylostalo, Ek, Zitting, \& Knuuttila, 2006). Reversed causality cannot be excluded in these studies but other studies demonstrated that dispositional optimism may predict subsequent pain, for instance after surgical intervention (Mahler \& Kulik, 2000; Powell, et 
al., 2012). In addition, experimental pain paradigms have found higher ischemic pain tolerance (Costello, et al., 2002), lower pain reports and lower cardiovascular reactivity during a cold pressor task in optimists as compared to pessimists (Geers, Wellman, Helfer, Fowler, \& France, 2008).

\section{Pain-specific Expectations and Pain}

Generalized expectations are not the only psychological factors that have been related to pain outcomes. The influence of pain-specific expectations on the subjective experience of pain is well documented. Expectation was identified as one of the core mechanisms underlying placebo analgesia (Benedetti, et al., 2003). The mere suggestion that a strong versus weak pain stimulus will be given alters subsequent pain ratings (Colloca, Sigaudo, \& Benedetti, 2008; Keltner, et al., 2006; Lorenz, et al., 2005). Interestingly, pain-specific expectations not only influence pain reports, but also the neural processes that underlie nociception and pain-relief (Colloca, et al., 2008; Lorenz, et al., 2005; Mirsky, 2007).

\section{Disentangling the Relationship between Generalized and Pain-specific Expectations}

It may be proposed that pain-specific expectations might be a mediating factor in the link between dispositional optimism and pain. Optimists typically expect positive outcomes in a variety of situations (Scheier \& Carver, 1985). Possibly optimists' general expectancy of positive outcomes extends to pain-specific expectations, thereby diminishing pain-sensitivity and avoidance behavior.

It has also been suggested that dispositional optimism interacts with situational factors in determining pain sensitivity (Geers, Wellman, Fowler, Helfer, \& France, 2010; Geers, et al., 2008). Especially under conditions where pain expectancies are manipulated (e.g. placebo or nocebo suggestions) the influence of dispositional optimism may become apparent. Previous studies found evidence for the idea that optimists may be more sensitive to placebo suggestions (Geers, Kosbab, Helfer, Weiland, \& Wellman, 2007; Geers, et al., 2010; Morton, Watson, El-Deredy, \& Jones, 2009), while pessimists are more likely to follow a nocebo suggestion (Geers, Helfer, Kosbab, Weiland, \& Landry, 2005). This would mean that pain-specific expectancies might only lead to lower reported pain intensity when dispositional optimism is high.

\section{The Present Research}

In two separate studies we seek to confirm and understand the relationship between dispositional optimism, pain-specific expectations and experimental pain sensitivity.

Study 1 was designed to test the mediation model in which dispositional optimism is expected to lead to lower reported pain intensity and higher tolerance for cold pressor pain through its influence on pain-specific expectations. Study 2 tests the moderation model, in 
which dispositional optimism is hypothesized to moderate the effects of induced pain expectations on experienced pain. Because previous studies found that the optimism and pessimism subscales of the Life Orientation Test may differentially predict various health outcomes (Brenes, et al., 2002; Robinson-Whelen, Kim, MacCallum, \& Kiecolt-Glaser, 1997), we analysed the results using both the total scale score as well as the subscale scores. In addition, both studies controlled for the influence of individual differences in fear of pain. Numerous studies have reported that pain-related fear is associated with increased pain expectations/sensitivity (Arntz, van Eck, \& Heijmans, 1990; Roelofs, Peters, Patijn, Schouten, \& Vlaeyen, 2004; Vlaeyen \& Linton, 2000).

\section{STUDY 1}

\section{METHODS}

\section{Participants}

Sixty-six students (51 female; $M_{\text {age }}=21.41 ; S D=2.36$ ) between the age of 18 and 35 participated in this study. Students were recruited by flyers at Maastricht University and participated in exchange for course credit or financial compensation. Exclusion criteria were non-native Dutch speaking, prior experience with the cold pressor task, high blood pressure or cardiovascular problems and current acute or chronic pain complaints. These criteria were verbally checked prior to scheduling.

\section{Apparatus}

For the cold pressor task, a Julabo ED-19A open heating bath circulator with Plexiglas bath tank was used. Dimensions of the bath opening (width $\times$ length / depth) were $36 \times 30 / 15$ centimeters. Circulated water was maintained at a temperature of $5^{\circ} \mathrm{Celsius}$ with a stability of \pm $0.03^{\circ} \mathrm{Celsius}$. A unit containing water at room temperature $\left(20^{\circ} \mathrm{Celsius}\right)$ was positioned next to the cold pressor apparatus.

\section{Measures}

\section{Dispositional optimism: Life Orientation Test Revised (LOT-R)}

Dispositional optimism, as a generalized positive outcome expectancy, was measured using the LOT-R (Scheier, Carver, \& Bridges, 1994). The LOT-R consists of 3 positively and 3 negatively framed items, as well as 4 filler items. All items are scored on a 5-point scale, ranging from 1 (= strongly agree) to 5 (= strongly disagree). In line with the original conceptualisation, the total score of the LOT-R was used to represent a person's level of dispositional optimism. In addition, optimism and pessimism subscale scores were calculated by summing the positive and nega- 
tive items respectively. A Cronbach's alpha of 79 for the LOT-R total score indicates that the internal consistency is satisfactory in this study. Cronbach's alpha for the optimism and pessimism subscale are .65 and .78 respectively.

\section{Fear of Pain: Fear of Pain Questionnaire Short Form (FPQ-SF)}

The FPQ-SF (Asmundson, Bovell, Carleton, \& McWilliams, 2008) was used to measure fear of pain. The FPQ-SF consists of 20 items describing situations causing minor, severe and medical pain. Participants indicate how fearful they are for the pain in the described situations on a scale from 1 (= not fearful at all) to 5 (= extremely fearful). The total score of the FPQ-SF was used in this study. In this study, internal consistency of the FPQ-SF is good with a Cronbach's alpha of .87.

\section{Expected / Experienced Pain Intensity Ratings and Pain Tolerance}

Pain-specific expectation was measured with a visual analogue scale (VAS). The question 'How much pain do you expect during the cold pressor task?' was followed by a $100 \mathrm{~mm}$ horizontal line, with 'no pain at all' at one end and 'extreme pain' at the other.

Experienced pain was assessed by verbal pain intensity ratings on a scale from 0 ( $=$ no pain at all) to 100 (= extreme pain) at several moments during the cold pressor task. In addition, pain tolerance (i.e. time from the start of immersion until hand withdrawal) was recorded. The maximum tolerance time was set at 300 seconds.

\section{Procedure}

The study was approved by the institutional review board and informed consent was obtained from each participant at arrival in the lab. After providing informed consent, participants received verbal instructions about the procedure. Before starting the cold water immersion, participants rated the expected pain intensity on the VAS. Next, to ensure equal skin temperature before the cold pressor task, participants immersed their non-dominant hand in a container with water at room temperature $\left(20^{\circ} \mathrm{Celsius}\right)$ for the duration of 1 minute. This immersion was immediately followed by the cold water immersion $\left(5^{\circ} \mathrm{Celsius)}\right.$. Participants received the instruction to immerse their hand in the cold water container 'for as long as they could'. They were instructed to immerse their hand up to the level of the wrist line in the water container, thereby horizontally stretching out their hand without resting it on the bottom of the container. At 5 and at 20 seconds after the start of the immersion the researcher prompted participants to give a verbal pain intensity rating (during immersion ratings). The experimenter wrote down the participants' ratings and prevented the im- 
mersion from exceeding the preset maximum time by instructing participants to withdraw their hand from the water when 5 minutes had elapsed. Right after participants extracted their hand from the water, they were prompted to indicate how much pain they experienced just before they withdrew their hand from the cold water (end immersion rating). At 20 seconds post-immersion, participants were asked to rate their pain intensity again (post-immersion rating). At the end of the session, participants completed the trait questionnaires (LOT-R and FPQ-SF) on the computer.

\section{Statistical Analyses}

Mean scores and standard deviations of the main variables of this study (i.e. dispositional optimism (total score), optimism/pessimism (subscales), fear of pain, expected and experienced pain intensity ratings and pain tolerance time were calculated. The strength and direction of the linear relation between these variables were estimated by Pearson correlation coefficients.

To test whether pain-specific expectations mediated the relation between dispositional optimism and pain experience, multiple regression analyses were performed following the guidelines of Baron and Kenny (1986) (see Figure 1). Because the relation of dispositional optimism and pain-specific expectations with early or late pain may differ, three separate mediation analyses were performed for pain during (20 second rating ${ }^{1}$ ), at the end of the immersion and 20 seconds post-immersion. In addition, a mediation analysis for pain tolerance was conducted. In a first regression analysis (path a), it was tested whether the predictor variable (dispositional optimism) was correlated with the outcome variable (pain tolerance / experienced pain intensity). Second, path b was examined to determine if the predictor variable (dispositional optimism) was significantly correlated with the mediator (expected pain intensity). Third, the outcome variable (pain tolerance / experienced pain intensity) was regressed on the mediator (expected pain intensity), whilst controlling for the predictor variable (dispositional optimism) to test path c. To confirm the mediation hypothesis, it was examined if in this latter regression analysis, the mediator (pain expectancy) was significantly correlated with the pain related outcome measures and whether the effect of the predictor variable (dispositional optimism) disappeared or was reduced, thus showing either full or partial mediation. Fear of pain was controlled for in all the regression analyses. Because experienced pain intensity at the end and post-immersion may be influenced by pain tolerance, this variable was controlled for in the analyses of the end and post-immersion pain ratings. All the regression analyses were repeated with the pessimism and optimism subscale instead of the total score of dispositional optimism in order to detect possible differential results.

\footnotetext{
1 For reasons of conciseness, all analyses will be reported for the 20 s during immersion rating. Analyses with the $5 \mathrm{~s}$ measure did not yield significantly different results and can be obtained from the corresponding author.
} 


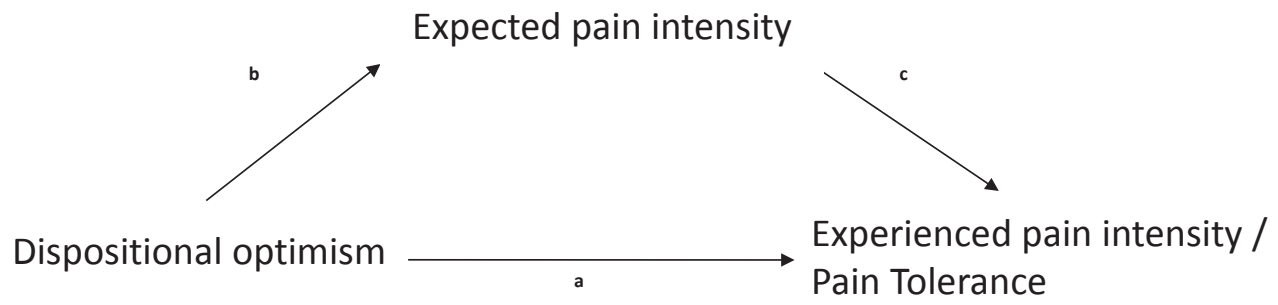

Fig. 1. Hypothesized mediation model.

\section{RESULTS}

\section{Descriptives and intercorrelations of main variables}

Table 1 shows the mean scores, standard deviations and intercorrelations of dispositional optimism (total score), optimism/pessimism (subscales), fear of pain, expected and experienced pain. The mean cold pressor pain tolerance was 195.29 seconds (SD=108.13 seconds). Thirty participants (45.5\%) immersed their hand for 300 seconds, the preset tolerance limit. No significant differences in expected pain $(t=1.07 ; p>.05)$, dispositional optimism $(t=-.61 ; p>.05)$ or fear of pain ( $t=1.14 ; p>.05)$ were found between participants who did and did not reach the preset tolerance time.

The simple correlations between the study variables showed that dispositional optimism correlated significantly with experienced pain intensity during immersion. On subscale level, the pessimism, but not the optimism subscale was found to correlate with experienced pain. Expected pain intensity correlated significantly with each of the experienced pain intensity ratings. Fear of pain was not significantly related to any of the other variables².

2 Bivariate correlation analyses were repeated in the group of participants who did not reach the 300 s tolerance limit and also for men and women separately, resulting in a comparable pattern of correlations. Additionally, no significant sex difference in optimism scores was found using an independent samples t-test. These results indicate that maxing out the immersion time or an even sex distribution might not alter the results in a significant manner. 
Table 1. Mean, standard devation, range and intercorrelations of the main variables of Study 1.

\begin{tabular}{|c|c|c|c|c|c|c|c|c|c|c|c|}
\hline & M & $S D$ & Range & & & & Corre & lations & & & \\
\hline & & & & 1 & 2 & 3 & 4 & 5 & 6 & 7 & 8 \\
\hline 1. Dispositional optimism & 21.71 & 3.87 & $12-29$ & & & & & & & & \\
\hline 2. Optimism subscale & 10.00 & 2.16 & $5-14$ & $.86^{* *}$ & & & & & & & \\
\hline 3. Pessimism subscale & 6.29 & 2.31 & $3-12$ & $-.88^{* *}$ & $-.51^{* *}$ & & & & & & \\
\hline 4. Fear of pain & 43.91 & 9.66 & $29-81$ & -.19 & -.12 & .20 & & & & & \\
\hline 5. Expected pain & 50.29 & 20.78 & $0-82$ & -.05 & -.09 & -.01 & .12 & & & & \\
\hline 6. Pain during immersion & 52.41 & 22.03 & $10-95$ & $-.28^{*}$ & -.18 & $.30^{*}$ & .08 & $.31^{*}$ & & & \\
\hline 7. Pain end immersion & 61.93 & 22.81 & $10-100$ & -.21 & -.08 & .03 & .03 & $.30^{*}$ & $.56^{* *}$ & & \\
\hline 8. Pain post immersion & 42.53 & 24.92 & $0-95$ & -.15 & -.10 & .16 & -.12 & $.31^{*}$ & $.41^{* *}$ & $.65^{* *}$ & \\
\hline 9. Tolerance time (seconds) & 195.29 & 108.13 & $23-300$ & -.03 & -.11 & -.12 & -.12 & -.12 & $-.46^{* *}$ & $-.62^{* *}$ & $-.29 *$ \\
\hline
\end{tabular}

\section{Dispositional Optimism, Expected Pain and Pain Experience: examining Mediation}

First, experienced pain intensity ratings and pain tolerance were regressed on dispositional optimism and control variable(s). Dispositional optimism was a significant predictor of pain intensity during immersion ( $\beta=-.27 ; t=-2.23 ; p<.05$ ). Dispositional optimism also contributed significantly $(B=-.25 ; t=-2.59 ; p<.05)$ to the prediction of pain intensity at the end of the immersion together with pain tolerance as a covariate $(\beta=-.64 ; t=-6.71 ; p<.001)$, but not to pain intensity post-immersion ( $\beta=-.20 ; t=-1.65 ; p>$.05). Subscale analyses showed that only the pessimism subscale is significantly related to pain intensity during immersion $(\beta=.29 ; t=2.38 ; p<.05)$ and pain intensity at the end of the immersion ( $\beta=.27 ; t=2.80 ; p<.05$ ). Pain tolerance was not significantly predicted by dispositional optimism, optimism and pessimism subscales or fear of pain.

Second, a regression analysis testing path b showed that neither dispositional optimism $(\beta=-.02 ; t=-.19 ; p>.05)$ nor fear of pain $(\beta=.12 ; t=.92 ; p>.05)$ contributed significantly in the prediction of expected pain intensity. Repeating the analysis with either the optimism or the pessimism subscale did not alter the results. This finding indicated that one of the prerequisites for testing mediation was not fulfilled.

Although mediation analyses had to be ceased, both Pearson correlations (Table 1) and regression analyses as described above showed dispositional optimism and expected pain to be significantly related to experienced pain intensity. Hence we further explored the relative contribution of dispositional optimism, fear of pain, and expected pain to pain intensity ratings 
by means of regression analyses in which all independent variables were simultaneously entered as predictors of the different outcome variables. Results of these regression analyses are summarized in Table 2. As explained above, pain tolerance was added as a control variable in the analyses of pain intensity ratings at the end of immersion and post-immersion. Expected pain was significantly associated with all pain intensity ratings. Dispositional optimism contributed significantly to the prediction of pain intensity during and at the end of the immersion.

Table 2. Result of regression analyses with dispositional optimism, fear of pain and expected pain as predictors of experienced pain in Study 1.

\begin{tabular}{llccc}
\hline Dependent variable & Predictor & $\beta$ & $\mathrm{t}$ & $\mathrm{p}$ \\
\hline Pain during immersion & & & & \\
\hline $\mathrm{R}^{2}=.17$ & Dispositional optimism & -.27 & -.23 & .03 \\
$F(3,62)=4.14$ & Fear of pain & -.00 & -.03 & .97 \\
$p=.007$ & Expected pain & .30 & 2.56 & .01 \\
\hline Pain end immersion & & & \\
$\mathrm{R}^{2}=.50$ & Dispositional optimism & -.24 & -2.63 & .01 \\
$F(4,61)=15.17$ & Fear of pain & -.12 & -1.30 & .20 \\
$p<.001$ & Expected pain & .23 & 2.49 & .02 \\
& Tolerance time & -.61 & -6.68 & .00 \\
\hline Pain post immersion & & & & \\
$\mathrm{R}^{2}=.23$ & Dispositional optimism & -.19 & -1.64 & .11 \\
$F(4,61)=4.50$ & Fear of pain & -.22 & -1.90 & .06 \\
$p=.003$ & Expected pain & .29 & 2.55 & .01 \\
& Tolerance time & -.29 & -2.53 & .01 \\
\hline
\end{tabular}

Additional subscale analyses pointed out that the pessimism subscale $(\beta=.30 ; t=2.59$; $p<.05)$ contributed significantly to the prediction of pain intensity during immersion, together with expected pain $(\beta=.32 ; t=2.72 ; p<.05)$. In the prediction of pain intensity at the end of the immersion, the pessimism subscale $(\beta=.28 ; t=3.04 ; p<.01)$ was significant together with pain tolerance time $(\beta=.59 ; t=-6.56 ; p<.01)$ and expected pain $(\beta=.25 ; t=2.73 ; p<.05)$. The optimism subscale did not contribute significantly to the prediction of any of the outcome variables. 


\section{DISCUSSION}

This study was designed to test a mediation model in which pain-specific expectations were hypothesized to account for the relation between dispositional optimism and pain. Both dispositional optimism and expected pain intensity were significantly related to experienced pain intensity during a cold pressor task. When analyses were repeated for the optimism and pessimism subscales of the Life Orientation Test, only the pessimism subscale showed a significant association with experienced pain. In contrast to what would be expected, fear of pain did not correlate with any of the outcome variables. Pain tolerance (although technically only measured in participants who did not reach the 300 seconds limit) was not explained by any of our predictor variables.

Although this study corroborates that both dispositional optimism and low pain expectancies were significantly associated with lower pain ratings, the mediating role of pain-specific expectations in the optimism-pain relationship was not confirmed. It may be argued that dispositional optimism does not lead to more positive spontaneous pain expectations, but that it possibly interacts with induced expectations to determine the experience of pain (cf. Geers, et al., 2005; Geers, et al., 2010). Therefore, the second study was designed to test a moderation model. Pain-specific expectations were induced by means of verbal instructions about the cold pressor task, resulting in a group with high pain expectations and one with low pain expectations. It is hypothesized that the suggestion of low pain is especially beneficial in participants scoring high on dispositional optimism.

A relatively high percentage of participants reached the preset tolerance limit of 300 seconds. Even though this is consistent with earlier reports (e.g. Chen, Dworkin, Haug, \& Gehrig, 1989), differences in pain tolerance may have influenced pain intensity ratings. Therefore in Study 2 participants were required to immerse their hand in the cold water container for a fixed period of one minute.

\section{STUDY 2}

\section{METHOD}

\section{Participants}

Participants ( $N=60 ; 36$ female; $M_{\text {age }}=21.83 ; S D=2.10$; Range $\left.=19-30\right)$ were recruited at Maastricht University. Volunteers received a financial compensation for their participation. Participants between 18 and 35 years were included if they did not participate in Study 1. Other in- and exclusion criteria were similar to those in Study 1. 


\section{Apparatus \& Measures}

The cold pressor apparatus and trait questionnaires (i.e. LOT-R and FPQ-SF) were the same as in Study 1. Cronbach alpha values for LOT-R total score, optimism subscale, pessimism subscale and FPQ-SF in Study 2 are .67, .39, .63 and .86 respectively. Again pain-specific expectation was measured by a VAS and verbal ratings of pain intensity were made during, at the end and post-immersion.

\section{Procedure}

To conceal research purposes, students of Maastricht University were invited to participate in a test of what was called 'a new procedure of the cold pressor task'. Approval for the procedure was obtained from the institutional review board. At arrival in the lab all participants received general information about the study and provided informed consent. Participants were then randomised into one of two conditions: the 'low pain expectation' or the 'high pain expectation' group. In both conditions, additional instructions about the 'new cold pressor procedure' were used to manipulate pain expectations. In the 'high pain expectation' group, participants were told that the water in the container was colder than according to the usual procedure (close to $0^{\circ} \mathrm{Celsius)}$. In the 'low pain expectation' group, participants were told that water temperature was warmer $\left(7 / 8^{\circ} \mathrm{Celsius}\right)$. In reality, participants in both groups were exposed to the same temperature $\left(5^{\circ} \mathrm{Celsius}\right)$. Participants were informed that the cold water immersion would have a duration of one minute. They subsequently immersed their hand in the room temperature container for one minute. Thereafter they indicated how painful they expected the cold pressor task to be on a VAS scale and immersed their hand in the cold water. Verbal pain reports were requested at 20 and 40 seconds (during immersion ratings) and at 60 seconds (end immersion rating). Immediately after this last rating, participants were instructed to extract their hand from the cold water container via the computer screen. After 20 seconds, they provided the post-immersion pain intensity rating. At the end of the session participants filled in the LOT-R and FPQ-SF.

\section{Statistical Analyses}

Independent samples t-tests were used to examine differences in age, dispositional optimism (total score), optimism/pessimism (subscales), fear of pain, expected and experienced pain ratings between the two conditions. Pearson correlation coefficients were calculated to explore the relations between the main variables.

The moderation hypothesis was tested following guidelines by Baron and Kenny (1986). Moderation was confirmed when the interaction term 'predictor $x$ moderator' was significant in the regression model whereby predictor, moderator and interaction term were simultaneously entered as predictors of the outcome variable. Continuous variables were centered prior to defining the interaction term. Regression analyses with expected and experienced pain ratings as outcome vari- 
ables were conducted. Pain intensity ratings during $\left(20\right.$ seconds $\left.^{3}\right)$, at the end, and post-immersion were used separately as outcome variables to represent (different moments of) the total pain experience. Condition, dispositional optimism and fear of pain were entered in the first step and the interaction term 'condition $x$ dispositional optimism' was entered in the second step of the regression analyses. Again, all regression analyses were repeated for the optimism and pessimism subscale.

\section{RESULTS}

\section{Descriptive Analyses and Manipulation Check}

Mean scores and standard deviations for the main variables of this study are presented in Table 3. There were no significant differences between the groups on any of the variables except for the optimism subscale. Participants in the low expectations group scored somewhat higher on this subscale. Supporting the effectiveness of the pain expectancy manipulation, expected pain intensity scores differed significantly between the 'low' and 'high' pain expectation group $(t=-2.51$; $p<.05)$. Pain intensity ratings as provided at the end of the immersion were significantly higher in the high pain expectancy group than in the low pain expectancy group. None of the participants withdrew their hand from the water before the end of the one-minute immersion period.

Table 3. Descriptives and differences of the main variables for the'Low' and 'High pain expectation'group in Study 2.

\begin{tabular}{|c|c|c|c|c|c|c|c|c|}
\hline & \multicolumn{3}{|c|}{ Low expectation group $(N=30)$} & \multicolumn{3}{|c|}{ High expectation group $(N=30)$} & \multirow[t]{2}{*}{$t$-value } & \multirow[t]{2}{*}{ Cohen's d } \\
\hline & M & $S D$ & Range & M & $S D$ & Range & & \\
\hline Age & 21.70 & 1.90 & $19-26$ & 21.97 & 2.34 & $19-30$ & -.49 & -.13 \\
\hline Dispositional optimism & 22.76 & 2.49 & $16-26$ & 21.30 & 3.39 & $12-28$ & 1.91 & .49 \\
\hline Optimism subscale & 10.73 & 1.68 & $7-14$ & 9.83 & 1.70 & $6-14$ & $2.06^{*}$ & .53 \\
\hline Pessimism subscale & 5.97 & 1.47 & $4-10$ & 6.53 & 2.05 & $4-12$ & -1.23 & -.31 \\
\hline Fear of pain & 42.30 & 10.25 & $26-63$ & 43.50 & 8.29 & $27-66$ & -.50 & -.13 \\
\hline Expected pain & 44.10 & 23.37 & $0-79$ & 58.57 & 21.19 & $0-91$ & $-2.51^{*}$ & -.65 \\
\hline Pain during immersion & 37.63 & 20.89 & $10-70$ & 42.83 & 19.86 & $5-80$ & -.99 & -.26 \\
\hline Pain end immersion & 61.93 & 22.81 & $0-90$ & 73.17 & 13.86 & $40-95$ & -2.31 & -.60 \\
\hline Pain post immersion & 42.53 & 24.92 & $5-90$ & 49.83 & 25.81 & $5-100$ & -1.11 & -.29 \\
\hline
\end{tabular}

${ }^{*} p<.05$

3 Identical to study 1 the rating at 20 seconds is reported as a measure of experienced pain during the immersion. Similar results were obtained when the 40 seconds ratings were analyzed. 


\section{Correlations}

Table 4 displays the Pearson correlation coefficients between dispositional optimism, optimism/ pessimism subscales, fear of pain, expected and experienced pain intensity. Neither dispositional optimism, the optimism and pessimism subscales, nor fear of pain showed a significant correlation with expected pain intensity. Dispositional optimism was significantly related to pain intensity ratings at the end of the immersion and post-immersion. Subscale analyses showed that the pessimism but not the optimism subscale was related to the end of the immersion and post-immersion ratings. Fear of pain showed a significant correlation with the end immersion rating only. Expected pain correlated significantly with all three ratings of experienced pain. ${ }^{4}$

Table 4. Correlation coefficients between the main variables of Study 2.

\begin{tabular}{lccccccc}
\hline & 1 & 2 & 3 & 4 & 5 & 6 & 7 \\
\hline 1. Dispositional optimism & & & & & & & \\
2. Optimism subscale & $.86^{* *}$ & & & & & & \\
3. Pessimism subscale & $-.87^{* *}$ & $-.48^{* *}$ & & & & & \\
4. Fear of pain & -.10 & -.01 & .17 & & & & \\
5. Expected pain & -.02 & -.01 & .03 & .16 & & & \\
6. Pain during immersion & -.02 & .06 & .13 & .01 & $.33^{*}$ & & \\
7. Pain end immersion & $-.27^{*}$ & -.13 & $.34^{* *}$ & $.30^{*}$ & $.31^{*}$ & $.55^{* *}$ & \\
8. Pain post immersion & $-.32^{*}$ & -.22 & $.32^{* *}$ & .19 & $.26^{*}$ & $.56^{* *}$ & $.71^{* *}$ \\
\hline$* 0<.05 ; * * 01$ & & & & & & &
\end{tabular}

\section{Optimism, Induced Expectations and Pain Experience: examining Moderation}

Regression analyses were conducted to examine the joint and independent predictive value of dispositional optimism, fear of pain, and condition on expected and experienced pain during, at the end and post-immersion. Table 5 presents the results of the regression analyses. For none of the outcome variables, the interaction between dispositional optimism and induced expectations accounted for a significant proportion of variance. Analyses were repeated for the two subscales separately. Neither the optimism nor pessimism subscale showed a significant interaction with induced expectations. Therefore the interaction terms were removed from the model.

4 Correlation analyses for the two conditions separately showed that the significance of the relations of optimism, fear of pain and pain-specific expectations with pain intensity ratings is restricted to the high pain expectations group. Coefficients for both groups separately can be obtained upon request. 
When considering main effects (step 1), condition was the only significant predictor of expected pain intensity. In addition, condition showed a trend towards significance in the prediction of experienced pain at the end of the immersion. Dispositional optimism significantly predicted pain intensity post-immersion, whereas fear of pain was a significant predictor of pain intensity at the end of the immersion. Repeating the analyses with the optimism and pessimism subscales demonstrated that the pessimism subscale significantly predicted pain intensity at the end of immersion $(\beta=.26$, $p<.05$ ) and post-immersion $(\beta=.29, p<.05)$. The optimism subscale was not related to the outcomes.

Table 5. Results of regression analyses with dispositional optimism, fear of pain, condition and dispositional optimism $x$ condition as predictors of experienced pain in Study 2.

\begin{tabular}{|c|c|c|c|c|c|c|c|c|}
\hline Dependent Variable & Model & Variable entered & $R^{2}$ & F & p & $\beta$ & $t$ & $p$ \\
\hline \multirow[t]{7}{*}{ Expected pain } & 1 & Dispositional optimism & .12 & 2.64 & .06 & .07 & .55 & .58 \\
\hline & & Fear of pain & & & & .15 & 1.21 & .23 \\
\hline & & Condition & & & & .32 & 2.49 & .02 \\
\hline & 2 & Dispositional optimism & .14 & 2.20 & .08 & .24 & 1.08 & .28 \\
\hline & & Fear of pain & & & & .15 & 1.17 & .25 \\
\hline & & Condition & & & & .33 & 2.55 & .01 \\
\hline & & Dispositional optimism $\times$ Condition & & & & -.20 & -.94 & .35 \\
\hline \multirow[t]{7}{*}{ Pain during immersion } & 1 & Dispositional optimism & .02 & .32 & .81 & -.01 & -.07 & .95 \\
\hline & & Fear of pain & & & & .00 & .01 & .99 \\
\hline & & Condition & & & & .13 & .92 & .36 \\
\hline & 2 & Dispositional optimism & .02 & .26 & .90 & -.08 & -.33 & .74 \\
\hline & & Fear of pain & & & & .00 & .03 & .98 \\
\hline & & Condition & & & & .12 & .89 & .38 \\
\hline & & Dispositional optimism $\times$ Condition & & & & .08 & .36 & .72 \\
\hline \multirow[t]{7}{*}{ Pain end immersion } & 1 & Dispositional optimism & .19 & 4.53 & .01 & -.19 & -1.53 & .13 \\
\hline & & Fear of pain & & & & .26 & 2.18 & .03 \\
\hline & & Condition & & & & .23 & 1.83 & .07 \\
\hline & 2 & Dispositional optimism & .23 & 4.08 & .01 & -.25 & -1.93 & .06 \\
\hline & & Fear of pain & & & & .27 & 2.27 & .03 \\
\hline & & Condition & & & & .21 & 1.73 & .09 \\
\hline & & Dispositional optimism $\times$ Condition & & & & -.19 & 1.54 & .13 \\
\hline \multirow[t]{7}{*}{ Pain post immersion } & 1 & Dispositional optimism & .13 & 2.76 & .05 & -.29 & -2.21 & .03 \\
\hline & & Fear of pain & & & & .15 & 1.22 & .23 \\
\hline & & Condition & & & & .07 & .51 & .61 \\
\hline & 2 & Dispositional optimism & .14 & 2.20 & .08 & -.42 & -1.92 & .60 \\
\hline & & Fear of pain & & & & .16 & 1.25 & .22 \\
\hline & & Condition & & & & .06 & .44 & .66 \\
\hline & & Dispositional optimism $\times$ Condition & & & & .16 & .77 & .45 \\
\hline
\end{tabular}




\section{DISCUSSION}

The second study was designed to test the hypothesis that dispositional optimism moderates the relation between induced pain expectations (high versus low) and expected as well as experienced pain intensity. In line with previous work (Arntz \& Claassens, 2004; Arntz, et al., 1990; Vlaeyen, et al., 2009), manipulation of pain-specific expectations using verbal instructions about the pain task was successful. However, dispositional optimism did not moderate the effect of induced expectations on expected or experienced pain. As in Study 1, results demonstrated that both pain-specific expectations and dispositional optimism correlate with pain intensity experienced in a cold pressor task. Dispositional optimism (and more specifically the pessimism subscale) significantly predicted post-immersion pain reports, over and above the influence of other variables. Pain intensity at the end of immersion was predicted by fear of pain and the pessimism subscale of the LOT-R. Although the current study did not provide support for the moderating effect of optimism on the influence of induced pain expectations, the results again demonstrated a significant association between both generalized and pain-specific expectations and the pain experience.

\section{GENERAL DISCUSSION}

Two studies examined the associations of dispositional optimism and pain-related expectations with pain tolerance and experienced pain intensity in healthy participants undergoing a cold pressor task. The following conclusions can be derived from the present findings. Firstly, the role of pain-related expectations in the pain experience was established once more. Secondly, dispositional optimism was independently related to experienced pain intensity in both studies, thereby confirming the hypothesized relation between dispositional optimism and pain. Analyses with the optimism and pessimism subscales separately indicated that this association was mainly driven by the pessimism subscale. Finally, the results failed to support our hypothesized mediation and moderation models explaining the association amongst dispositional optimism, pain-specific expectations and pain sensitivity.

These studies add to the bulk of literature on the relation between pain-related expectations and reports of experienced pain (Devine \& Spanos, 1990; Keltner, et al., 2006). In both studies, pain-specific expectations - both spontaneous and induced - correlated significantly with verbal pain ratings and this appeared to be independent from dispositional optimism and fear of pain.

The key variable of interest in this study was dispositional optimism, which has repeatedly been ascribed pain-protective characteristics (Costello, et al., 2002; Geers, et al., 2008; Novy, et al., 1998; Sipila, et al., 2006). In line with the literature, both studies demonstrated that dispositional optimism as indexed by the LOT-R total score is related to pain intensity ratings. It should be noted however that dispositional optimism predicted reported pain during and at the end of the immersion in the first study and post-immersion in the second study. Possibly procedural and task-specific differences, as discussed below, might have contributed to this difference. Never- 
theless, the significant effect of dispositional optimism on reported pain was consistently found in both studies. Interestingly, we found this relation despite controlling for fear of pain or painspecific expectations.

Since both subscales of the Life Orientation Test have been ascribed differential predictive value, all the analyses were repeated for the optimism and pessimism subscales. The observation that pessimism is more strongly associated with health outcomes (Brenes, et al., 2002; RobinsonWhelen, et al., 1997) was confirmed by our data. Only the pessimism subscale contributed to the overall effect of dispositional optimism on experienced pain. This finding stresses the importance of investigating whether positive and/or negative outcome expectancies are accountable for the relation of dispositional optimism with several (health-related) outcome measures. Moreover, optimism and pessimism might be differentially related to certain underlying mechanisms of the dispositional optimism-pain link. A study by Ramirez-Maestre and colleagues (2012b) found that optimism and pessimism (subscales) lead to better adjustment in pain patients, through the use of active versus passive coping strategies respectively.

Both studies controlled for the influence of fear of pain, a known determinant of expected and experienced pain. Unexpectedly, fear of pain was not related to experienced pain or pain tolerance in Study 1. In line with prior research (Arntz, et al., 1990; Leeuw, et al., 2007; McCracken, Gross, Sorg, \& Edmands, 1993; Vlaeyen \& Linton, 2000), fear of pain was significantly related to experienced pain in the second study.

The present studies were specifically designed to investigate the role of pain-specific expectations in the relation between dispositional optimism and pain. In the first study, a mediation model was tested in which it was hypothesized that higher levels of dispositional optimism would translate into less negative pain expectations, resulting in lower experienced pain and higher pain tolerance in a cold pressor task. Surprisingly, dispositional optimism did not correlate significantly with specific expectations about cold pressor pain, disconfirming the hypothesized mediation model. Study 2 tested a moderation model in which dispositional optimism was expected to interact with induced expectations. The importance of the interaction of more stable characteristics and situational factors was argued before in studies describing the influence of dispositional optimism on placebo or nocebo responding (Geers, et al., 2005; Geers, et al., 2007; Geers, et al., 2010). Results of the second study show that dispositional optimism does not moderate the relation between induced expectations and expected and experienced pain. In conclusion, neither the mediation nor the moderation model was supported. Although on theoretical grounds one would expect that global positive expectations would translate into positive expectations towards specific situations (in this case a pain situation), research in other domains have cautioned against comparing generalized and situational expectations (Klein \& Zajec, 2008). It has been argued that optimistic expectations are expressed strategically, being more extreme in situations in which the risk of disconfirmation is low (Armor \& Taylor, 1998). It could be speculated that a painful situation is a situation in which the risk of disconfirmation of optimistic expectations is considered too high. These findings suggest that alternative explanations should be considered for a better understanding of the optimism-pain link. 
One of the possible underlying mechanisms, repeatedly related to optimism, is coping with stress and pain (Scheier \& Carver, 1985; Solberg Nes \& Segerstrom, 2006). The tendency of optimists to cope in a more active and less avoidant manner as well as optimists'flexibility in dealing with stressors, have been related to general well-being. Dispositional optimism has also been related to more adaptive pain coping (Geers, et al., 2008; Novy, et al., 1998; Ramirez-Maestre, et al., 2012b). Optimism was shown to be positively related to for instance the coping strategies diverting attention and behavioral activity and negatively to pain catastrophizing (Bargiel-Matusiewicz \& Krzyszkowska, 2009). These coping strategies, in turn predicted better adjustment to chronic pain (Ramirez-Maestre, et al., 2012b).

Another candidate mechanism, also described in placebo literature, is cognitive reappraisal (Wiech, Ploner, \& Tracey, 2008). Possibly, optimistic people expect as much pain as less optimistic people, but they may attach another meaning to the pain. The translation of generalized positive outcome expectancies into pain-specific expectations might not be in terms of lower expected pain intensity. It could be that optimists reappraise pain or that they find benefits in a painful situation instead of dwelling on the negative consequences.

One might also argue that the relation between dispositional optimism and pain could be the result of a self-report bias in optimists. Higher effect sizes are typically found for the relation of optimism with subjective as compared to objective health measures (Rasmussen, et al., 2009). However, significant relations of optimism with objective measures such as immune functioning or psychophysiological measures have been reported (Costello, et al., 2002; Segerstrom, 2005). Moreover, Geers and colleagues (2008) discarded individual differences in self-representational bias as an explanation for the relation between optimism and pain sensitivity by demonstrating that scores on the public self-awareness scale were not predictive of cold pressor pain.

Some limitations of the present studies may be noted. First of all, procedural differences between the two studies may limit a direct comparison of their results. For instance, immersion with tolerance measurement versus a fixed one-minute immersion and measurement of expected pain intensity before versus after the immersion in the room temperature container, might have contributed to an asymmetry between the results of both studies. Furthermore, in both studies optimism and fear of pain were measured after completion of the cold pressor task. Although trait measures were used to measure dispositional optimism and fear of pain, it cannot be excluded that the cold pain experience might have influenced the level of reported optimism and fear of pain. Furthermore, a larger sample size would possibly have added statistical power to the moderation analyses in Study 2. Additionally, these studies were conducted in a laboratory setting with healthy participants. It is unclear to what degree these results can be generalized to the daily experience of chronic pain, therefore replication in a clinical population is warranted. A last comment that needs to be made addresses the correlational approach that was applied in these studies. In examining the influence of optimism on the pain experience, manipulation of optimism is necessary to infer conclusions about the causal status of this personality trait.

In conclusion, the results of these two studies provide evidence for the association between dispositional optimism (in this case mainly driven by less negative outcome expectan- 
cies), pain-specific expectations, fear of pain (albeit to a lesser degree) and pain intensity during or after a cold pressor task. Furthermore, the current findings suggest that pain-specific expectations do not mediate the relation between dispositional optimism and pain. Also, the interaction between optimism and induced expectations does not seem to explain differences in pain experience. Dispositional optimism and pain expectations seem to be independently associated with experimentally induced cold pressor pain. Further research should address the causal status of optimism, and in addition try to clarify the proposed mechanisms underlying the pain protective influence of optimism. Knowledge on the mechanisms of resilience can provide alternative starting points for specifically targeted clinical applications. Not only have resilience factors been related to less negative pain-related outcomes (i.e. Karoly \& Ruehlman, 2006; Ong, et al., 2010; Wright, et al., 2008), preliminary findings with interventions aimed at increasing resilience appear to be promising (Carson, et al., 2005). Insight in mediating and moderating variables of resilient processes can help to further shape such interventions.

\section{ACKNOWLEDGMENTS}

We thank Astrid Dello, Sandra Nijsten and Ina Schabram for their valuable input in these studies and for their assistance in the data collection. This study was supported by a grant from the Netherlands Foundation of Scientific Research.

\section{AUTHOR CONTRIBUTIONS}

All the authors contributed to the experimental design, discussed the results and commented on the manuscript. 


\section{REFERENCES}

Achat, H., Kawachi, I., Spiro, A., 3rd, DeMolles, D. A., \& Sparrow, D. (2000). Optimism and depression as predictors of physical and mental health functioning: the Normative Aging Study. Annals of Behavioral Medicine, 22, 127-130.

Affleck, G., Tennen, H., Zautra, A., Urrows, S., Abeles, M., \& Karoly, P. (2001). Women's pursuit of personal goals in daily life with fibromyalgia: a value-expectancy analysis. Journal of Consulting and Clinical Psychology, 69, 587-596.

Armor, D. A., \& Taylor, S. E. (1998). Situated optimism: Specific outcome expectancies and self-regulation. In M. P. Zanna (Ed.), Advances in experimental social psychology. (Vol. 30, pp. 309-379). New York: Academic Press.

Arntz, A., \& Claassens, L. (2004). The meaning of pain influences its experienced intensity. Pain, 109, $20-25$.

Arntz, A., van Eck, M., \& Heijmans, M. (1990). Predictions of dental pain: the fear of any expected evil, is worse than the evil itself. Behaviour Research and Therapy, 28, 29-41.

Asmundson, G. J., Bovell, C. V., Carleton, R. N., \& McWilliams, L. A. (2008). The Fear of Pain Questionnaire-Short Form (FPQ-SF): factorial validity and psychometric properties. Pain, 134, 51-58.

Bargiel-Matusiewicz, K., \& Krzyszkowska, A. (2009). Dispositional optimism and coping with pain. European Journal of Medical Research, 14 Suppl 4, 271-274.

Baron, R. M., \& Kenny, D. A. (1986). The moderator-mediator variable distinction in social psychological research: conceptual, strategic, and statistical considerations. Journal of Personality and Social Psychology, 51, 1173-1182.

Benedetti, F., Pollo, A., Lopiano, L., Lanotte, M., Vighetti, S., \& Rainero, I. (2003). Conscious expectation and unconscious conditioning in analgesic, motor, and hormonal placebo/nocebo responses. Journal of Neuroscience, 23, 43154323.

Brenes, G. A., Rapp, S. R., Rejeski, W. J., \& Miller, M. E. (2002). Do optimism and pessimism predict physical functioning? Journal of Behavioral Medicine, 25, 219-231.

Carson, J. W., Keefe, F. J., Lynch, T. R., Carson, K. M., Goli, V., Fras, A. M., \& Thorp, S. R. (2005). Loving-kindness meditation for chronic low back pain: results from a pilot trial. Journal of holistic nursing : official journal of the American Holistic Nurses' Association, 23, 287-304.

Chen, A. C., Dworkin, S. F., Haug, J., \& Gehrig, J. (1989). Human pain responsivity in a tonic pain model: psychological determinants. Pain, 37, 143-160.

Colloca, L., Sigaudo, M., \& Benedetti, F. (2008). The role of learning in nocebo and placebo effects. Pain, 136, $211-218$.

Costello, N. L., Bragdon, E. E., Light, K. C., Sigurdsson, A., Bunting, S., Grewen, K., \& Maixner, W. (2002). Temporomandibular disorder and optimism: relationships to ischemic pain sensitivity and interleukin-6. Pain, 100, 99-110.

Devine, D. P., \& Spanos, N. P. (1990). Effectiveness of maximally different cognitive strategies and expectancy in attenuation of reported pain. Journal of Personality and Social Psychology, 58, 672-678.

Geers, A. L., Helfer, S. G., Kosbab, K., Weiland, P. E., \& Landry, S. J. (2005). Reconsidering the role of personality in placebo effects: dispositional optimism, situational expectations, and the placebo response. Journal of Psychosomatic Research, 58, 121-127.

Geers, A. L., Kosbab, K., Helfer, S. G., Weiland, P. E., \&Wellman, J. A. (2007). Further evidence for individual differences in placebo responding: an interactionist perspective. Journal of Psychosomatic Research, 62, 563-570.

Geers, A. L., Wellman, J. A., Fowler, S. L., Helfer, S. G., \& France, C. R. (2010). Dispositional Optimism Predicts Placebo Analgesia. Journal of Pain. 
Geers, A. L., Wellman, J. A., Helfer, S. G., Fowler, S. L., \& France, C. R. (2008). Dispositional optimism and thoughts of wellbeing determine sensitivity to an experimental pain task. Annals of Behavioral Medicine, 36, 304-313.

Karoly, P., \& Ruehlman, L. S. (2006). Psychological "resilience" and its correlates in chronic pain: findings from a national community sample. Pain, 123, 90-97.

Keltner, J. R., Furst, A., Fan, C., Redfern, R., Inglis, B., \& Fields, H. L. (2006). Isolating the modulatory effect of expectation on pain transmission: a functional magnetic resonance imaging study. Journal of Neuroscience, 26, 4437-4443.

Klein, B., \& Zajec, L. (2008). Imagining a rosy future: The psychology of optimism. In K. D. Markman, W. M. P. Klein \& J. A. Suhr (Eds.), Handbook of imagination and mental simulation. New York: Psychology press.

Leeuw, M., Goossens, M. E., Linton, S. J., Crombez, G., Boersma, K., \& Vlaeyen, J. W. (2007). The fear-avoidance model of musculoskeletal pain: current state of scientific evidence. Journal of behavioral medicine, 30, 77-94.

Linton, S. J., \& Shaw, W. S. (2011). Impact of psychological factors in the experience of pain. Physical therapy, 91, 700711.

Lorenz, J., Hauck, M., Paur, R. C., Nakamura, Y., Zimmermann, R., Bromm, B., \& Engel, A. K. (2005). Cortical correlates of false expectations during pain intensity judgments--a possible manifestation of placebo/nocebo cognitions. Brain, Behavior and Immunity, 19, 283-295.

Mahler, H. I. M., \& Kulik, J. A. (2000). Optimism, pessimism and recovery from coronary bypass surgery: prediction of affect, pain and functional status. Psychology, Health \& Medicine, 5, 347-358.

Mangelli, L., Gribbin, N., Buchi, S., Allard, S., \& Sensky, T. (2002). Psychological well-being in rheumatoid arthritis: relationship to 'disease' variables and affective disturbance. Psychotherapy and Psychosomatics, 71, 112-116.

McCracken, L. M., Gross, R. T., Sorg, P. J., \& Edmands, T. A. (1993). Prediction of pain in patients with chronic low back pain: effects of inaccurate prediction and pain-related anxiety. Behaviour Research and Therapy, 31, 647-652.

Mirsky, J. B. (2007). Expectancy and the placebo effect: How cognitive processing utilizes the rACC to alter the perception of pain. Mind Matters: The Wesleyan Journal of Psychology, 2, 19-28.

Morton, D. L., Watson, A., El-Deredy, W., \& Jones, A. K. (2009). Reproducibility of placebo analgesia: Effect of dispositional optimism. Pain, 146, 194-198.

Novy, D. M., Nelson, D. V., Hetzel, R. D., Squitieri, P., \& Kennington, M. (1998). Coping with chronic pain: sources of intrinsic and contextual variability. Journal of Behavioral Medicine, 21, 19-34.

Ong, A. D., Zautra, A. J., \& Reid, M. C. (2010). Psychological resilience predicts decreases in pain catastrophizing through positive emotions. Psychology and Aging, 25, 516-523.

Powell, R., Johnston, M., Smith, W. C., King, P. M., Chambers, W. A., Krukowski, Z., McKee, L., \& Bruce, J. (2012). Psychological risk factors for chronic post-surgical pain after inguinal hernia repair surgery: a prospective cohort study. European Journal of Pain, 16, 600-610.

Ramirez-Maestre, C., Esteve, R., \& Lopez, A. E. (2012a). The path to capacity: resilience and spinal chronic pain. Spine, 37, E251-E258.

Ramirez-Maestre, C., Esteve, R., \& Lopez, A. E. (2012b). The role of Optimism and Pessimism in Chronic Pain Patients Adjustment. The Spanish Journal of Psychology, 15, 286-294.

Rasmussen, H. N., Scheier, M. F., \& Greenhouse, J. B. (2009). Optimism and physical health: a meta-analytic review. Annals of Behavioral Medicine, 37, 239-256. 
Robinson-Whelen, S., Kim, C., MacCallum, R. C., \& Kiecolt-Glaser, J. K. (1997). Distinguishing optimism from pessimism in older adults: is it more important to be optimistic or not to be pessimistic? Journal of Personality and Social Psychology, 73, 1345-1353.

Roelofs, J., Peters, M. L., Patijn, J., Schouten, E. G., \& Vlaeyen, J. W. (2004). Electronic diary assessment of pain-related fear, attention to pain, and pain intensity in chronic low back pain patients. Pain, 112, 335-342.

Scheier, M. F., \& Carver, C. S. (1985). Optimism, coping, and health: assessment and implications of generalized outcome expectancies. Health Psychology, 4, 219-247.

Scheier, M. F., \& Carver, C. S. (1992). Effects of optimism on psychological and physical well-being: Theoretical overview and empirical update. Cognitive Therapy and Research, 16, 201-228.

Scheier, M. F., Carver, C. S., \& Bridges, M. W. (1994). Distinguishing optimism from neuroticism (and trait anxiety, selfmastery, and self-esteem): a reevaluation of the Life Orientation Test. Journal of Personality and Social Psychology, 67, 1063-1078.

Segerstrom, S. C. (2005). Optimism and immunity: do positive thoughts always lead to positive effects? Brain, Behavior and Immunity, 19, 195-200.

Sipila, K., Ylostalo, P. V., Ek, E., Zitting, P., \& Knuuttila, M. L. (2006). Association between optimism and self-reported facial pain. Acta Odontologica Scandinavica, 64, 177-182.

Solberg Nes, L., \& Segerstrom, S. C. (2006). Dispositional optimism and coping: a meta-analytic review. Personality and Social Psychology Review, 10, 235-251.

Sturgeon, J. A., \& Zautra, A. J. (2010). Resilience: a new paradigm for adaptation to chronic pain. Current pain and headache reports, 14, 105-112.

Vlaeyen, J. W., Hanssen, M., Goubert, L., Vervoort, T., Peters, M., van Breukelen, G., Sullivan, M. J., \& Morley, S. (2009). Threat of pain influences social context effects on verbal pain report and facial expression. Behaviour Research and Therapy, 47, 774-782.

Vlaeyen, J. W., \& Linton, S. J. (2000). Fear-avoidance and its consequences in chronic musculoskeletal pain: a state of the art. Pain, 85, 317-332.

Vlaeyen, J. W., \& Linton, S. J. (2012). Fear-avoidance model of chronic musculoskeletal pain: 12 years on. Pain, in press.

Wiech, K., Ploner, M., \& Tracey, I. (2008). Neurocognitive aspects of pain perception. Trends in Cognitive Sciences, 12, 306-313.

Wright, L. J., Zautra, A. J., \& Going, S. (2008). Adaptation to early knee osteoarthritis: the role of risk, resilience, and disease severity on pain and physical functioning. Annals of Behavioral Medicine, 36, 70-80. 


\section{Optimism lowers pain: Evidence of the causal status and underlying mechanism(s)}

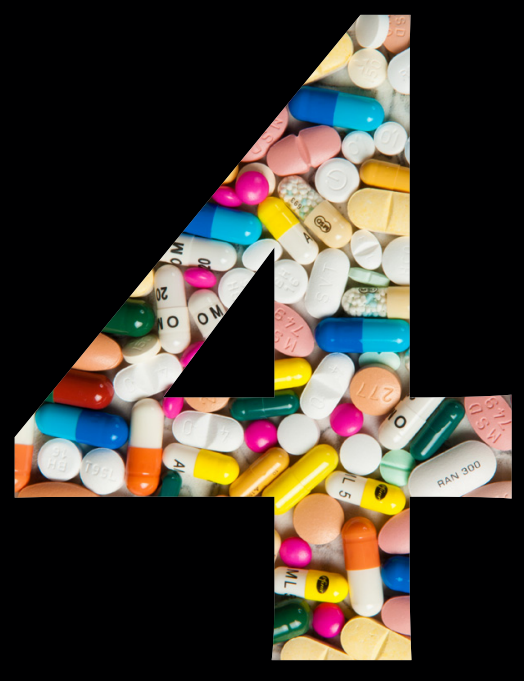

This chapter is published as: Hanssen, M. M., Peters, M. L., Vlaeyen, J. W. S., Meevissen, Y. M. C. \& Vancleef, L. M. G. (2013). Optimism lowers pain: evidence of the causal status and underlying mechanism(s), Pain, 154(1), 53-58. 



\section{ABSTRACT}

Previous studies have demonstrated a relation between dispositional optimism and lower pain sensitivity, but the causal status of this link remains unclear. This study sought to test the causal status by experimentally inducing a temporary optimistic state by means of writing about and visualizing a future best possible self. In addition, we explored pain expectations and (situational) pain catastrophizing as possible underlying mechanisms of the link between optimism and pain. Seventy-nine university students participated in a cold pressor task (CPT). Before the CPT, half of them received the optimism manipulation, the other half a control manipulation. Induced optimism was related to lower pain intensity ratings during the CPT compared to the control group, hereby experimentally confirming causality. This effect was not explained by pain related expectations about the task. Situational pain catastrophizing however did seem to mediate the relation between optimism and pain. This study is the first study to confirm the causal status of optimism towards pain. Additionally, the results show that positive interventions might provide a useful alternative in reducing pain catastrophizing as an extremely relevant target in pain treatment. 



\section{INTRODUCTION}

Optimism has shown to be related to better psychological and physical well-being, especially in times of adversity (Carver, Scheier, \& Segerstrom, 2010; Rasmussen, Scheier, \& Greenhouse, 2009; Scheier \& Carver, 1985, 1992; Scheier, Carver, \& Bridges, 1994). When confronted with pain, optimists show both better adjustment (Affleck, et al., 2001; Allison, Guichard, \& Gilain, 2000; Brenes, Rapp, Rejeski, \& Miller, 2002; Novy, Nelson, Hetzel, Squitieri, \& Kennington, 1998; Wong \& Fielding, 2007) and less pain-sensitivity (Allison, et al., 2000; Costello, et al., 2002; Geers, Wellman, Helfer, Fowler, \& France, 2008; Kurtz, Kurtz, Given, \& Given, 2008). Despite accumulating evidence on the relation between optimism and pain however, two important issues still need to be resolved.

First, it is not unthinkable that less pain leads to more optimism instead of the reverse. Although longitudinal (Allison, et al., 2000; Luger, Cotter, \& Sherman, 2009; Mahler \& Kulik, 2000) and laboratory (Geers, et al., 2008; Hanssen, Vancleef, Vlaeyen, \& Peters, 2014) studies provide preliminary evidence, the causal status of optimism towards pain has not been confirmed by experimental data so far. Second, information about the mechanism(s) underlying the relationship between optimism and pain is still scarce. Understanding the mechanisms of resilience can be used to stimulate adaptive responses to pain. From the literature, several possible working mechanisms can be extracted.

A first mechanism that could explain the relation between optimism and pain, is the expectation of pain. Dispositional optimism has been defined as a generalized positive outcome expectancy (Scheier \& Carver, 1985). From a theoretical point of view one could expect this generalized positive outcome expectancy to translate into more positive (or less negative) expectations about pain. The role of pain-related expectations in the experience of pain has been emphasized repeatedly (Colloca, Sigaudo, \& Benedetti, 2008; Keltner, et al., 2006; Lorenz, et al., 2005), but at least one study (Hanssen, et al., 2014) disconfirmed that pain expectancy is the underlying mechanism explaining the relation between optimism and pain.

A second possible mechanism underlying the optimism-pain association might be the appraisal of pain. Optimists are less inclined to process negative information (Geers, et al., 2008; Isaacowitz, 2005; Karademas, Kafetsios, \& Sideridis, 2007; Segerstrom, 2001; Vancleef \& Peters, 2008) and tend to shift their focus to the positive features of a situation. More specifically, optimism was previously found to be negatively associated with pain catastrophizing (Bargiel-Matusiewicz \& Krzyszkowska, 2009; Sinclair, 2001). Pain-specific negative appraisals (Sullivan, Bishop, \& Pivik, 1995) typically result in heightened levels of pain intensity (Keefe, et al., 2001; Keefe, Rumble, Scipio, Giordano, \& Perri, 2004; Vlaeyen, et al., 2009). A recent correlational study suggested that indeed pain catastrophizing could mediate the relationship between optimism and pain (Hood, Pulvers, Carrillo, Merchant, \& Thomas, 2012). Whether optimism actually leads to less catastrophizing about upcoming pain remains to be established.

The aim of the present study is to investigate whether optimism is causally related to experimental pain sensitivity. Optimism is induced with a Best Possible Self manipulation. This manipulation entails writing and visualizing about a positive future and was previously found 
to successfully induce a temporary state of optimism (Meevissen, Peters, \& Alberts, 2011; Peters, Flink, Boersma, \& Linton, 2010). It is hypothesized that participants report less pain during and after a cold pressor task following the Best Possible Self exercise than following a neutral writing and visualization exercise. Additionally, the role of two potential explanatory mechanisms is investigated. More specifically, it is examined whether the relation between induced optimism and reported pain intensity is mediated by expected pain intensity or situational pain catastrophizing.

\section{METHOD}

\section{Participants}

Seventy-nine students from Maastricht University between the age of 18 and 35 years old participated in this experiment. Their participation was compensated by means of course credit or a financial compensation. Informed consent was obtained from each participant at the beginning of the experiment. Participants were excluded if they had prior experience with the cold pressor task or with the writing and visualisation exercise. The final sample of 79 participants consisted of 15 men and 64 women, with a mean age of $22.59(S D=2.86)$.

\section{Apparatus}

A Plexiglas bath tank of $36 \times 30 / 15 \mathrm{~cm}(\mathrm{~W} \times \mathrm{L} / \mathrm{D})$ Julabo ED-19A (Julabo ${ }^{\circledast}$ Seelbach, Germany) with open heating bath circulator was used for the cold pressor task (CPT). The water was maintained circulating and at a constant temperature of $5^{\circ} \mathrm{C}\left( \pm .03^{\circ} \mathrm{C}\right)$. A plastic unit with water at room temperature $\left(20^{\circ} \mathrm{C}\right)$ was placed next to the Julabo bath tank.

\section{Optimism manipulation}

Participants were randomly assigned to perform either a Best Possible Self (BPS) or a Typical Day (TD) writing and visualisation exercise. Both exercises have successfully been used in the past as respectively an optimism induction or a control exercise (Meevissen, et al., 2011; Peters, et al., 2010). Both exercises consisted of the following elements: First, participants were instructed to think about their best possible self (experimental condition) or about a typical day (control condition) for the duration of one minute. Next, they were requested to write about this topic uninterrupted for 15 minutes. Finally, they were asked to imagine the story they wrote down as vividly as possible during 5 minutes.

The instructions for the BPS exercise, that were also adopted in other studies (Meevissen, et al., 2011; Peters, et al., 2010; Sheldon \& Lyubomirsky, 2006), were based on the pioneering work of King (2001). The instructions for the TD exercise, were based on the work of Sheldon and Lyubomirsky (2006). Forty participants performed the Best Possible Self and thirty-nine the Typical Day Exercise. 


\section{Measures}

\section{Dispositional optimism}

To ensure that there were no baseline differences in optimism between participants before the experimental manipulation, dispositional optimism was measured with the revised Life Orientation Test (Scheier, et al., 1994). This questionnaire consists of 3 positively and 3 negatively framed items, such as 'In uncertain times, I usually expect the best' or' if something can go wrong for me, it will' and 4 filler items. Items are scored on a 5-point Likert scale, ranging from 1 (= strongly disagree) to 5 (= strongly agree). The LOT-R results in a total score, reflecting a broad generalized positive outcome expectancy with higher scores representing higher levels of optimism. The LOT-R was found to be a valid and reliable measurement instrument (Scheier, et al., 1994). Cronbach's alpha in the current sample is .69.

\section{(Situational) Pain Catastrophizing}

Pain catastrophizing was measured with the Dutch version of the Pain Catastrophizing Scale (Sullivan, et al., 1995; Van Damme, Crombez, Bijttebier, Goubert, \& Van Houdenhove, 2002). Participants were asked to indicate to what extent each of 13 statements applied to them when in pain. Items such as 'I keep thinking about how much it hurts' or 'I wonder whether something serious might happen' are answered on a 5-point Likert scale ranging from 0 (= not at all) to 4 (=always). The PCS was administered at the beginning of the experiment to check whether there were no initial differences in pain catastrophizing between participants in the two conditions.

After pain induction, situational pain catastrophizing (S-PCS) was assessed. The instructions of the PCS were adjusted in such a way that all items referred to the experience of the CPT (2011). Situational pain catastrophizing, has been shown to correlate more strongly to experimental pain responses than a trait measure of pain catastrophizing (Campbell, et al., 2010). Indices for internal consistency in the current sample were $\mathrm{a}(\mathrm{PCS})=.89$ and $\mathrm{a}(\mathrm{S}-\mathrm{PCS})=.91$.

\section{Expected and experienced pain intensity ratings}

To measure expected pain intensity, participants were asked to answer the question 'How much pain do you expect during the cold pressor task?' on a Visual Analogue Scale (VAS) ranging from 0 (='no pain at all') to 100 (='extreme pain').

Experienced pain intensity ratings were obtained by asking participants to verbally communicate with a number between 0 and 100 how much pain they felt ranging from 0 (= no pain at all) to 100 (= extreme pain).

\section{Manipulation Check}

Future expectations

Expectations for positive and negative future outcomes were measured with the questionnaire for Future Expectations (FEX). This scale is an adaptation of the Subjective Probability Task (SPT; Macleaod, 1996), that has previously been demonstrated to be sensitive to an optimism manipulation 
(Meevissen, et al., 2011; Peters, et al., 2010). The FEX consists of an equal number of positive and negative statements referring to future outcomes. These positive and negative future outcomes are equally distributed across five domains ('health','professional,' 'social','personal' \& 'general').

Ten statements such as 'You will have health problems' or 'People will find you dull and boring' result in a total score for negative expectations (FEX-Neg). Ten statements such as 'You will get a lot of satisfaction out of life' or 'You will make good and lasting friendships' make up a total score for positive expectations (FEX-Pos). Participants are asked to judge the likelihood of each statement on a 7 -point scale, with 1 ='not likely at all to occur' to 7 ='extremely likely to occur'. Internal consistency for both scales in this sample were $\mathrm{a}(\mathrm{FEX}$-Pos $)=.80$ and $\mathrm{a}(\mathrm{FEX}-\mathrm{Neg})=.85$ for the pre-manipulation measurement and $\mathrm{a}(\mathrm{FEX}$-Pos $)=.87$ and $\mathrm{a}(\mathrm{FEX}$-Neg $)=.89$ in the post-manipulation phase.

Positive and negative Mood

State mood was measured on a VAS ranging from 0 (=not at all) to 100 (=extremely). Responses to the questions 'How positive are you feeling at this moment?' and 'How negative are you feeling at this moment?' resulted in a state measure for positive mood (MOOD-Pos) and negative mood (MOOD-Neg). The measurement of affect was used as a secondary manipulation check. Previous studies have found effects of the BPS manipulation on both future expectations and (positive) affect (Meevissen, et al., 2011; Peters, et al., 2010).

Quality of writing and imagery

Two VAS scales ranging from 0 to 100 were administered as a check for possible qualitative differences between the BPS and TD exercise (cf. (Peters, et al., 2010). Participants were asked to answer the following questions: 'How well could you imagine yourself in the situation you described in your writing?' (not at all - extremely well) and 'How vivid were the pictures you imagined?' (not vivid at all - very vivid).

\section{Procedure}

Participants were recruited for participation in a study examining the influence of visualisation on pain during a cold pressor task. On arrival at the lab, participants were welcomed and informed consent forms were signed. Baseline measures (LOT-R, PCS, VAS Mood Pre-manipulation and FEX pre-manipulation) were obtained and participants were randomly assigned to the Best Possible Self or the Typical Day condition. Subsequently, the writing and visualisation exercise was explained. Participants started out with thinking about their topic for one minute. Thereafter, the experimenter left the room for the duration of the writing part (15 min.), to set the participant at ease during the exercise. When the experimenter came back in, she instructed the participant to visualize about the written stories for another 5 minutes. After the writing and visualisation exercise, participants completed the post-manipulation measures of future expec- 
tations and mood, as well as the control measure concerning the quality of the writing and imagery. Participants then received detailed instructions about the one-minute CPT and the pain rating procedure. They were also instructed about the correct manner of immersing their nondominant hand in the water, which is immersed up to the level of the wrist with a horizontally stretched out hand that is not in contact with the bottom of the container. Ratings of expected pain intensity were obtained before participants immersed their non-dominant hand in a room temperature container $\left(20^{\circ} \mathrm{C}\right)$. The latter was done in order to acquire equal skin temperature. Next, the cold pressor task was conducted and the researcher prompted pain intensity ratings at 20, 40 and 60 seconds during the immersion and at 20 seconds after participants withdrew their hand from the cold water. Participants who were unable to complete the one-minute immersion were asked to provide a pain intensity rating the moment they withdrew their hand (as an end rating) and 20 seconds later for the post-immersion rating. After termination of the CPT, participants completed the VAS Mood post-immersion and the S-PCS. Participants were compensated and thanked for their participation.

\section{Statistical Analyses}

Mean and standard deviation were calculated for baseline measures (LOT-R, PCS Trait, FEX-Pos Pre-manipulation, FEX-Neg Pre-manipulation, MOOD-Pos Pre-manipulation and MOOD-Neg Premanipulation) for the two conditions.

Independent samples $t$-tests and a Chi-square test were used for the randomisation check on sex, age and baseline measures. Pearson correlations were calculated to represent the associations between the baseline measures.

A manipulation check was performed on post- minus pre-measurement difference scores of negative and positive future expectations and state mood measures ( $\triangle$ FEX-Pos, $\triangle$ FEX-Neg, $\triangle \mathrm{MOOD}$-Pos and $\triangle$ MOOD-Neg). Independent samples t-tests were used to detect significant differences in change between the conditions. Differences between quality of writing and visualisation were also investigated using independent samples t-tests.

Before analysing data on pain intensity during and post-immersion, missing data were replaced. For the pain ratings during immersion, the "last value put forward" method was used. All missing values during immersion were caused by early hand withdrawal. Eleven participants did not complete the one-minute immersion (range: $14-55$ s). These participants provided a pain intensity rating immediately upon hand withdrawal from the cold water. This rating score was imputed at every subsequent missing value during the immersion phase. One post-immersion score was missing in the dataset and replaced by means of a linear regression equation based on the three during immersion ratings of the concerning condition.

The influence of induced optimism on pain intensity ratings during immersion was tested with a repeated measures ANOVA with time $(20 \mathrm{~s} ; 40 \mathrm{~s} ; 60 \mathrm{~s})$ as a within subject factor, and condition (BPS; TD) as a between subject factor. The effect of induced optimism (BPS; TD) on pain intensity ratings post-immersion was examined with an independent samples t-test. 
Based on results of the preceding analyses, mediation was only tested for pain reports during immersion. Preliminary analyses were performed to explore mediation effects of expected pain intensity and situational pain catastrophizing. Independent samples t-tests were performed to test if these candidate mediators differed significantly between conditions. Next, relations between candidate mediators and reported pain intensity during immersion were explored with Pearson correlation coefficients. Mediation analyses were then conducted for each candidate mediator that was found to differ significantly between the BPS and TD condition.

Multiple regression analyses were performed following guidelines of Baron and Kenny (Baron \& Kenny, 1986). As a first step in testing mediation, it was tested whether condition correlated with the mean pain intensity rating during immersion. As a second step in testing mediation, the relation between condition and the candidate mediator was tested. As a third step in testing mediation, both condition and mediator were entered in the regression analysis as predictors of reported pain during immersion. Mediation was confirmed if the first two steps were met and if the condition effect showed to diminish when controlled for the mediator.

\section{RESULTS}

\section{Baseline Descriptives}

Mean scores and standard deviations for both conditions separately are shown in Table 1. Independent samples t-tests indicated that there were no significant differences between the two conditions for these baseline measurements.

In addition, no significant differences were found between both conditions with regard to age $(t(77)=-.45 ; p=.65)$ and $\operatorname{sex}\left(x^{2}(1,79)=.84 ; p=.36\right)$.

Table 1. Means, standard deviations (SD) randomisation check, and correlations between baseline variables.

\begin{tabular}{|c|c|c|c|c|c|c|c|c|c|c|}
\hline \multirow{3}{*}{$\begin{array}{l}\text { Variable } \\
1 . \text { LOT-R }\end{array}$} & \multicolumn{5}{|c|}{ Mean (SD) } & \multicolumn{5}{|c|}{ Correlation } \\
\hline & TOTAL $(N=79)$ & \multicolumn{2}{|c|}{$\operatorname{BPS}(N=40)$} & \multicolumn{2}{|c|}{$\mathrm{TD}(N=39)$} & \multirow[t]{2}{*}{1} & \multirow[t]{2}{*}{2} & \multirow[t]{2}{*}{3} & \multirow[t]{2}{*}{4} & \multirow[t]{2}{*}{5} \\
\hline & $22.23 \quad(3.10)$ & 22.35 & $(3.33)$ & 22.10 & $(2.87)$ & & & & & \\
\hline 2. PCS & $16.25 \quad(8.02)$ & 16.07 & $(9.40)$ & 16.44 & $(6.43)$ & $-.40^{* *}$ & & & & \\
\hline 3. FEX Pos Pre-Manipulation & $54.47 \quad(5.40)$ & 54.95 & $(5.39)$ & 53.97 & $(5.45)$ & $.47^{* *}$ & $-.26^{*}$ & & & \\
\hline 4. FEX Neg Pre-Manipulation & $31.18 \quad(8.55)$ & 29.90 & $(7.70)$ & 32.49 & $(9.26)$ & $-.59 * *$ & $.44^{* *}$ & $-.58^{* *}$ & & \\
\hline 5. MOOD Pos Pre-Manipulation & $73.63(13.54)$ & 73.78 & $(13.17)$ & 73.49 & $(14.07)$ & $.36^{* *}$ & $-.28^{*}$ & $.43^{* *}$ & $-.42^{* *}$ & \\
\hline 6. MOOD Neg Pre-Manipulation & $21.35(16.93)$ & 19.93 & $(16.41)$ & 22.82 & $(17.55)$ & $-.28 * *$ & $.27^{*}$ & $-.43^{* *}$ & $.37^{* *}$ & $-.71^{* *}$ \\
\hline
\end{tabular}

BPS, best possible self; TD, typical day; LOT-R, Revised Life Orientation Test; PCS, Pain Catastrophizing Scale; FEX, Future Expectations; Pos, positive; Neg, negative; MOOD, state measure for mood. ${ }^{*} p<.05 ;{ }^{* *} p<.01$ 
Table 1 also shows correlations between baseline scores of optimism, pain catastrophizing, positive future expectations, negative future expectations, positive mood and negative mood. All variables are found to correlate significantly in the expected direction.

\section{Manipulation check}

Independent samples t-tests were performed with change (post - pre) scores of FEX-Pos, FEXNeg, MOOD-Pos and MOOD-Neg to examine the effect of the optimism manipulation. As shown in Table 2, the BPS manipulation led to significantly larger changes in positive and negative future expectations, as well as on positive mood, compared to the TD manipulation.'

Additional independent samples t-test were performed to control for possible qualitative (in contrast to content-related) differences between BPS and TD manipulation. With mean scores of $77.24(S D=15.17)$ in the BPS condition and 79.44 (SD=21.29) in the TD condition, no significant difference in quality of imagination during the writing process was found $(t(77)=-.52 ; p=-.60)$. Also, with regard to the vividness of the visualisation there was no significant difference $(t(77)=-1.19$; $p=.24)$ between the BPS $(M=67.63 ; S D=23.48)$ and the TD condition $(M=73.49 ; S D=19.96)$.

Table 2. Means, standard deviations (SD), and significant differences between conditions of manipulation check variables.

\begin{tabular}{|c|c|c|c|}
\hline \multirow{3}{*}{$\begin{array}{l}\text { Variable } \\
\text { FEX Pos Change }\end{array}$} & \multicolumn{2}{|c|}{ Mean (SD) } & \multirow{3}{*}{$\begin{aligned} t \text {-value } \\
4.47^{* *}\end{aligned}$} \\
\hline & BPS & TD & \\
\hline & $2.63 \quad(2.83)$ & $-.18 \quad(2.75)$ & \\
\hline FEX Neg Change & $-4.70(4.30)$ & $-1.03(2.80)$ & $-4.51^{* *}$ \\
\hline MOOD Pos Change & $9.70 \quad(9.24)$ & $2.36(11.60)$ & $3.12^{* *}$ \\
\hline MOOD Neg Change & $-5.35(10.03)$ & $-.62(16.21)$ & 1.60 \\
\hline
\end{tabular}

BPS, best possible self; TD, typical day; FEX, Future Expectations; Pos, positive; Neg, Negative; Mood, state measure for mood, ${ }^{*} p<.05 ;{ }^{* *} p<.01$

\section{The influence of induced optimism on pain}

Figure 1 presents mean pain intensity ratings during and post immersion in both the BPS and the TD condition. As presented in Figure 1, the mean scores of reported pain intensity are systematically lower in the BPS condition (with $M(20 s)=46.40$, $s d=21.52 ; M(40 s)=60.15, s d=23.88$;

1 Similar results were obtained when the manipulation check was performed using Ancova's with each post-manipulation measure as dependent variable and condition and pre-manipulation measure as independent variables. 
$M(60 s)=66.09, s d=25.14$ and $M(20 s$ post $)=35.15, s d=24.54)$ compared to the TD condition (with $M(20 s)=53.59, s d=20.80 ; M(40 s)=70.13, s d=17.45 ; M(60 s)=80.59, s d=15.74$ and $M(20$ s post $)=45.39$, sd=21.44). Differences between conditions were tested for during immersion and post-immersion ratings separately.

A repeated measures ANOVA with a Greenhouse-Geisser correction revealed a significant time effect $(F(1,77)=93.39, p<.001$ for the pain reports during immersion. In support of our main hypothesis, a significant condition effect $(F(1,77)=6.04, p<.05)$ indicates that participants in the BPS condition had significantly lower pain intensity ratings across all three time points than participants in the TD condition. The absence of a'time $x$ condition' interaction $(F(1,77)=2.27, p=.124)$ indicates that the differences between the BPS and TD groups did not vary as a function of time.

Pain intensity post-immersion was significantly lower in the BPS condition compared to the TD condition with $t(77)=1.97, p=.05$ ).

\section{Mediation of the relation between optimism and reported pain intensity}

Reported pain intensity significantly differed between conditions during, but not post-immersion. Therefore, mediation was tested for this period only. Moreover, because no interaction effect with time was found, further analyses were based on the mean of pain intensity ratings during immersion, with $M(s d)=57.55(21.15)$ in the BPS condition and $M(s d)=68.10(16.70)$ in the TD condition.

Table 3 shows the results of independent samples t-tests and correlation analyses for situational pain catastrophizing, expected pain intensity and mean pain intensity during immersion.

Table 3. Means, standard deviations (SD), and results of independent samples t tests and correlation analyses for mean pain intensity during immersion and candidate mediators.

\begin{tabular}{|c|c|c|c|c|c|}
\hline \multirow[t]{2}{*}{ Mediator } & \multicolumn{2}{|c|}{ Mean (SD) } & \multirow[t]{2}{*}{ t-value } & \multicolumn{2}{|c|}{ Correlation } \\
\hline & BPS & TD & & 1 & 2 \\
\hline 1. Reported pain intensity Immersion & $57.55(21.15)$ & $68.10(16.70)$ & $-2.46^{*}$ & & \\
\hline 2. Expected pain intensity & $48.03(24.66)$ & $51.18(21.98)$ & -.60 & $.30^{* *}$ & \\
\hline 3. Situational pain catastrophizing & $14.88(19.31)$ & $19.31 \quad(8.67)$ & $-2.03^{*}$ & $.60^{* *}$ & $.31^{* *}$ \\
\hline
\end{tabular}

BPS, best possible self; TD, typical day, ${ }^{*} p<.05 ;{ }^{* *} p<.01$

Regression analyses were performed to test mediation for situational pain catastrophizing, since only this variable significantly differed between the BPS and TD condition. First, condition was significantly related to mean pain intensity ratings during immersion $(\beta=.27 ; t=2.46$; $p<.05)$. Second, condition was significantly related to situational pain catastrophizing $(B=.23$; $t=2.03 ; p<.05$ ). As a third step in testing mediation, both condition and mediator (S-PCS) were added to condition as predictor of mean pain intensity ratings during immersion. 


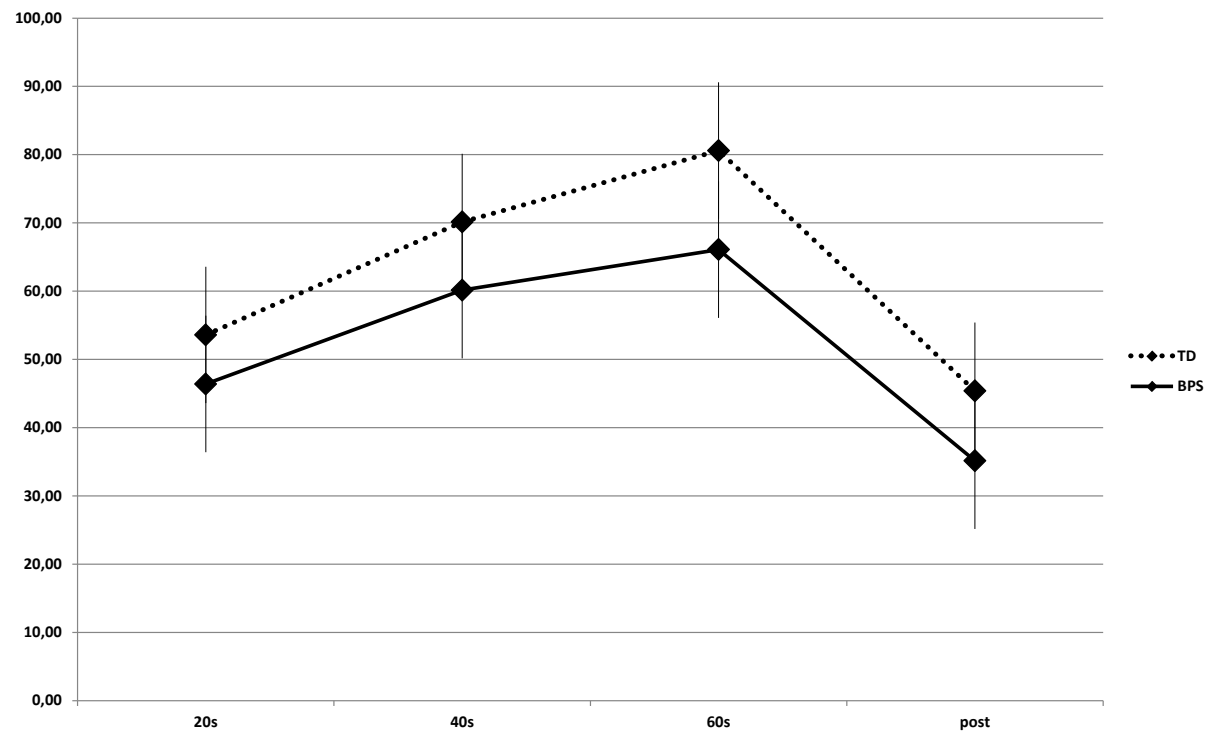

Fig. 1. Pain intensity ratings at 20,40, and $60 \mathrm{~s}$ during and $20 \mathrm{~s}$ after immersion in the BPS and TD conditions.

The last regression analysis showed situational catastrophizing as a strong predictor of reported pain intensity $(B=.57 ; t=6.17 ; p<.001)$, reducing the influence of condition on pain intensity to non-significance $(B=.14 ; t=1.53 ; p>.05)$, hereby confirming mediation. A Sobel's test indicated that the reduction in the beta coefficients is borderline significant $(S=1.93 ; S E=2.59 ; p=0.053)$.

\section{DisCUSSION}

The aim of this study was to examine two important issues, namely the causal status of optimism towards pain and the potential underlying mechanisms of this relation. Using a Best Possible Self manipulation, a temporary state of optimism was successfully induced in half of the participants. This manipulation led to lower pain intensity ratings during a cold pressor task compared to a control manipulation, confirming the hypothesized causal relation between optimism and pain. Furthermore, situational pain catastrophizing seemed to mediate the relation between induced optimism and pain during the CPT.

First of all, this study provides evidence for the causal status of optimism towards pain. Previous laboratory and longitudinal studies confirmed the relation between optimism and pain (Allison, et al., 2000; Costello, et al., 2002; Geers, et al., 2008; Hanssen, et al., 2014; Luger, et al., 2009; Mahler \& Kulik, 2000). Although previous studies provided preliminary evidence for the causal status of optimism towards pain-related outcomes, no study so far used an experimental design to confirm causality. In this study, we therefore took it one step further and experimentally in- 
duced optimism in half of the participants to investigate the direct effect on pain in a laboratory controlled situation. In line with our hypothesis, induced optimism led to lower pain intensity ratings during the cold pressor task.

In order to induce optimism, we used a writing and visualisation exercise that proved to be successful in previous studies to induce a temporary and even prolonged state of optimism (Meevissen, et al., 2011; Peters, et al., 2010). In line with these studies, the manipulation significantly altered future expectations and positive mood. In this study, future expectations were measured with FEX, an adaptation of the SPT that was previously used as a measure of momentary optimism. In contrast with SPT, FEX consists of an equal amount of positive and negative statement that are balanced over 5 domains ('health','professional,',social,',personal' \&'general'). Furthermore, to our judgment, the transformation has led to a higher probability of occurrence of especially the negative items. Interestingly, dispositional optimism significantly correlates to both positive and negative future expectations as measured with the FEX in contrast to the single correlation with positive expectations as measured by the SPT that was found by Peters, Flink and Linton (2010).

Second, we were not only interested in the causal status of optimism, but we also wanted to examine the underlying mechanism in the optimism - pain association. Two processes, being expectation and appraisal toward pain were investigated. More specifically, expected pain intensity and situational pain catastrophizing were tested as possible mediators in the relation between induced optimism and pain ratings during a CPT.

The first proposed candidate for mediation was expected pain intensity. The conceptualisation of dispositional optimism as a generalized positive outcome expectancy (Scheier \& Carver, 1985) and the previously established links between expected and perceived pain intensity (Colloca, et al., 2008; Keltner, et al., 2006; Lorenz, et al., 2005) raised the possibility of a mediation model with expected pain intensity. However, this model was disconfirmed in our previous study (Hanssen, et al., 2014). Also in the present study, expected pain intensity was found to be associated with pain intensity ratings during immersion, but induced optimism did not influence expectations, again disconfirming the role of expected pain intensity as a mediator.

A second mechanism that was investigated for the optimism - pain association was negative appraisal. Negative appraisals of pain as measured with the situational pain catastrophizing scale seemed to mediate the relation between optimism and pain rating during immersion. This finding is in line with the finding that optimists do not seem to focus on negative information (Geers, et al., 2008; Isaacowitz, 2005; Karademas, et al., 2007; Segerstrom, 2001; Vancleef \& Peters, 2008). Moreover, our data confirms and strengthens previous findings (Bargiel-Matusiewicz \& 
Krzyszkowska, 2009; Hood, et al., 2012; Sinclair, 2001) by showing that induced optimism directly leads to less situational pain catastrophizing during a cold pressor task. Previously, it has been postulated that positive emotions can counter downward spirals of negativity (Fredrickson, 2001; Garland, et al., 2010). In a similar vein, our results show that general positive appraisals can counter pain-specific negative appraisals.

This study has certain limitations that should be noted. Firstly, in this study pain reports were used as a measure of pain experience. Although reported pain intensity is widely used as a measure for the experience of pain, a behavioural measure would strengthen these findings. Secondly, eleven participants did not complete the cold pressor task, and therefore the data for the missing time points of these participants were imputed. Although results with and without imputed data yielded the same results, this should be borne in mind in interpreting the results. Thirdly, only the short-term effect of the optimism manipulation on experimentally induced pain was measured in this study. Future research should further investigate long-term effects as well as the influence of optimism on continuing processes in response to chronic pain. Lastly, only negative (mediation and outcome) variables were included in this study. The influence of optimism on adaptive (in addition to less maladaptive) processes could contribute to understanding the strength of optimism.

This study is of substantial theoretical and clinical importance. First, to our knowledge this study is the first that supports the causal status of optimism towards pain in a laboratory controlled experimental setting. Secondly, the results stress that positive interventions might provide a useful alternative in reducing pain catastrophizing as a highly relevant target in pain treatment. The first results of interventions aimed at building resilience in chronic pain patients are promising and appear to be able to reduce the negative impact of pain (Carson, et al., 2005). Thirdly, this study demonstrates that the BPS writing and visualisation exercise seems to provide a reliable paradigm and new opportunities for the study of optimism in the context of pain.

\section{ACKNOWLEDGMENTS}

We thank Katharina Pittner, Anne Schraa, Henrietta Steinhart and Anne van der Vorst for their valuable input in this study and for their assistance in the data collection. This study was supported by a grant from the Netherlands Foundation of Scientific Research. There is no conflict of interest regarding the material discussed in this manuscript. 


\section{REFERENCES}

Affleck, G., Tennen, H., Zautra, A., Urrows, S., Abeles, M., \& Karoly, P. (2001). Women's pursuit of personal goals in daily life with fibromyalgia: a value-expectancy analysis. Journal of Consulting and Clinical Psychology, 69, 587-596.

Allison, P. J., Guichard, C., \& Gilain, L. (2000). A prospective investigation of dispositional optimism as a predictor of health-related quality of life in head and neck cancer patients. Quality of Life Research, 9, 951-960.

Bargiel-Matusiewicz, K., \& Krzyszkowska, A. (2009). Dispositional optimism and coping with pain. European Journal of Medical Research, 14 Suppl 4, 271-274.

Baron, R. M., \& Kenny, D. A. (1986). The moderator-mediator variable distinction in social psychological research: conceptual, strategic, and statistical considerations. Journal of Personality and Social Psychology, 51, 1173-1182.

Brenes, G. A., Rapp, S. R., Rejeski, W. J., \& Miller, M. E. (2002). Do optimism and pessimism predict physical functioning? J Behav Med, 25, 219-231.

Campbell, C. M., Kronfli, T., Buenaver, L. F., Smith, M. T., Berna, C., Haythornthwaite, J. A., \& Edwards, R. R. (2010). Situational versus dispositional measurement of catastrophizing: associations with pain responses in multiple samples. Journal of Pain, 11, 443-453 e442.

Carson, J. W., Keefe, F. J., Lynch, T. R., Carson, K. M., Goli, V., Fras, A. M., \&Thorp, S. R. (2005). Loving-kindness meditation for chronic low back pain: results from a pilot trial. Journal of holistic nursing : official journal of the American Holistic Nurses' Association, 23, 287-304.

Carver, C. S., Scheier, M. F., \& Segerstrom, S. C. (2010). Optimism. Clinical Psychology Review.

Colloca, L., Sigaudo, M., \& Benedetti, F. (2008). The role of learning in nocebo and placebo effects. Pain, 136, 211-218.

Costello, N. L., Bragdon, E. E., Light, K. C., Sigurdsson, A., Bunting, S., Grewen, K., \& Maixner, W. (2002). Temporomandibular disorder and optimism: relationships to ischemic pain sensitivity and interleukin-6. Pain, 100, 99-110.

Fabian, L. A., McGuire, L., Goodin, B. R., \& Edwards, R. R. (2011). Ethnicity, catastrophizing, and qualities of the pain experience. Pain Medicine, 12, 314-321.

Fredrickson, B. L. (2001). The role of positive emotions in positive psychology. The broaden-and-build theory of positive emotions. The American psychologist, 56, 218-226.

Garland, E. L., Fredrickson, B., Kring, A. M., Johnson, D. P., Meyer, P. S., \& Penn, D. L. (2010). Upward spirals of positive emotions counter downward spirals of negativity: insights from the broaden-and-build theory and affective neuroscience on the treatment of emotion dysfunctions and deficits in psychopathology. Clinical Psychology Review, 30, 849-864.

Geers, A. L., Wellman, J. A., Helfer, S. G., Fowler, S. L., \& France, C. R. (2008). Dispositional optimism and thoughts of wellbeing determine sensitivity to an experimental pain task. Annals of Behavioral Medicine, 36, 304-313.

Hanssen, M. M., Vancleef, L. M. G., Vlaeyen, J. W. S., \& Peters, M. L. (2014). More optimism, less pain! The influence of generalized and pain-specific expectations on experienced cold-pressor pain. Journal of Behavioral Medicine, 37, 47-58.

Hood, A., Pulvers, K., Carrillo, J., Merchant, G., \& Thomas, M. (2012). Positive Traits Linked to Less Pain through Lower Pain Catastrophizing. Personality and Individual Differences, 52, 401-405.

Isaacowitz, D. M. (2005). The gaze of the optimist. Personality and Social Psychology Bulletin, 31, 407-415.

Karademas, E. C., Kafetsios, K., \& Sideridis, G. D. (2007). Optimism, self-efficacy and information processing of threatand well-being related information. Stress and Health, 23, 285-294. 
Keefe, F. J., Lumley, M., Anderson, T., Lynch, T., Studts, J. L., \& Carson, K. L. (2001). Pain and emotion: new research directions. Journal of Clinical Psychology, 57, 587-607.

Keefe, F. J., Rumble, M. E., Scipio, C. D., Giordano, L. A., \& Perri, L. M. (2004). Psychological aspects of persistent pain: current state of the science. Journal of Pain, 5, 195-211.

Keltner, J. R., Furst, A., Fan, C., Redfern, R., Inglis, B., \& Fields, H. L. (2006). Isolating the modulatory effect of expectation on pain transmission: a functional magnetic resonance imaging study. Journal of Neuroscience, 26, 4437-4443.

King, L. A. (2001). The health benefits of writing about life goals. Personality and Social Psychology Bulletin, 27, 798-807.

Kurtz, M. E., Kurtz, J. C., Given, C. W., \& Given, B. A. (2008). Patient optimism and mastery-do they play a role in cancer patients' management of pain and fatigue? Journal of Pain and Symptom Management, 36, 1-10.

Lorenz, J., Hauck, M., Paur, R. C., Nakamura, Y., Zimmermann, R., Bromm, B., \& Engel, A. K. (2005). Cortical correlates of false expectations during pain intensity judgments--a possible manifestation of placebo/nocebo cognitions. Brain, Behavior, and Immunity, 19, 283-295.

Luger, T., Cotter, K. A., \& Sherman, A. M. (2009). It's all in how you view it: pessimism, social relations, and life satisfaction in older adults with osteoarthritis. Aging and Mental Health, 13, 635-647.

MacLeod, A. K. (1996). Affect, emotional disorder, and future-directed thinking. Cognition and Emotion, 10, 69-86.

Mahler, H. I. M., \& Kulik, J. A. (2000). Optimism, pessimism and recovery from coronary bypass surgery: prediction of affect, pain and functional status. Psychology, Health \& Medicine, 5, 347-358.

Meevissen, Y. M., Peters, M. L., \& Alberts, H. J. (2011). Become more optimistic by imagining a best possible self: Effects of a two week intervention. Journal of Behavior Therapy and Experimental Psychiatry, 42, 371-378.

Novy, D. M., Nelson, D. V., Hetzel, R. D., Squitieri, P., \& Kennington, M. (1998). Coping with chronic pain: sources of intrinsic and contextual variability. J Behav Med, 21, 19-34.

Peters, M. L., Flink, I. K., Boersma, K., \& Linton, S. J. (2010). Manipulating optimism: Can imagining a best possible self be used to increase positive future expectancies? The Journal of Positive Psychology, 5, 204-2011.

Rasmussen, H. N., Scheier, M. F., \& Greenhouse, J. B. (2009). Optimism and physical health: a meta-analytic review. Annals of Behavioral Medicine, 37, 239-256.

Scheier, M. F., \& Carver, C. S. (1985). Optimism, coping, and health: assessment and implications of generalized outcome expectancies. Health Psychology, 4, 219-247.

Scheier, M. F., \& Carver, C. S. (1992). Effects of optimism on psychological and physical well-being: Theoretical overview and empirical update. Cognitive Therapy and Research, 16, 201-228.

Scheier, M. F., Carver, C. S., \& Bridges, M. W. (1994). Distinguishing optimism from neuroticism (and trait anxiety, selfmastery, and self-esteem): a reevaluation of the Life Orientation Test. Journal of Personality and Social Psychology, 67, 1063-1078.

Segerstrom, S. C. (2001). Optimism and attentional bias for negative and positive stimuli. Personality and Social Psychology Bulletin, 27, 1334-1343.

Sheldon, K. M., \& Lyubomirsky, S. (2006). How to increase and sustain positive emotion: The effects of expressing gratitude and visualizing best possible selves. The Journal of Positive Psychology, 1, 73-82.

Sinclair, V. G. (2001). Predictors of pain catastrophizing in women with rheumatoid arthritis. Archives of Psychiatric Nursing, 15, 279-288.

Sullivan, M. J., Bishop, S. R., \& Pivik, J. (1995). The Pain Catastrophizing Scale: Development and Validation. Psychological Assessment, 7, 524-532. 
Van Damme, S., Crombez, G., Bijttebier, P., Goubert, L., \& Van Houdenhove, B. (2002). A confirmatory factor analysis of the Pain Catastrophizing Scale: invariant factor structure across clinical and non-clinical populations. Pain, 96, 319-324.

Vancleef, L. M., \& Peters, M. L. (2008). Examining content specificity of negative interpretation biases with the Body Sensations Interpretation Questionnaire (BSIQ). Journal of Anxiety Disorders, 22, 401-415.

Vlaeyen, J. W., Hanssen, M., Goubert, L., Vervoort, T., Peters, M., van Breukelen, G., Sullivan, M. J., \& Morley, S. (2009). Threat of pain influences social context effects on verbal pain report and facial expression. Behaviour Research and Therapy, $47,774-782$.

Wong, W. S., \& Fielding, R. (2007). Quality of life and pain in Chinese lung cancer patients: Is optimism a moderator or mediator? Quality of Life Research, 16, 53-63. 


\section{Optimism, motivational coping and well-being: evidence supporting the importance of flexible goal adjustment}

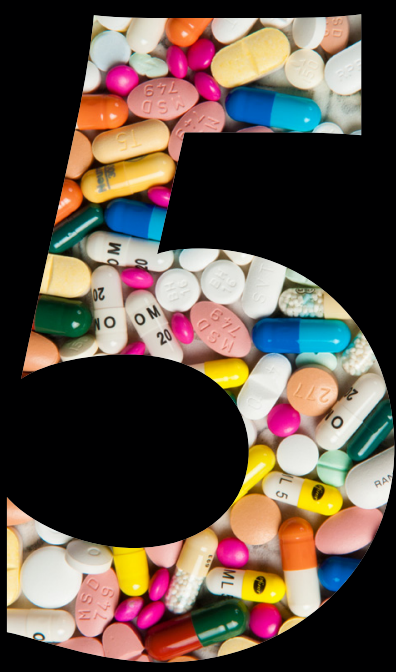

This chapter is accepted for publication as: Hanssen, M. M., Vancleef, L. M. G., Vlaeyen,J. W. S., Hayes, A. F., Schouten, E. G. W. \& Peters, M. L. (in press). Optimism, motivational coping and well-being: Evidence supporting the importance of flexible goal adjustment. Journal of Happiness Studies. 



\section{ABSTRACT}

It has repeatedly been shown that dispositional optimism, a generalized positive outcome expectancy, is associated with greater physical and psychological well-being. Coping has been proposed to mediate this purportedly causal relationship. From an expectancy-value perspective on motivation, optimists' confidence leads them to tenaciously pursue goals. However, the ability to flexibly adjust goals might serve optimists' ability to deal with adversity particularly well. This study investigated motivational coping (tenacious goal pursuit and flexible goal adjustment) as the mechanism linking dispositional optimism to several indices of well-being (general wellbeing, depression, anxiety and physical complaints) by means of a questionnaire study in the general population. Results of this study confirmed that motivational coping — primarily in the form of flexible goal adjustment - mediates the relationship between optimism and all indices of well-being except physical complaints. Furthermore, coping by flexibly adjusting one's goals is generally a more prominent pathway to well-being than tenaciously pursuing those goals. 



\section{INTRODUCTION}

The role personality plays in determining well-being has long been a topic of interest in psychological research (Caspi, Roberts, \& Shiner, 2005). Well-being is a complex construct that has been defined in various ways (Ryan \& Deci, 2001). One personality factor that seems inextricably linked with greater well-being in a broad sense is optimism (Carver, et al., 1994; Carver, Scheier, \& Segerstrom, 2010; Rasmussen, Scheier, \& Greenhouse, 2009; Scheier \& Carver, 1992). Moreover, in times of adversity, such as in response to chronic injuries, diseases or medical procedures, optimists consistently report fewer psychological and physical complaints (Carver, et al., 2010; Rasmussen, et al., 2009). Coping has been proposed as a potential mediator of these relationships (Carver, et al., 2010; Scheier \& Carver, 1985, 1992; Scheier, Weintraub, \& Carver, 1986).

Dispositional optimism has been defined as a generalized positive outcome expectancy (Scheier \& Carver, 1985). Optimists generally expect good things to happen to them, while pessimists anticipate negative outcomes. According to the expectancy-value model of motivation, the combination of the outcome expectancy and the value of a goal determines goal-directed behaviour (Carver \& Scheier, 1998). It has been argued that optimists' confidence about the future leads them to continue effort towards desired goals, even 'when the going gets tough'. In contrast, pessimists' tendency to doubt future outcomes facilitates a reduction in goal-directed effort and goal disengagement (Carver, et al., 2010; Slutske, Caspi, Moffitt, \& Poulton, 2005). In line with the fundamental premises of the expectancy-value model of motivation, optimists have typically been described as approach or engagement copers (Carver, et al., 2010; Solberg Nes \& Segerstrom, 2006). Pessimists, on the other hand, have been found to make greater use of avoidant or disengagement coping (Carver, et al., 2010; Roth \& Cohen, 1986; Solberg Nes \& Segerstrom, 2006).

Although optimists' tendency to pursue desired goals tenaciously has generally been related to indices of higher well-being, the adaptive nature of favourable beliefs and tenacity in goal pursuit has been argued (Carver, et al., 2010). For instance, optimists appear reluctant to reduce efforts after poor outcomes when gambling (Gibson \& Sanbonmatsu, 2004). In general, optimists seem to experience more goal conflict (Segerstrom \& Nes, 2006). Moreover, overly optimistic expectations have been associated with a failure to recognize or act upon threat (Weinstein, 1989).

In contrast to these observations, however, dispositional optimists are assumed to display great flexibility in coping and goal pursuit. It has been found that optimists switch flexibly between several coping strategies to meet the demands of the situation (Carver, et al., 2010; Solberg Nes \& Segerstrom, 2006). Dispositional optimism has been linked to several measures of goal dis- and/or re-engagement (Brandtstädter \& Renner, 1990; Rasmussen, Wrosch, Scheier, \& Carver, 2006; Solberg Nes \& Segerstrom, 2006; Wrosch \& Scheier, 2003). Aspinwall and Richter (1999), for example, found that optimists were more likely than pessimists to disengage from unsolvable anagrams in order to allocate their effort to solvable anagrams.

Although several classifications exist in the coping literature, the need for an emphasis on functional and motivational aspects within the study of coping has been argued (Skinner, Edge, Altman, \& Sherwood, 2003; Van Damme, Crombez, \& Eccleston, 2008). Brandstädter and Renner 
(1990) proposed a dynamic perspective on coping. In their dual process model of coping, tenacious goal pursuit and flexible goal adjustment are introduced as two broad motivational coping strategies. Tenacious goal pursuit is an assimilative coping mode in which life circumstances are adjusted to reach a desired condition. Flexible goal adjustment, on the other hand, refers to the process of accommodation, in which personal preferences or goals are adjusted to meet the constraints of a situation.

These motivational coping tendencies have successfully explained higher quality of life in older age (Brandtstädter \& Renner, 1990) and in general (Wrosch \& Scheier, 2003; Wrosch, Scheier, Miller, Schulz, \& Carver, 2003). Motivational coping might mediate the relationship between dispositional optimism and well-being. Flexible goal adjustment especially seems to buffer the negative consequences of stressful circumstances (Schmitz, Saile, \& Nilges, 1996). Since optimism has specifically been related to well-being despite adversity, flexible goal adjustment might be of particular importance with respect to explaining the relationship between optimism and well-being.

This study investigates the role of motivational coping in the association between dispositional optimism and well-being. We examine and compare the direct and indirect effects of optimism on four indices of well-being: general well-being, depression, anxiety and physical complaints, through two motivational coping strategies in a parallel multiple mediator model. We hypothesize that motivational coping (flexible goal adjustment and tenacious goal pursuit) mediates the effect of dispositional optimism on well-being. Furthermore, we hypothesize that the indirect effect of optimism on well-being is larger through flexible goal adjustment than through tenacious goal pursuit.

\section{METHOD}

\section{Participants}

The participants were 254 individuals (177, or 69\% female) with a mean age of 35.31 (SD=15.04). ${ }^{1}$ The recruitment strategy included flyers at Maastricht University and advertisements in regional newspapers. Fluency in the Dutch language and an age between 18 and 65 were necessary conditions to participate. Inclusion criteria were checked via email prior to participation. Participation was voluntarily, with a chance of winning an iPod or gift coupons by lottery as an incentive. In this sample, the reported levels of education were junior (16.5\%) or senior/academic education (35.8\%) and secondary (46.9\%) or primary education (0.8\%).

\footnotetext{
1 One male did not report his age. In the analyses we report, we imputed this participant's missing age with the mean age for men (39.89 years).
} 


\section{Measures}

\section{Dispositional optimism}

The Dutch Version of the Life Orientation Test Revised (LOT-R) was used to measure dispositional optimism (Scheier, Carver, \& Bridges, 1994). Dispositional optimism was measured by means of 3 positive and 3 negative items, such as 'In uncertain times, I usually expect the best' or 'If something can go wrong for me, it will.' Four filler items are added to conceal the aim of the assessment. The response format used was a 5-point scale, ranging from 1 (=strongly agree) to 5 (=strongly disagree). Reliability and validity of the LOT-R has been established as satisfactory (Scheier, et al., 1994). The total score was computed as the average response to the positive and reversed negative items, such that higher scores reflect greater dispositional optimism (Cronbach's alpha $=0.83)^{2}$

\section{Tenacious Goal Pursuit and Flexible Goal Adjustment}

Motivational coping was assessed by means of a Dutch translation of the Flexible Goal Adjustment (FGA) and Tenacious Goal Pursuit (TGP) scales (Brandtstädter \& Renner, 1990). Psychometric properties of the English version of the scales have been reported to be good (Brandtstädter \& Renner, 1990). Both scales consist of 15 items measuring assimilative and accommodative tendencies at a dispositional level. Items such as 'I can be very obstinate in pursuing my goals' or 'After a serious disappointment, I soon turn to new tasks' are used to measure accommodative (TGP) and assimilative (FGA) coping respectively. The items are scored on a scale ranging from 0 (= not agree at all) to 4 (= totally agree). In this study, Cronbach's alpha for TGP and FGA were 0.82 and 0.86 , respectively. Higher scores reflect greater tenacious goal pursuit and more flexible goal adjustment.

\section{Well-being questionnaire: General well-being}

General well-being was measured with the 12-item Dutch Well-Being Questionnaire (W-BQ12; Bradley, 2000; Pouwer, Snoek, van der Ploeg, Ader, \& Heine, 2000; Riazi, Bradley, Barendse, \& Ishii, 2006). The Dutch version of the W-BQ12 is shown to be a valid and reliable measure of well-being in people with diabetes (Pouwer, et al., 2000). Although originally designed to be suitable for use by people with chronic diseases (avoiding somatic items), it can nevertheless be used as a generic measure for general well-being (Pouwer, et al., 2000; Speight, McMillan, Barrington, \& Victor, 2007). The questionnaire consists of 12 items, which comprise three subscales of 4 items each. The 'negative well-being' subscale assesses (the absence of) negative feelings related to anxiety or depression. The 'positive well-being' subscale consists of items measuring feelings of

2 There has been some debate in the literature whether the LOT-R is unidimensional or bidimensional with optimism and pessimism factors. We conducted a confirmatory factor analysis comparing a unidimensional to a bidimensional model and found that although the bidimensional model did fit better, the correlation between the two factors was -0.80 . Thus, we treat the LOT-R as a unidimensional measure of optimism given the strong negative correlation between optimism and pessimism. 
happiness and satisfaction. In addition to these two subscales measuring hedonic aspects of well-being, the 'energy' subscale of the WBQ-12 measures a eudaimonic aspect of well-being (i.e. vitality). In this study only the total score was used as an indication of self-reported general wellbeing. All items were scored on a Likert scale ranging from 0 (= not at all) to 3 (= all the time). Individual items were reversed according to the guidelines and the average response was used in the analysis (Cronbach's alpha =0.92). Higher scores on the scale reflect greater general well-being.

\section{Anxiety and Depression}

The Dutch version of the Hospital Anxiety and Depression Questionnaire (HADS) developed by Zigmond and Snaith (1983) was used in this study to measure anxiety and depression. Psychometric properties of both the English and Dutch version have been found to be satisfactory (Spinhoven, et al., 1997; Zigmond \& Snaith, 1983). Both the depression and anxiety subscale consist of 7 items that are scored on a 4-point Likert scale. The average response to items in each subscale was used as the quantification of anxiety (Cronbach's alpha $=0.85$ ) and depression (Cronbach's alpha $=0.87)$ in the analysis, with higher scores reflecting higher levels of anxiety/depression.

\section{Physical Complaints}

Participants were asked to indicate to what extent they experience a series of physical complaints. On the physical complaints list, the following answering format was used: $0=$ never or hardly ever, $1=$ less than 3 or 4 times a year, 2 =almost every month, $3=$ almost every week, $4=$ more than once a week. Items consisted of the following physical complaints: nausea, headache, back pain, fatigue, musculoskeletal pain, stomach-ache and dizziness. The average response across all items was used as a measure of the frequency of common physical complaints (Cronbach's alpha $=.80)$.

\section{Procedure}

Participants who expressed interest in response to our recruitment efforts received additional information about the study by e-mail. They were informed that the study was being conducted in order to evaluate the quality of certain questionnaires. Detailed instructions about the online procedure were provided and qualifications for inclusion in the study were checked via email.

Participants were then directed to our assessment page, located in a secure online environment. Following the provision of informed consent, demographic variables were measured. Participants then completed several questionnaires in which each item was presented separately on screen. The procedure did not allow items to be skipped. Other questionnaires that are not part of the scope of this article were also included in this assessment battery. Total assessment time was 45 to 60 minutes. 


\section{Statistical Analyses}

Descriptive statistics and Pearson correlation coefficients between dispositional optimism, motivational coping strategies (flexible goal adjustment; tenacious goal pursuit) and indices of wellbeing (general well-being; depression; anxiety; physical complaints) were calculated.

In order to test whether the relationship between dispositional optimism and well-being is mediated by motivational coping (hypothesis 1), an observed variable path analysis corresponding to Figure 1 was conducted using Mplus v6.0 (Muthén \& Muthén, 2011). This model includes all possible direct and indirect effects of optimism on general well-being, anxiety, depression and physical complaints, with the indirect effects operating through the two motivational coping strategies. A model with multiple mediators such as this contains two specific indirect effects of optimism on each outcome, one through each motivational coping strategy, as well as a total indirect effect defined as the sum of the two specific indirect effects. As is widely-recommended (e.g., Hayes, 2013; Hayes \& Scharkow, 2013), inference for indirect effects was based on bias-corrected bootstrap confidence intervals using 10,000 bootstrap samples. Mediation is established if the confidence interval for an indirect effect does not straddle zero.

To examine whether the indirect effect of optimism is significantly larger through flexible goal adjustment than through tenacious goal pursuit (hypothesis 2), these specific indirect effects were formally compared, for each outcome, also using a bootstrap confidence interval for the difference between indirect effects (see Hayes, 2013, pp. 140-143; MacKinnon, 2000; Preacher \& Hayes, 2008).

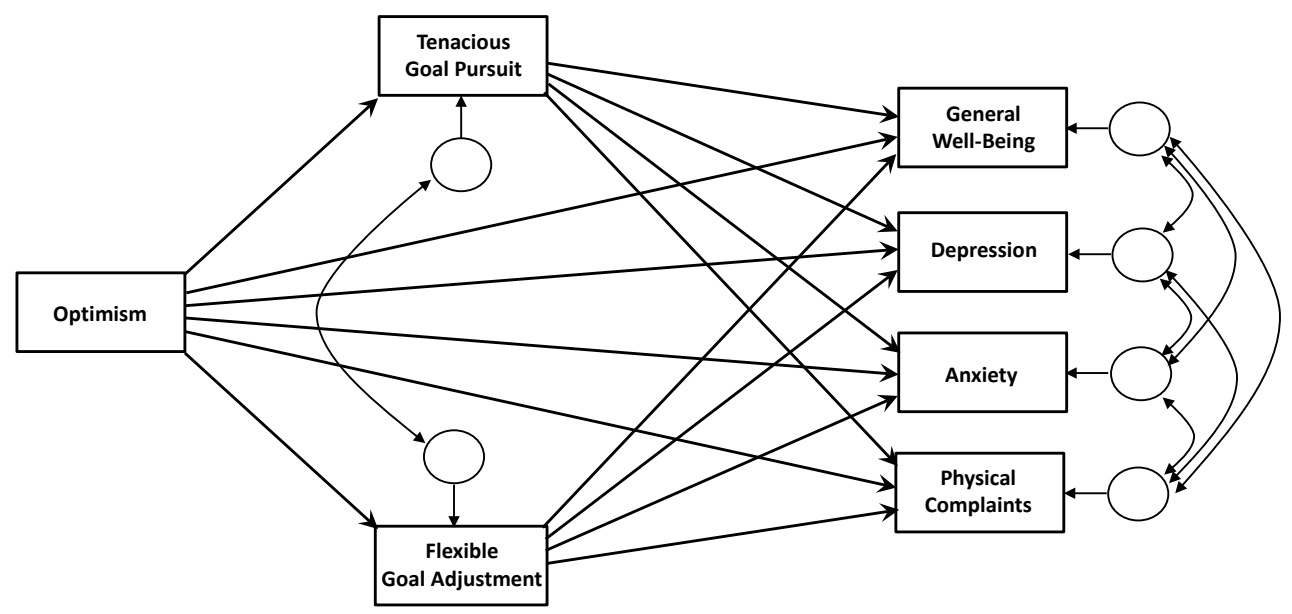

Figure 1. The Theoretical and Estimated Model Depicting Direct and Indirect Effects of Dispositional Optimism on Well-Being Through Motivational Coping Strategies. 


\section{RESULtS}

\section{Descriptive statistics}

Descriptive statistics as well as correlation coefficients between dispositional optimism, motivational coping and indices of well-being are presented in Table 1. The correlations between dispositional optimism, motivational coping strategies (flexible goal adjustment and tenacious goal pursuit) and well-being (general well-being, depression, anxiety, and physical complaints) were all statistically significant. As expected, the relatively more optimistic participants scored higher in both tenacious goal pursuit and flexible goal adjustment. Furthermore, participants relatively higher in these motivational coping strategies reported greater general well-being, lower depression and anxiety, and fewer physical complaints.

Table 1. Descriptive statistics and intercorrelations between measured variables.

\begin{tabular}{|c|c|c|c|c|c|c|c|c|c|c|}
\hline & \multirow[b]{2}{*}{ Mean } & \multirow[b]{2}{*}{$S D$} & \multirow[b]{2}{*}{$a$} & \multirow{2}{*}{$\begin{array}{l}\text { Observed } \\
\text { Range }\end{array}$} & \multicolumn{6}{|c|}{ Pearson correlations } \\
\hline & & & & & 1 & 2 & 3 & 4 & 5 & 6 \\
\hline 1. Optimism & 3.48 & 0.75 & .83 & $1.00-5.00$ & & & & & & \\
\hline 2. Tenacious goal pursuit & 2.21 & 0.52 & .82 & $0.80-3.46$ & .40 & & & & & \\
\hline 3. Flexible goal adjustment & 2.37 & 0.57 & .86 & $0.27-3.66$ & .70 & .36 & & & & \\
\hline 4. General well-being & 1.98 & 0.62 & .92 & $0.17-3.00$ & .70 & .42 & .67 & & & \\
\hline 5. Depression & 0.65 & 0.62 & .87 & $0.00-3.00$ & -.65 & -.35 & -.58 & -.74 & & \\
\hline 6. Anxiety & 0.89 & 0.63 & .85 & $0.00-2.57$ & -.59 & -.28 & -.55 & -.71 & .64 & \\
\hline 7. Physical complaints & 1.36 & 0.82 & .80 & $0.00-3.71$ & -.39 & -.17 & -.37 & -.56 & .46 & .56 \\
\hline
\end{tabular}

$n=254 . a=$ Cronbach's alpha. All correlations are statistically different from zero with $p$-value no larger than 0.01 .

\section{Mediation analysis}

We hypothesized that dispositional optimism is related to indices of well-being and that these relationships are mediated by flexible goal adjustment and tenacious goal pursuit. The correlations between optimism and the four well-being measures in Table 1 substantiate that optimists tend to experience more well-being than those who are less optimistic.

The path analysis corresponding to Figure 1 was conducted using maximum likelihood estimation with Mplus 6.0. In accordance with the recommendation of Preacher and Hayes (2008), the covariances between the errors in estimation of the mediators were freely estimated. 
We also freely estimated the covariances between the errors in estimation of each outcome. ${ }^{3}$ Not depicted in Figure 1, we included sex and age as controls in the model by adding paths from these covariates to all mediators and outcomes in order to eliminate any association between key variables in the model that could be attributed to sex differences or shared covariation with age. ${ }^{4}$ The resulting model is saturated, meaning as many parameters are estimated as degrees of freedom available. Therefore, fit is necessarily perfect.

The model coefficients can be found in Table 2, and Table 3 provides the indirect effects of optimism through motivational coping along with bootstrap confidence intervals. The total indirect effect offers information about motivational coping (i.e., summed across the indirect effects through the two coping strategies) as a mediator. Specific indirect effects of flexible goal adjustment and tenacious goal pursuit describe mediation by the individual motivational coping tendencies. The direct effects (in the first row of Table 2) estimate the relationship between optimism and the well-being outcomes through mechanisms or processes (e.g., spuriousness) not explicitly modelled.

Table 2. Unstandardized model coefficients (standard errors in parentheses).

\begin{tabular}{|c|c|c|c|c|c|c|}
\hline \multirow[b]{2}{*}{ Predictor Variable } & \multicolumn{6}{|c|}{ Outcome Variable } \\
\hline & $\begin{array}{c}\text { Tenacious } \\
\text { Goal } \\
\text { Pursuit }\end{array}$ & $\begin{array}{c}\text { Flexible } \\
\text { Goal } \\
\text { Adjustment }\end{array}$ & Well-Being & Depression & Anxiety & $\begin{array}{c}\text { Physical } \\
\text { Complaints }\end{array}$ \\
\hline Optimism & $\begin{array}{l}0.270^{* * *} \\
(0.040)\end{array}$ & $\begin{array}{l}0.540^{* * *} \\
(0.034)\end{array}$ & $\begin{array}{l}0.335^{* * *} \\
(0.049)\end{array}$ & $\begin{array}{l}-0.328^{* * *} \\
(0.053)\end{array}$ & $\begin{array}{l}-0.327^{* * *} \\
(0.060)\end{array}$ & $\begin{array}{l}-0.312^{* *} \\
(0.009)\end{array}$ \\
\hline Tenacious Goal Pursuit & & & $\begin{array}{l}0.150^{* *} \\
(0.053)\end{array}$ & $\begin{array}{l}-0.075 \\
(0.058)\end{array}$ & $\begin{array}{l}-0.030 \\
(0.065)\end{array}$ & $\begin{array}{c}0.007 \\
(0.097)\end{array}$ \\
\hline Flexible Goal Adjustment & & & $\begin{array}{l}0.364^{* * *} \\
(0.064)\end{array}$ & $\begin{array}{l}-0.322^{* * *} \\
(0.069)\end{array}$ & $\begin{array}{l}-0.288^{* * *} \\
(0.078)\end{array}$ & $\begin{array}{l}-0.216+ \\
(0.116)\end{array}$ \\
\hline Sex $(1=$ male, $0=$ female $)$ & $\begin{array}{c}0.005 \\
(0.067)\end{array}$ & $\begin{array}{c}0.135^{*} \\
(0.056)\end{array}$ & $\begin{array}{c}0.076 \\
(0.057)\end{array}$ & $\begin{array}{l}0.221^{* * *} \\
(0.061)\end{array}$ & $\begin{array}{l}-0.026 \\
(0.069)\end{array}$ & $\begin{array}{l}-0.308^{* *} \\
(0.103)\end{array}$ \\
\hline Age & $\begin{array}{l}-0.002 \\
(0.002)\end{array}$ & $\begin{array}{c}0.003 \\
(0.002) \\
\end{array}$ & $\begin{array}{l}-0.003+ \\
(0.002)\end{array}$ & $\begin{array}{l}0.006^{* *} \\
(0.002)\end{array}$ & $\begin{array}{c}0.000 \\
(0.002)\end{array}$ & $\begin{array}{c}0.001 \\
(0.003)\end{array}$ \\
\hline$R$-squared & $0.164^{* * *}$ & $0.510^{* * *}$ & $0.581^{* * *}$ & $0.512^{* * *}$ & $0.383^{* * *}$ & $0.200^{* * *}$ \\
\hline
\end{tabular}

3 Fixing these covariances to zero resulted in a statistically significant reduction in fit, signifying the importance of allowing the remaining variance in these variables to correlate after accounting for their associations resulting from their determinants in the model.

4 Preliminary analyses revealed that males reported significantly higher depression, and fewer physical complaints than females, and older participants reported less optimism, lower tenacious goal pursuit, lower general well-being, and higher depression than younger participants. 
As can be seen from the total indirect effects of optimism in Table 3 (TGP + FGA), aggregated coping mechanisms significantly mediate the relationship between dispositional optimism and general well-being, anxiety, and depression, but not physical complaints. Based on the coefficients in Table 2 and the bootstrap confidence intervals for the total indirect effects, more optimistic participants tend to pursue goals more tenaciously, and are more inclined to adjust their goals based on the demands of the situation as compared to low optimistic participants. These strategies in turn are associated with increased general well-being and reduced anxiety and depression.

The total indirect effects aggregate across the specific indirect pathways of influence, and as discussed in Hayes (2013), they can mask or otherwise obscure the effects operating at the level of the specific mediators depending on the size and sign of those specific indirect effects. In a multiple mediator model, the specific indirect effects quantify the influence of one variable and another through a third while statistically holding constant the other mediators in the model. An examination of the specific indirect effects in Table 3 shows that the mediation of the effect of optimism on well-being operates primarily through flexible goal adjustment, with negative indirect effects on depression and anxiety and a positive indirect effect on general well-being. The only statistically significant specific indirect effect through tenacious goal pursuit was on general well-being, with optimism associated with more positive general well-being.

Finally, as can be seen in Table 2, the direct effect of optimism on well-being was statistically significant for all outcome variables, meaning that optimism is related to well-being after accounting for the indirect process through motivational coping. That is, holding differences in motivational coping constant, the more optimistic the greater well-being (higher general wellbeing and lower anxiety, depression, and physical symptoms).

\section{Comparison of indirect effects}

The prior analysis reveals evidence of an indirect effect of optimism on several measures of wellbeing primarily through flexible goal adjustment and not through tenacious goal pursuit. A difference in significance of indirect effects does not imply they are significantly different. A formal test of difference between these specific indirect effects (TGP - FGA) can be found in Table 3, along with bias-corrected 95\% confidence intervals for the differences. As can be seen, for general well-being, anxiety, and depression, the two specific indirect effects were statistically different (as the bootstrap confidence interval for the difference does not straddle zero), but they were not different for physical complaints. These results bolster our claim that of the two coping strategies we examined, flexible goal adjustment is the primary mechanism through which dispositional optimism influences well-being. 
Table 3. Unstandardized indirect effects of optimism, including contrasts between indirect effects and between total indirect and direct effect.

\begin{tabular}{|c|c|c|c|}
\hline Effect of optimism on & & Point estimate & $\begin{array}{l}\text { Bias-corrected bootstrap 95\% } \\
\text { confidence Interval }\end{array}$ \\
\hline \multirow[t]{4}{*}{ general well-being through... } & TGP & 0.040 & 0.011 to 0.076 \\
\hline & FGA & 0.196 & 0.109 to 0.297 \\
\hline & $T G P+F G A$ & 0.237 & 0.145 to 0.339 \\
\hline & TGP - FGA & -0.156 & -0.264 to -0.059 \\
\hline \multirow[t]{4}{*}{ depression through... } & TGP & -0.020 & -0.064 to 0.016 \\
\hline & FGA & -0.174 & -0.271 to -0.083 \\
\hline & $\mathrm{TGP}+\mathrm{FGA}$ & -0.194 & -0.295 to -0.101 \\
\hline & TGP - FGA & 0.154 & 0.047 to 0.262 \\
\hline \multirow[t]{4}{*}{ anxiety through... } & TGP & -0.008 & -0.048 to 0.028 \\
\hline & FGA & -0.155 & -0.250 to -0.061 \\
\hline & $\mathrm{TGP}+\mathrm{FGA}$ & -0.163 & -0.259 to -0.067 \\
\hline & TGP - FGA & 0.147 & 0.039 to 0.252 \\
\hline physical complaints & TGP & 0.002 & -0.053 to 0.061 \\
\hline \multirow[t]{3}{*}{ through... } & FGA & -0.117 & -0.248 to 0.013 \\
\hline & $\mathrm{TGP}+\mathrm{FGA}$ & -0.115 & -0.248 to 0.021 \\
\hline & TGP - FGA & 0.119 & -0.024 to 0.270 \\
\hline
\end{tabular}

Note: Bootstrap confidence intervals are based on 10,000 bootstrap samples.

TGP = Tenacious Goal Pursuit, FGA = Flexible Goal Adjustment

\section{Discussion}

The beneficial impact of dispositional optimism on physical and psychological well-being is well documented (Carver, et al., 1994; Carver, et al., 2010; Rasmussen, et al., 2009; Scheier \& Carver, 1985, 1992). The relationships between dispositional optimism and general well-being, depression, anxiety and physical complaints adds to the available evidence establishing that optimists experience greater subjective well-being than pessimists. More importantly, however, this study provides new evidence regarding the mechanism by which this effect may operate. We sought to investigate two motivational coping strategies as the mechanism linking dispositional optimism and several indices of well-being, and found evidence consistent with mediation by motivational coping. Similar to what others have found (Brandtstädter \& Renner, 1990; Rasmussen, et al., 2006; Solberg Nes \& Segerstrom, 2006; Wrosch \& Scheier, 2003; 
Wrosch, et al., 2003), optimists in our study were more inclined than pessimists to pursue goals tenaciously while also flexibly adjusting goals based on the situation. Moreover, it was primarily flexible goal adjustment that seemed to translate into greater well-being. There was no indirect effect of optimism through tenacious goal pursuit except for one measure of well-being, and that indirect effect was smaller than the effect through flexible goal adjustment. These results underscore that motivational coping at least partially explains the relationship between dispositional optimism and certain indices of well-being (Carver, et al., 1994; Carver, et al., 2010; Rasmussen, et al., 2009; Scheier \& Carver, 1992).

These results also confirm our hypothesis that the indirect effect of optimism on wellbeing would be larger through flexible goal adjustment than through tenacious goal pursuit. These results contribute to the conviction that flexible goal adjustment protects people from negative consequences in stressful circumstances and promotes quality of life (Schmitz, et al., 1996; Wrosch \& Scheier, 2003; Wrosch, et al., 2003). While these findings are consistent with research linking optimism and goal disengagement and reengagement (Brandtstädter \& Renner, 1990; Rasmussen, et al., 2006; Wrosch \& Scheier, 2003; Wrosch, et al., 2003), reconciling them with predictions from the expectancy-value model of motivation is challenging. In this framework, optimistic expectations by definition lead to well-being through continued goal attainment. However, our results attest to the greater importance of optimists' flexibility instead of tenacity in the pursuit of goals towards well-being.

Our results invite speculations on the role of flexible goal adjustment in an expectancyvalue framework of motivation. First of all, it is interesting that flexible goal adjustment has been described as a strategy to stay engaged instead of turning effort away. Adaptive self-regulation includes not only behavioural but also cognitive responses. Goal adjustment strategies, such as redefining values, goal conceptualisations and internal standards for evaluations of goal progress are actually engagement enhancing strategies (Carver \& Scheier, 2000). Secondly, it should be noted that goals are organised in a hierarchical structure (Carver \& Scheier, 1998). Disengagement of a behavioural goal on a lower level might therefore secure goal attainment on a higher level. The broadening effect of positive emotions and cognitions might support a focus on the bigger picture (Fredrickson, 2001, 2004), thereby enhancing flexible goal pursuit. Finally, a discrepancy between general and specific optimistic expectations has been reported (Armor \& Taylor, 1998; Hanssen, Peters, Vlaeyen, Meevissen, \& Vancleef, 2013; Hanssen, Vancleef, Vlaeyen, \& Peters, 2014; Scheier \& Carver, 1992). Both generalized and specific expectations might influence goal-directed behaviour differently (Neff \& Geers, 2013). It is not inconceivable that generalized expectations influence the pursuit of higher order goals in particular.

Another area of research that might be helpful in understanding adaptive self-regulation in optimists is based on the principles of the Self Determination Theory (SDT; Ryan \& Deci, 2000). According to SDT, the type of motivation determines self-regulatory processes (Deci \& Ryan, 2000). Thompson and Gaudreau (2008) found that students with generalized positive expecta- 
tions engage in academic activities mainly because of pleasure (intrinsic motivation), while the engagement of students with generalized negative expectations is based on extrinsic motivation. These latter findings provided evidence for the mediating role of self-determined motivation in the association of optimism/pessimism with coping (Thompson \& Gaudreau, 2008). The SDT-inspired Dualistic model of Passion (Vallerand, et al., 2003) describes two types of passion for activities that seem closely linked to the two types of motivational coping in the dual process model of coping (Brandtstädter \& Renner, 1990). A harmonious passion, which results from an autonomous internalisation (linked to intrinsic motivation), fosters flexible engagement in the loved activity. An obsessive passion, which results from a controlled internalisation (linked to extrinsic motivation), leads to a rigid persistence of the important activity. The study of harmonious versus obsessive passions might lead to new insights regarding adaptive self-regulation in optimists.

A few important limitations should be noted. First, although the model we proposed and estimated is a causal one, with optimism purportedly influencing coping which in turn influences well-being, statistics cannot establish cause, and our data are merely correlational in nature. Experimental research can provide useful information about the way in which optimists pursue goals. Second, even after accounting for the contribution of motivational coping strategies, optimism was still related to well-being (i.e., the direct effects were statistically significant). This finding suggests the existence of additional processes linking dispositional optimism to well-being that our model does not account for. Third, this study was based on a general community sample rather than people who experience adversity in some form day after day. Replication using a sample of people who regularly experience adversity (such as chronic pain sufferers, cancer patients, and so forth) could provide more information about the role of flexibility in how optimists deal with stressful circumstances.

In conclusion, motivational coping seems to be one mechanism by which optimism can influence several aspects of well-being. We found that flexible goal adjustment stands out as a particularly important motivational coping strategy relative to the tenacious pursuit of goals that may in turn influence psychological well-being. Future research should focus on flexible goal adjustment as displayed by optimists in order to understand better how this coping strategy could facilitate the effectiveness of interventions aimed at dealing with adversity in life.

\section{ACKNOWLEDGEMENTS}

This work was supported by the Netherlands Organisation of Scientific Research [Grant number 453-07-005]. The contribution of Dr. Vancleef was sponsored by the Netherlands Organisation of Scientific Research [Grant number 451-09-026]. Johan W.S. Vlaeyen was supported by the Odysseus Grant "The Psychology of Pain and Disability Research Program" funded by the Research Foundation, Flanders, Belgium (FWO Vlaanderen, Belgium). 


\section{REFERENCES}

Armor, D. A., \& Taylor, S. E. (1998). Situated optimism: Specific outcome expectancies and self-regulation. In M. P. Zanna (Ed.), Advances in experimental social psychology. (Vol. 30, pp. 309-379). New York: Academic Press.

Aspinwall, L. G., \& Richter, L. (1999). Optimism and self-mastery predict more rapid disengagement from unsolvable tasks in the presence of alternatives. Motivation and Emotion, 23, 221-245.

Bradley, C. (2000). The 12-item Well-being Questionnaire. Origins, current state of development, and availability. Diabetic Medicine, 7, 445-451.

Brandtstädter, J., \& Renner, G. (1990). Tenacious goal pursuit and flexible goal adjustment: explication and age-related analysis of assimilative and accommodative strategies of coping. Psychology and Aging, 5, 58-67.

Carver, C. S., Pozo-Kaderman, C., Harris, S. D., Noriega, V., Scheier, M. F., Robinson, D. S., Ketcham, A. S., Moffat, F. L., Jr., \& Clark, K. C. (1994). Optimism versus pessimism predicts the quality of women's adjustment to early stage breast cancer. Cancer, 73, 1213-1220.

Carver, C. S., \& Scheier, M. (1998). On the Self-Regulation of Behavior. New York: Cambridge University Press.

Carver, C. S., \& Scheier, M. F. (2000). Scaling back goals and recalibration of the affect system are processes in normal adaptive self-regulation: understanding 'response shift' phenomena. Social Science \& Medicine, 50, 1715-1722.

Carver, C. S., Scheier, M. F., \& Segerstrom, S. C. (2010). Optimism. Clinical Psychology Review, 30, 879-889.

Caspi, A., Roberts, B. W., \& Shiner, R. L. (2005). Personality development: stability and change. Annual Review of Psychology, 56, 453-484.

Deci, E. L., \& Ryan, R. M. (2000). The "what"and "why"of goal pursuits: Human needs and the self-determination of behavior. Psychological Inquiry, 11, 227-268.

Fredrickson, B. L. (2001). The role of positive emotions in positive psychology. The broaden-and-build theory of positive emotions. The American Psychologist, 56, 218-226.

Fredrickson, B. L. (2004). The broaden-and-build theory of positive emotions. Philosophical transactions of the Royal Society of London. Series B, Biological sciences, 359, 1367-1378.

Gibson, B., \& Sanbonmatsu, D. M. (2004). Optimism, pessimism, and gambling: the downside of optimism. Personality and Social Psychology Bulletin, 30, 149-160.

Hanssen, M. M., Peters, M. L., Vlaeyen, J. W., Meevissen, Y. M., \& Vancleef, L. M. (2013). Optimism lowers pain: evidence of the causal status and underlying mechanisms. Pain, 154, 53-58.

Hanssen, M. M., Vancleef, L. M., Vlaeyen, J. W. S., \& Peters, M. L. (2014). More optimism, less pain! The influence of generalized and pain-specific expectations on experienced cold-pressor pain. Journal of Behavioral Medicine, $37,47-58$.

Hayes, A. F. (2013). An introduction to mediation, moderation, and conditional process analysis: A regression-based approach. New, York, NY: The Guilford Press.

Hayes, A. F., \& Scharkow, M. (2013). The relative trustworthiness of inferential tests of the indirect effect in statistical mediation analysis: Does method really matter? Psychological Science, 24, 1918-1927.

MacKinnon, D. P. (2000). Contrasts in multiple mediator models. In J. Rose, L. Chassin, C. C. Presson \& S. J. Sherman (Eds.), Multivariate applications in substance use and research: New methods for new questions. (pp. 141-160). Mahwah, NJ: Lawrence Erlbaum Associates.

Muthén, L. K., \& Muthén, B. O. (2011). Mplus users guide (6th ed.). Los Angeles, CA: Author. 
Neff, L. A., \& Geers, A. L. (2013). Optimistic expectations in early marriage: a resource or vulnerability for adaptive relationship functioning? Journal of Personality and Social Psychology, 105, 38-60.

Pouwer, F., Snoek, F. J., van der Ploeg, H. M., Ader, H. J., \& Heine, R. J. (2000). The well-being questionnaire: evidence for a three-factor structure with 12 items (W-BQ12). Psychological Medicine, 30, 455-462.

Preacher, K. J., \& Hayes, A. F. (2008). Asymptotic and resampling methods for assessing and comparing indirect effects in multiple mediator models. Behavior Research Methods, 40, 879-891.

Rasmussen, H. N., Scheier, M. F., \& Greenhouse, J. B. (2009). Optimism and physical health: a meta-analytic review. Annals of Behavioral Medicine, 37, 239-256.

Rasmussen, H. N., Wrosch, C., Scheier, M. F., \& Carver, C. S. (2006). Self-regulation processes and health: the importance of optimism and goal adjustment. Journal of Personality, 74, 1721-1747.

Riazi, A., Bradley, C., Barendse, S., \& Ishii, H. (2006). Development of the Well-being questionnaire short-form in Japanese: the W-BQ12. Health and Quality of Life Outcomes, 4, 40.

Roth, S., \& Cohen, L. J. (1986). Approach, avoidance, and coping with stress. American Psychologist, 41, 813-819.

Ryan, R. M., \& Deci, E. L. (2000). Intrinsic and Extrinsic Motivations: Classic Definitions and New Directions. Contemp Educ Psychol, 25, 54-67.

Ryan, R. M., \& Deci, E. L. (2001). On happiness and human potentials: a review of research on hedonic and eudaimonic well-being. Annual Review of Psychology, 52, 141-166.

Scheier, M. F., \& Carver, C. S. (1985). Optimism, coping, and health: assessment and implications of generalized outcome expectancies. Health Psychology, 4, 219-247.

Scheier, M. F., \& Carver, C. S. (1992). Effects of optimism on psychological and physical well-being: Theoretical overview and empirical update. Cognitive Therapy and Research, 16, 201-228.

Scheier, M. F., Carver, C. S., \& Bridges, M. W. (1994). Distinguishing optimism from neuroticism (and trait anxiety, selfmastery, and self-esteem): a reevaluation of the Life Orientation Test. Journal of Personality and Social Psychology, 67, 1063-1078.

Scheier, M. F., Weintraub, J. K., \& Carver, C. S. (1986). Coping with stress: divergent strategies of optimists and pessimists. Journal of Personality and Social Psychology, 51, 1257-1264.

Schmitz, U., Saile, H., \& Nilges, P. (1996). Coping with chronic pain: flexible goal adjustment as an interactive buffer against pain-related distress. Pain, 67, 41-51.

Segerstrom, S. C., \& Nes, L. S. (2006). When Goals Conflict But People Prosper: The Case of Dispositional Optimism. Journal of research in personality, 40, 675-693.

Skinner, E. A., Edge, K., Altman, J., \& Sherwood, H. (2003). Searching for the structure of coping: a review and critique of category systems for classifying ways of coping. Psychological Bulletin, 129, 216-269.

Slutske, W. S., Caspi, A., Moffitt, T. E., \& Poulton, R. (2005). Personality and problem gambling: a prospective study of a birth cohort of young adults. Archives of General Psychiatry, 62, 769-775.

Solberg Nes, L., \& Segerstrom, S. C. (2006). Dispositional optimism and coping: a meta-analytic review. Personality and Social Psychology Review, 10, 235-251.

Speight, J., McMillan, C., Barrington, M., \& Victor, C. (2007). Review of scales of positive mental health validated for use with adults in the UK: Technical report. In (pp. 246). Edinburgh, Scotland. 
Spinhoven, P., Ormel, J., Sloekers, P. P., Kempen, G. I., Speckens, A. E., \& Van Hemert, A. M. (1997). A validation study of the Hospital Anxiety and Depression Scale (HADS) in different groups of Dutch subjects. Psychological Medicine, 27, 363-370.

Thompson, A., \& Gaudreau, P. (2008). From optimism and pessimism to coping: The mediating role of academic motivation,. International Journal of Stress Management, 15, 269-288.

Vallerand, R. J., Blanchard, C., Mageau, G. A., Koestner, R., Ratelle, C., Leonard, M., Gagne, M., \& Marsolais, J. (2003). Les passions de l'ame: on obsessive and harmonious passion. J Pers Soc Psychol, 85, 756-767.

Van Damme, S., Crombez, G., \& Eccleston, C. (2008). Coping with pain: a motivational perspective. Pain, 139, 1-4.

Weinstein, N. D. (1989). Optimistic biases about personal risks. Science, 246, 1232-1233.

Wrosch, C., \& Scheier, M. F. (2003). Personality and quality of life: the importance of optimism and goal adjustment. Quality of life research: an international journal of quality of life aspects of treatment, care and rehabilitation, 12 Suppl 1, 59-72.

Wrosch, C., Scheier, M. F., Miller, G. E., Schulz, R., \& Carver, C. S. (2003). Adaptive self-regulation of unattainable goals: goal disengagement, goal reengagement, and subjective well-being. Personality \& Social Psychology Bulletin, 29, 1494-1508.

Zigmond, A. S., \& Snaith, R. P. (1983). The hospital anxiety and depression scale. Acta Psychiatrica Scandinavica, 67, 361-370. 
General discussion

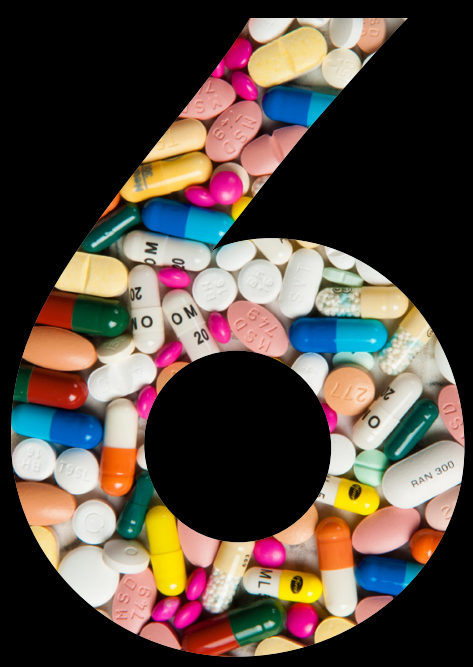



Dispositional optimism has repeatedly been related to lower pain-sensitivity and higher wellbeing despite pain (Costello, et al., 2002; Geers, Wellman, Helfer, Fowler, \& France, 2008). The aim of this dissertation was to further unravel the link between dispositional optimism and pain/ well-being, hereby addressing two important remaining questions: 'Is optimism causally related to pain?' and 'What are the underlying mechanisms in the relation between optimism and pain/ (pain-related) well-being?'In the four empirical chapters of this dissertation, seven studies investigating causality and/or mechanisms in the relationship between optimism and pain/well-being were described. In this chapter, an overview of the general conclusions of these studies will be presented. This will be followed by a discussion of the findings, including methodological issues, theoretical and clinical implications. Throughout this chapter, recommendations for future research will be made.

\section{SUMMARY OF THE MAIN FINDINGS}

\section{Is optimism causally related to pain?}

The link between dispositional optimism and pain is robust (Allison, Guichard, \& Gilain, 2000; Geers, et al., 2008; Ramirez-Maestre \& Esteve, 2013; Sturgeon \& Zautra, 2010; Wright, Zautra, \& Going, 2008). Additional evidence for this association was found in two lab studies that were conducted in the context of this dissertation (chapter 3). In both studies dispositional optimism was significantly related to pain reports during/after an experimental pain induction. The conclusion of these studies is in line with other laboratory studies (Geers, et al., 2008; Hood, Pulvers, Carrillo, Merchant, \&Thomas, 2012) and longitudinal research (Allison, et al., 2000; Luger, Cotter, \& Sherman, 2009; Mahler \& Kulik, 2000; Peters, et al., 2007) linking optimism to pain sensitivity and/ or pain-related well-being. Although these studies suggest that the association might be causal, no study had used an experimental design to confirm causality.

Chapter 4 describes an experiment in which we sought to test the causal status of optimism towards pain by inducing a temporary optimistic state in participants prior to a cold pressor immersion. To manipulate the level of optimism, we used the Best Possible Self writing- and visualisation exercise that successfully had been used for this purpose in previous research (Meevissen, Peters, \& Alberts, 2011; Peters, Flink, Boersma, \& Linton, 2010). As hypothesized, the induction of optimism resulted in lower reported pain intensity ratings during a cold pressor task than performing the control exercise. The results of this experiment indicate that optimism is not only negatively related to pain sensitivity, but that it might effectively lead to lower pain sensitivity. A causal link between optimism and pain-sensitivity was established. 


\section{What are the underlying mechanisms in the relation between optimism and pain/(pain-related) well-being?}

To gather more information about the possible mechanisms that may underlie the relationship between dispositional optimism and pain and/or (pain-related) well-being, tentative candidates were selected following the current theoretical insights.

Based on the conceptualisation of dispositional optimism in an expectancy-value framework (Carver \& Scheier, 1998), the first depicted mechanism was pain-specific expectancy. Optimism, as a generalized positive outcome expectancy, may guide specific expectations in new and ambiguous situations (Carver \& Scheier, 2002; Scheier \& Carver, 1985). A mediation model in which pain-specific expectations explain the optimism-pain link was therefore tested. Alternatively, a moderation model in line with research showing that generalized optimistic expectations interact with situational placebo expectations (Geers, Helfer, Kosbab, Weiland, \& Landry, 2005; Geers, Kosbab, Helfer, Weiland, \& Wellman, 2007) was investigated. In summary, it was hypothesized that a generalized positive outcome expectancy would translate into or interact with less negative pain-specific expectations, hereby leading to diminished pain sensitivity.

In chapter 3, both the hypothesized mediation (study 1) and moderation model (study 2) were disconfirmed. In the two studies described in this chapter, dispositional optimism (or a generalized outcome expectancy) was positively related to pain reports during/post a cold pressor immersion. Pain-specific expectancy (measured as expected pain intensity) was also positively related to cold pressor pain reports. However, generalized expectations did not lead to or interact with pain-specific expectations. Hence, both sets of expectations were only independently related to reported cold pressor pain.

The conclusion of Chapter 4 was in line with these findings. In the latter study, expected and experienced cold pressor pain were measured after an optimism or control manipulation (Best Possible Self versus Typical Day writing- and visualisation exercise). It was hypothesized that induced optimism would lead to lower expected pain reports and in turn to diminished pain sensitivity (= mediation hypothesis). The results of this study pointed out that induced optimism did not lead to lower expected pain ratings. Induced optimism and pain-related expectations were independently related to pain reports during the cold pressor task. Taken together, the results of chapter 3 and 4 did not provide evidence for pain-specific expectations ('expected pain intensity') as an underlying mechanism in the optimism-pain relationship.

Following predictions of the fear avoidance model of pain (Vlaeyen \& Linton, 2000, 2012), pain catastrophizing was selected as a second putative candidate to explain the relation between optimism and pain sensitivity. Previous research had already reported on the association of dispositional optimism with catastrophic appraisals of pain (Bargiel-Matusiewicz \& 
Krzyszkowska, 2009; Sinclair, 2001). Chapter 4 provides evidence for a mediation model in which induced optimism, at least partially, leads to lower pain sensitivity through situational pain catastrophizing. Conducting the Best Possible Self writing- and visualisation exercise led to lower levels of pain sensitivity as well as pain catastrophizing during a cold pressor task than writing and visualising about a Typical Day. Thus evidence was found for pain catastrophizing as an underlying mechanism in the relationship between optimism and pain sensitivity.

Optimism might not only be related to more benign interpretations of pain-related information, but to a specific pattern of interpretation of ambiguity in general. Vancleef and Peters (2008) found that optimism protects against threatening interpretations of ambiguity in several domains. In line with basic postulations of information processing theories (Butler \& Mathews, 1983), optimists' general tendency to make less catastrophic interpretations might protect them from experiencing distress. Chapter 2 describes three studies on optimists' interpretation of ambiguity in general. With the aim of exploring information processing of optimists more into depth, it was also examined whether optimists make more positive in addition to less negative interpretations of ambiguity.

Three studies with an adapted version of the Body Sensations Interpretation Questionnaire (BSIQ; Clark, et al., 1997) showed that optimists make less negative and (to a lesser degree) more positive interpretations of ambiguous situations. Using an open-ended version of the adapted BSIQ, dispositional optimism was related to participants' but not raters' coding of the self-generated responses. It was concluded that specific interpretation and possibly also reinterpretation patterns might be a mechanism through which optimists are protected against psychological complaints in stressful circumstances such as the confrontation with chronic pain.

One mechanism that typically has been put forward to explain the benefits of optimism, is coping (Carver, Scheier, \& Segerstrom, 2010; Scheier \& Carver, 1985). In line with a recent shift in pain research (Crombez, Eccleston, Van Damme, Vlaeyen, \& Karoly, 2012; Van Damme, Crombez, \& Eccleston, 2008), motivational coping was investigated as a last hypothesized mechanism in the relation between optimism and well-being (chapter 5). Data of a questionnaire study in healthy participants showed that dispositional optimism was significantly related to motivational coping (tenacious goal pursuit and flexible goal adjustment) and to several indices of subjective well-being (i. e. anxiety, depression, general well-being and physical complaints). Motivational coping tendencies mediated the relationship between optimism and well-being. In addition, results indicated that flexible goal adjustment was the primary mechanism through which dispositional optimism related to well-being. Findings of chapter 5 suggest that motivational coping, specifically flexible goal adjustment, might be an important underlying mechanism in the relation between dispositional optimism and higher well-being despite pain. 


\section{General discussion}

\section{Causality}

Optimism research is typically correlational in nature. Longitudinal work however suggests that optimism leads to less pain or pain-related disability (Allison, et al., 2000; Luger, et al., 2009; Mahler \& Kulik, 2000; Peters, et al., 2007). This notion is strengthened by recent work indicating that optimism is prospectively related to acute as well as chronic post-operative pain (Pinto, Mclntyre, Ferrero, Almeida, \& Araujo-Soares, 2013; Powell, et al., 2012). In addition, a review by Goodin and Bulls (2013) shows convincing evidence for the association of optimism with better adjustment to chronic and post-operative pain. Support for a possible protective influence of optimism towards pain not only originates from research in clinical samples, but also from lab studies in which healthy participants are exposed to experimentally induced pain (Geers, Wellman, Fowler, Helfer, \& France, 2010; Geers, et al., 2008; Hood, et al., 2012). None of those studies however provided a direct demonstration of the causal status towards pain.

To further the study of optimism, researchers sought to temporarily manipulate optimism. For instance, Fosnaugh, Geers and Wellman (2009) successfully induced an optimistic orientation in healthy participants using both a covert (scrambled sentence task) and an overt (future thinking exercise) technique. A scrambled sentence task, identical to the covert technique of Fosnaugh and colleagues (2009) was thereafter used in our research group to demonstrate that optimism counteracts an ego-depletion effect (In Den Bosch-Meevissen, Peters, \& Alberts, in press). Although manipulation checks (affect and future expectations) did not reveal priming effects in the latter study, the activation of the optimism construct led to undiminished task persistence in participants high in baseline optimism.

The Best Possible Self exercise, based on the work of King (2001) has been used most frequently to investigate the effects of optimism, after it was shown to successfully induce an optimistic state in a single session or after a two-weeks visualisation period (Meevissen, et al., 2011; Peters, et al., 2010). Therefore, this exercise was selected to experimentally test the causal status of optimism towards pain in this dissertation. Findings of chapter 4 provide an initial confirmation of the causal relation between optimism and pain sensitivity.

Using the BPS exercise, additional evidence was found for a causal link between optimism and sustained task persistence despite repeated self-control acts (In Den Bosch-Meevissen, Hanssen, \& Peters, in preparation). Moreover, visualising a positive future even counteracted the depleting effect of cold pressor pain on executive task performance (Boselie, Vancleef, Smeets, \& Peters, 2014). These findings implicate that optimism might also protect individuals with chronic pain by countering an ego-depletion effect that may result from the continuous cognitive interruption of pain.

Thus, evidence for causal effects of optimism is accumulating. However, the subject of replication deserves attention. Although the study described in Chapter 4 provides evidence for the relation between experimentally induced optimism and decreased pain sensitivity, this find- 
ing was not replicated by Boselie and colleagues (2014). They found that an optimism induction led to less cognitive interference by pain, but not to lower pain intensity ratings. The single measurement of pain intensity (end immersion) in their study as opposed to multiple measurements of pain intensity (during, end and post-immersion) in the study of chapter 4 might be responsible for this dissimilarity. In all three studies of this dissertation relating (induced or dispositional) optimism to cold pressor pain, a significant relation between optimism and reported pain was found, but the time point for which the relation was significant differed between studies. Further investigation of the causal relationships of optimism with a range of pain-related outcomes is strongly recommended.

Support for the efficacy of the Best Possible Self exercise is also growing. In all aforementioned and additional studies (Peters, Vieler, \& Lautenbacher, in preparation; Renner, Schwarz, Peters, \& Huibers, 2014), writing and visualising about a positive future led to increments of positive and decrements of negative future expectations. The Best Possible Self manipulation therefore appears to be a reliable technique to induce a temporary optimistic state. In contrast to the techniques used by Fosnaugh and colleagues (2009), the BPS manipulation not only impacts on optimism, but also on (in particular positive) mood. A recent study by Peters, Meevissen and Hanssen (2013) addressed the issue of discriminant validity by comparing the Best Possible Self exercise with a gratitude exercise. Because the overall impact of the gratitude exercise (not the BPS exercise) was low, no conclusion regarding BPS specificity was reached.

It can be questioned whether it is truly possible to convincingly manipulate optimism without impacting on mood, as optimism and positive mood may be viewed as cognitive and emotional counterparts. According to the self-regulation theory, the expectation of positive outcomes yields a mix of positive feelings, while the anticipation of negativity leads to negative feelings (Carver \& Scheier, 1998). Moreover, evidence for the association between optimism and positive mood is extensive (Raikkonen, Matthews, Flory, Owens, \& Gump, 1999; Segerstrom, Taylor, Kemeny, \& Fahey, 1998). Thus, any optimism manipulation will possibly also impact on mood.

Further unravelling the characteristics of the BPS manipulation would add useful information to the study of optimism. The manipulation consists of several elements that might add to the BPS and/or optimism effect, including a focus on positivity, adaptation of a broad time perspective, future orientation, concreteness of goals (possibly including action plans) and vividness of positive future scenarios. To investigate effective components of the Best Possible Self manipulation, a content analysis of participants'scripts is currently being conducted in our research group.

\section{Generalized versus specific expectations}

Optimism has been defined as a generalized positive outcome expectancy (Carver \& Scheier, 1998; Scheier \& Carver, 1985). Hence, optimists generally expect positive as opposed to negative events to occur in their lives. Although a generalized outcome expectancy pertains a sense of confidence/doubt in relation to life rather than to a specific context, one could speculate that a 
generalized expectation particularly guides specific expectations in new, uncertain and challenging situations (Carver \& Scheier, 2002; Carver, et al., 2010; Scheier \& Carver, 1985). This speculation was put to the test in chapter 3 and 4 . Students who had no prior experience with the cold pressor task were invited to participate in a CPT study. It was expected that their pain-specific expectations ('expected CPT pain') would be shaped by their level of optimism. Surprisingly, optimism did not lead to (or interact with) pain-specific expectations in participants who conducted the cold pressor task for the first time in their lives. Results of this dissertation do provide evidence for the independent influence of both sets of expectations towards cold pressor pain.

Recent literature also reports independent contributions of generalized and specific expectations in the prediction of for instance post-operative quality of life in cancer patients (Thornton, Perez, Oh, \& Crocitto, 2012) and marital satisfaction (Neff \& Geers, 2013). The association between generalized and specific expectations seems to be limited (Armor \& Taylor, 1998; Klein \& Zajac, 2009). Moreover, while generalized forms of optimism have been related to healthpromotion and constructive problem-solving, domain-specific optimism has been associated with the reverse pattern (Neff \& Geers, 2013; Radcliffe \& Klein, 2002). The ease with which both sets of expectations may be disconfirmed by experience may be responsible for this difference. Since generalized expectations are less easily disconfirmed, they may be related to lower levels of distress in situations in which individuals are confronted with threatening information. In turn these lower levels of distress and the maintained confidence enable adaptive coping with adversity. Specific expectations on the other hand are more susceptible for disconfirmation by experience, possibly leading to higher levels of distress, feelings of doubt and maladaptive coping with the experienced adversity.

It has been argued that optimists display specific optimistic expectations strategically, being less extreme when the chance of disconfirmation is high. Hence, dispositional optimism has been related to 'situated optimism', which refers to the ability to take into account situational demands and immediate personal needs in the expression of optimistic expectations (Armor \& Taylor, 1998). The idea of situated optimism is in line with Lewin's (1948) paradox that effective self-regulation is the result of how high one can set goals and expectations while staying in touch with reality. A broad time perspective, in which past, present and future is considered, is related to both a high morale and active coping with the situation at hand (Lewin, 1948; Zimbardo \& Boyd, 1999). The strategic expression of optimistic expectations might explain why optimism was not related to lower pain expectancy ratings in chapter 3 and 4.

Thus, optimism was not confirmed as an antecedent of specific expectations by our findings. It should however be acknowledged that only 'expected pain intensity' was measured in this dissertation. However, specific expectations are a complex construct and several types of specific expectations have been mentioned in the literature (Haanstra, et al., 2012). Evidence for the interaction between generalized and specific expectations has typically been found in relation to placebo treatment expectations (Geers, et al., 2005; Geers, et al., 2007). Since beliefs about pain treatments and self-regulation strategies determine their efficacy (Benedetti, et al., 2003; Martijn, Tenbült, Merchkelbach, Dreezens, \& de Vries, 2002), it might be interesting to further 
investigate whether an interaction of optimism with this type of expectations influences the experience of pain. Bandura (1977) emphasized that weighing expected consequences with the purpose of determining goal-directed behaviour also includes individuals' perception of his/her own ability to perform certain behaviour or to deal with certain situations. Adapted to the situation of pain, not only expected pain intensity or treatment efficacy beliefs, but also self-efficacy expectations might influence the pain experience. Since optimism has been related to a sense of personal efficacy (Cozzarelli, 1993), specific self-efficacy expectations might mediate or moderate the optimism-pain link.

Interestingly, the current thesis seems to provide evidence for Scheier and Carver's (1985) conviction that behaviour is predicted best when levels of specificity match. In each of these studies, expected pain was related to pain ratings at more time points than generalized expectations. However, both sets of expectations accounted for a significant percentage of explained variance in pain ratings. The independent influence of both sets of expectations suggests different working mechanisms and further investigation of their content is warranted.

\section{Optimistic information processing}

According to the Fear Avoidance model, catastrophic appraisals of pain lead to increased fear of pain, avoidance behaviour and disability (Crombez, et al., 2012; Vlaeyen \& Linton, 2000, 2012). This dissertation adds evidence to earlier observations suggesting that optimism protects against pain catastrophizing (Bargiel-Matusiewicz \& Krzyszkowska, 2009; Sinclair, 2001). In this dissertation, it was demonstrated that induced optimism is related to less catastrophic appraisals about pain during a cold pressor task (chapter 4). Moreover, three studies with an adapted Body Sensations Interpretation Questionnaire (Clark, et al., 1997) indicated that optimism is related to more positive interpretations of ambiguity (albeit to a lesser degree) in addition to less negative interpretations (chapter 2).

The study with the open-ended version of the BSIQ (chapter 2) showed a remarkable finding. Optimism was significantly related to less negative and more positive interpretations of ambiguity when considering participants'valence ratings of their self-generated responses. Only one significant relation (optimism - total ranking negative experiences) was found with coders' ratings. This difference between coders' and participants' ratings indicates there might be more than meets the eye. Not only in relation to specific expectations, but also regarding appraisals, the studies in this dissertation focussed on the threat value of ambiguous stimuli only. However, other types of appraisals might be at least as important in interpreting ambiguity than appraisals of threat. It has been argued that appraisals concerning coping efficacy or control can prevent initial appraisals of threat to escalate (Casey, Oei, \& Newcombe, 2004; Casey, Oei, Newcombe, \& Kenardy, 2004). Possibly appraisals of coping efficacy and/or control led to less negative and more positive ratings of their self-generated responses in optimists.

In the discussion of chapter 2, it was suggested - based on the principles of the learned helplessness theory of Seligman (1972) - that appraisals of coping efficacy and control might 
protect optimists from depressive feelings following stressful circumstances. Related to this, Renner, Schwarz, Peters and Huibers (2014) recently investigated whether BPS imagery protects against dysfunctional depression-related attitudes after a negative mood induction. Although they did find that the BPS reinstates mood after such a manipulation, they did not find evidence for the protective influence of optimism on dysfunctional cognitions. Further research in a population with more dysfunctional cognitions seems necessary to reach further conclusions. Moreover, evaluating optimism in relation to appraisals of different content (threat, coping efficacy and control) could shed a clearer light on the role of appraisals in the relation between optimism and (well-being despite) pain. The role of personal control in the efficacy of placebo treatment has been stressed (Geers, et al., 2013).

Optimists tend to reappraise situations in a positive manner (Nes \& Segerstrom, 2006). Positive reappraisals of the situation might be the result of optimists' focus on the bigger picture (Fredrickson, 2001) and/or the anticipation of a positive future (Scheier \& Carver, 1985). This broader perspective might help participants to see positive elements in difficult situations or at least reduce the subjective cost of aversive events. It has been mentioned before that generalized positive outcome expectancies are not easily disconfirmed (Armor \& Taylor, 1998). Possibly positive (re-)interpretations serve the cause of maintaining a positive outlook on life.

A bidirectional relation between fear and cognitive biases is supported by emerging evidence in the field of anxiety research (Mathews \& Mackintosh, 2000; Mathews \& MacLeod, 1994; Muris \& Field, 2008). In relation to optimism and positive biases, evidence is scarce. Research on early stages of information processing has found that optimists are reluctant to attend to negative information and more inclined to focus on positive stimuli (Karademas, Kafetsios, \& Sideridis, 2007; Segerstrom, 2001). A recent eye-tracking study found a preference for positive stimuli related to both dispositional and induced optimism (Peters, et al., in preparation). It would be interesting to investigate whether optimism is also related to the selective attentional broadening effect that has been ascribed to positive affect (Fredrickson \& Branigan, 2005; Vanlessen, Rossi, De Raedt, \& Pourtois, 2013; Wadlinger \& Isaacowitz, 2006). Information about how optimists process information could help to refine cognitive training programs.

\section{Optimism and motivational coping}

In pain research, the importance of motivational factors has been emphasized (Crombez, et al., 2012; Van Damme, et al., 2008; Vlaeyen \& Linton, 2012). Pain does not only interfere with daily activities, but also with individuals' pursuit of goals. Moreover, 'finding a solution for the pain' might become an important, but detrimental goal in pain patients' lives (Eccleston \& Crombez, 2007). In line with the adaptation of a motivational perspective in the study of pain, motivational coping tendencies (tenacious goal pursuit and flexible goal adjustment) were investigated as an underlying mechanism in the relationship between optimism and well-being.

The hypothesized mediation model was confirmed and flexible goal adjustment proved to be of particular importance in explaining the relation between optimism and well-being. 
Understanding the findings in an expectancy-value framework is challenging (Carver \& Scheier, 1998). This theory postulates that optimists' sense of confidence leads to continued effort towards a goal, while pessimists' sense of doubt leads to disengagement. Notwithstanding, our findings indicate that optimism is specifically related to flexible goal adjustment as opposed to tenacious goal pursuit. Carver and Scheier (2000) previously discussed that strategies used to flexibly adjust goals actually seem to enhance engagement instead of disengagement. Moreover, since goals are organised in a hierarchy, disengagement of a goal on a lower level might enhance engagement on a higher level (Carver \& Scheier, 1998). Optimists' tendency to focus on the bigger picture may be related to a focus on higher order goals (Fredrickson, 2001; Fredrickson \& Branigan, 2005). The ability of optimists to flexibly adjust goals might enable them to stay engaged in what makes their life worth living in difficult situations.

Possibly optimism also leads to flexibility in relation to the attentional interruption of pain. Engaging in a concurrent goal has been found to inhibit attentional bias towards pain-related information (Schrooten, et al., 2012; Van Damme, Legrain, Vogt, \& Crombez, 2010). Since optimists have been found more inclined to focus on the positive elements of a situation (Karademas, et al., 2007; Segerstrom, 2001), they might benefit maximally from the availability of alternative non-pain goals.

The idea that concurrent goals might counter the fear-avoidance response is not new. In 1930, Nissen reported that rats crossed electrified grids (hereby not avoiding pain) in order to explore novel spaces. This finding, among others, inspired the development of the concept of intrinsic motivation. Behaviour that is intrinsically motivated is behaviour that is inherently rewarding and that satisfies innate psychological needs (i. e. the need for autonomy or self-determination). Extrinsic motivation on the other hand refers to behaviour that is based on the contingencies that are attached to it. Extrinsically motivated behaviour can vary from actions maintained by internal/external reinforcement and punishment (low autonomy) to performing certain behaviour because the overarching goal is intrinsically motivated (high autonomy). It is argued that intrinsic motivation and higher levels of autonomy promote goal engagement and positive affect (Ryan \& Deci, 2000).

One of the research venues that recently has been proposed in pain research is inspired by Deci and Ryan's (1985) Self-Determination Theory (Crombez, et al., 2012; Van Damme \& Kindermans, 2014). It is suggested that autonomous motivation might lead to less interruption by pain and higher task persistence than controlled motivation. In certain subgroups (i. e. dancers, athletes, musicians) however, persistence seems to lead to detrimental effects, such as higher frequency or longer duration of injuries (Rip, Fortin, \& Vallerand, 2006; Vallerand, 2008; Vallerand, Paquet, Philippe, \& Charest, 2010).

Vallerands' Dualistic Model of Passion (Vallerand, et al., 2003), which is inspired on Self-Determination principles, provides an explanation of why some people show inflexible persistence in maladaptive behaviour. More specifically, this model describes two distinct types of passion that one can have for a favoured activity. An obsessive passion results from a controlled internalisation of the activity into one's identity. This type of passion leads people to experience an uncontrollable urge to engage in the activity, despite failure experiences or negative consequences, 
and this creates conflict with other activities in life. Obsessive passion has also been related to alternative goal suppression (Belanger, Lafreniere, Vallerand, \& Kruglanski, 2013). A harmonious passion on the other hand, results from an autonomous internalisation of the activity into identity. A harmonious passion has been found to lead people to engage in their favoured activity by choice, hereby promoting a harmonious co-existence with other activities in life and higher levels of positive affect (Vallerand, et al., 2003).

It has been found that optimists' engagement in academic activities is intrinsically motivated (Thompson \& Gaudreau, 2008). It might be interesting to further investigate to which degree intrinsically motivated and/or self-determined behaviour and harmonious passion promote well-being in optimists.

\section{METHODOLOGICAL ISSUES}

Several methodological issues may have influenced the (impact of) the findings in this dissertation. First, the results mainly rely on self-report measures. In chapter 3, pain tolerance was measured, but the correlational analyses with dispositional optimism did not yield significant results. It is not unthinkable that the findings in this dissertation are (in part) based on a self-report bias in optimists. Typically a stronger relationship between optimism and subjective as opposed to objective health measures is found (Rasmussen, Scheier en Greenhouse, 2009). Nevertheless, research shows that optimism impacts on immune functioning and psychophysiology (Costello, et al., 2002; Segerstrom, 2005). For instance, Brydon, Walker, Wawrzyniak, Chart, \& Steptoe (2009) found that dispositional optimism buffers stress-induced immune changes and negative mood. The causal status of optimism towards stress-related cortisol levels was confirmed by In Den Bosch-Meevissen, Peters and Nicolson (in preparation). They found that visualizing about a Best Possible Self for a period of two weeks led to a diminished stress response during a Trier Social Stress Task. In addition, Geers and colleagues (2008) formally tested the hypothesis that the optimism pain link is attributable to self-report. They rejected this hypothesis based on a non-significant link between public self-awareness and cold pressor pain. Notwithstanding these results refuting the self-report hypothesis, it is recommended to (continue to) include distinct types of measurements in optimism research.

Second, the measurement of dispositional optimism as a unidimensional construct as opposed to a bidimensional construct consisting out of an optimism and a pessimism factor remains a source of ambiguity. The starting point in each study of this dissertation was the original conceptualisation of dispositional optimism, as measured with the revised Life Orientation Test (Scheier, Carver, \& Bridges, 1994). However, subscale analyses were consistently performed on the data and the results generally showed no significant deviation from findings emerging from analyses with optimism as a one-factor construct. However, results as reported in chapter 3 provide support for the idea that the optimism and pessimism subscale of the LOT-R might have differential predictive value, with stronger associations between pessimism and health out- 
comes (Brenes, Rapp, Rejeski, \& Miller, 2002; Robinson-Whelen, Kim, MacCallum, \& Kiecolt-Glaser, 1997). In line with research on positive and negative affect (Watson, Clark, \& Carey, 1988; Watson, Clark, \& Tellegen, 1988), it has been argued that optimism and pessimism are related to different working mechanisms. For instance, a study by Ramirez-Maestre and colleagues (2012) found that optimism and pessimism (subscales) lead to better adjustment in pain patients, through the use of active versus passive coping strategies respectively.

As mentioned before, most studies in this dissertation did not show a differential impact of both subscales on mechanisms and outcome measures. From a theoretical point of view, it is difficult to imagine that generalized positive and negative outcome expectations co-exist. From a statistical point of view, arguments can back up both a one and two-factor solution. The twofactor solution mostly receives support from a better model fit, while a strong correlation between the subscales suggests a one factor solution. For instance, the whopping correlation of .80 between optimism and pessimism in chapter 5 did not seem to justify the additional complexity of the analyses that the use of two factors would bring. Staying attentive to this issue in investigating dispositional optimism seems warranted.

Third, the study population in this dissertation includes healthy participants only. The advantage of a healthy population for pain research lies in the fact that their relative lack of experience enables investigating mechanisms that could contribute to the development of chronic pain. However, it is unclear whether these results can be generalized to the daily experience of individuals suffering from chronic pain. We are currently addressing the research questions of chapter 2 (general interpretation patterns) and chapter 5 (motivational coping) in 2 studies in chronic pain patients. Replication of these studies in a sample of individuals who experience pain on a regular basis might provide more insight in optimist's interpretation patterns of pain- and non-pain related ambiguous situations and their flexibility in dealing with adversity.

Fourth, respecting the limitations of one study always leads to a selection of variables included in the study. Direct evaluation of certain combinations of variables would add useful information to the study of optimism. First, the combined study of resilience and risk factors could help to integrate both research lines. In chapter 3 of this study, the influence of fear of pain was controlled for in both studies. In all other studies, only dispositional optimism was measured. Second, multiple mediator analyses can provide extra information about the nature of the relationships between optimism and pain/(pain-related) well-being. In this dissertation, several mediators have been identified. However, it would be interesting to additionally focus on their relative combined contribution.

A last methodological issue we would like to address is the correlational approach that was used in several studies in this dissertation. Causal inferences can only be made based on experimental work. The manipulation of optimism that was used in chapter 4 has been called a positive move forward (Keefe \& Wren, 2013). It is argued that the line of experimental work on optimism should be continued in order to provide evidence for some of the causal relationships between optimism and certain mechanism that have been found based on correlational work in this dissertation. 


\section{THEORETICAL IMPLICATIONS}

One of the crucial findings in this dissertation is the causal relationship between optimism and pain. Moreover, we found preliminary evidence for mechanisms that might underlie the protective influence of optimism towards pain. These main findings can be integrated with theories on risk and resilience towards pain.

\section{The Fear-Avoidance Model (FAM)}

The leading model in pain research, the fear-avoidance model (Vlaeyen \& Linton, 2000), postulates that when pain is appraised in a threatening manner, this leads to a negative fear-based vicious circle leading to pain-related disability. The model also describes that a non-threatening cognitive appraisal of the pain promotes functional recovery. Recently, several changes to the Fear-Avoidance model have been suggested, among which the proposition to create more insight in the pathway of confrontation (Crombez, et al., 2012; Vlaeyen \& Linton, 2000; Wideman, et al., 2013). Based on the findings in this dissertation, an alternative model is composed addressing the protective role of dispositional optimism instead of the role of 'negative affectivity' and 'threatening illness information' as risk factors towards pain-related disability. Possible working mechanisms are tentatively added to the pathway of confrontation in the fear-avoidance. Some of the elements in this model have been substantiated by research conducted in the context of this dissertation. This however does not dispel the speculative nature of the proposed model, but the proposed conceptualisation summarizes the topics of this dissertation and generates new hypotheses for future research.

\section{Dispositional optimism}

Based on the findings in this dissertation, it is argued that optimism as a generalized outcome expectancy protects from entering the negative downward spiral and promotes entering the positive upward spiral. Not only generalized expectations, but also specific expectations are supposed to play an important role. However, future research should shed more light on their interaction and on the content of both sets of expectations in relation to pain-related outcomes.

\section{Catastrophizing versus neutral positive (re-)interpretation:}

It has been concluded that dispositional optimism leads to lower levels of pain catastrophizing (Chapter 4) and possibly to more positive appraisals (chapter 2). Future research could focus on several questions. First, do neutral or positive appraisals lead to functional recovery? Second, what is the content of these appraisals (threat-related, coping efficacy or control)? Third, what is the role of reinterpretation in the relation between optimism and functional recovery? 


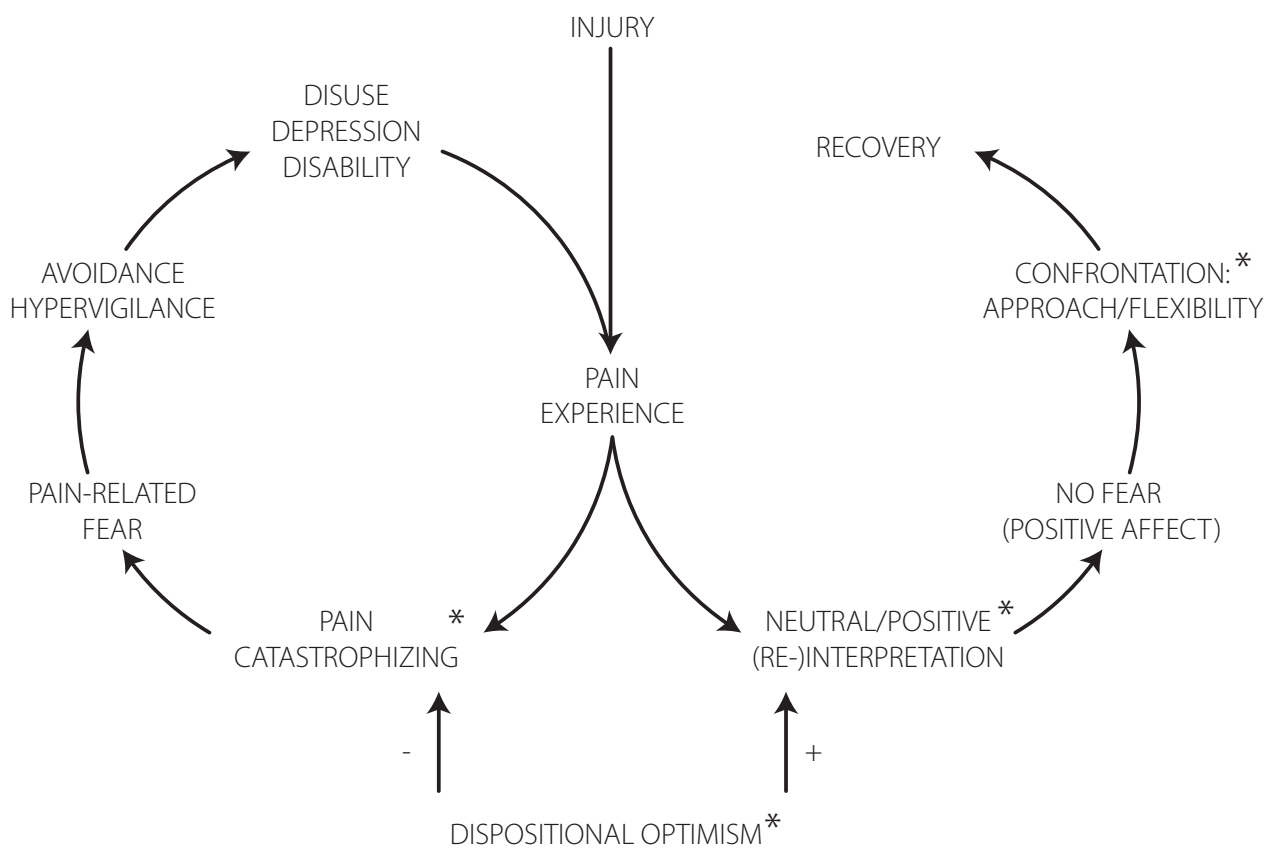

Fig. 1. Speculative fear-avoidance model based on the findings in this dissertation.

Note: * indication of parts of the model for which preliminary evidence was found in this dissertation.

\section{Pain-related fear versus no fear or positive feelings}

Although dispositional optimism was unrelated to fear of pain in chapter 3 of this dissertation, it has been negatively related to post-operative anxiety (Pinto, et al., 2013). It remains unclear whether the mere absence of fear (as hypothesized in Vlaeyen \& Linton, 2000) or rather the presence of positive emotions paves the way to functional recovery. The latter seems to be an interesting avenue to explore, based on the general findings of the broaden-and-build model of positive emotions (Fredrickson, 2001; Fredrickson \& Branigan, 2005; Fredrickson, Mancuso, Branigan, \& Tugade, 2000).

\section{Avoidance/hypervigilance versus confrontation: approach/flexibility}

The pathway of confrontation in the fear-avoidance model depicted approach tendencies as an essential mechanism in promoting functional recovery. Findings in this dissertation emphasize the role of flexible goal adjustment towards well-being. Both coping tendencies might enhance engagement in important higher order goals despite chronic pain. It would be interesting to explore the role of certain type of goals and passionate activities, since they might provide more insight in the positive upward spiral towards better well-being despite pain. In addition, it may be interesting to investigate flexibility in relation to the attentional interruption of pain in relation to optimism and resilience. 


\section{What can we learn from research on resilience?}

An important theory in positive psychology is the Broaden-and-Build Model (Fredrickson, 2001; Fredrickson \& Branigan, 2005). Central to this model is the broadening influence of positive emotions on attention and momentary thought-action repertoires. In the long run, positive emotions build enduring physical, cognitive and social resources.

It has been argued that the broadening effect of positive emotions might counter the narrowing effect of negative emotions (Zautra, Smith, Affleck, \&Tennen, 2001). This idea is often referred to as the undoing hypothesis. The undoing hypothesis explains how long term positive effects of positive emotions can serve as an antidote against the immediate (and disabling in case of chronic stressors) effects of negative emotions (Fredrickson \& Levenson, 1998; Fredrickson, et al., 2000; Garland, et al., 2010).

Information on the negative downward spiral of the fear-avoidance model was mainly inspired by research in the field of anxiety (Vlaeyen \& Linton, 2000). Fear, as a negative emotion that serves the function of signalling danger, narrows cognitive, behavioural and motivational processes (Vlaeyen \& Linton, 2000). It is suggested that repeated positive experiences broaden those processes, as suggested by the broaden-and-build theory (Fredrickson, 2001; Fredrickson \& Branigan, 2005). Insight in the positive upward spiral of the fear-avoidance model might be gained by borrowing insights from the study of positive emotions. As mentioned before, certain type of goals and passions are particularly related to positive emotions and the ability to the ability to maintain a broad perspective in life (Vallerand, 2008; Vallerand, et al., 2003). This tendency might help to deal with the experience of pain while staying open to other aspects in life.

\section{CLINICAL IMPLICATIONS}

\section{Roze-tinted glasses for everyone?}

This dissertation provides clear evidence for the beneficial influence of being optimistic on (painrelated) well-being. Also, emerging evidence underscores the possibility of inducing an optimistic state in individuals. However, simply making everyone optimistic may be impossible as well as inappropriate. Levels of dispositional optimism as a trait, seems to be (in part) a product of repeatedly experiencing positive situations that in turn enhance the accessibility of positive scenarios for the future (Blackwell, et al., 2013; Scheier \& Carver, 1985; Sharot, Korn, \& Dolan, 2011). However, inducing a temporary optimistic state and a focus on positivity might promote positive experiences and quality of life despite pain. Furthermore, we can definitely learn from optimists, who naturally seem to benefit from their positive outlook on life. A better understanding of the mechanisms that lead to higher well-being despite pain in optimists might help to refine interventions for chronic pain patients. 


\section{Best Possible Self \& Positive Psychology Interventions}

The Best Possible Self exercise might be an effective intervention tool for chronic pain patients. An essential adaptation of this exercise for the use in chronic pain patients pertains the focus on a 'Best Possible Self Despite Pain'. Constructing a satisfactory self-representation 'despite pain' seems to be an essential feature of the acceptance of pain (McCracken, Carson, Eccleston, \& Keefe, 2004). Research on self-discrepancies shows that subjective distances between patients 'actual self' and their (often pain-free) 'ideal self' triggers depressive feelings (Higgins, 1987; Kindermans, et al., 2011). The more ones'future self-representation depends on the absence or presence of pain (self-pain enmeshment), the higher the risk for maladjustment towards pain (Morley, Davies, \& Barton, 2005). To relate this to the notion of time perspective (Lewin, 1948), the 'Best Possible Self Despite Pain' exercise might enhance an adaptive interplay between future optimistic expectations and the demands of the present reality. The 'Best Possible Self Despite Pain' exercise is considered a useful tool in a psychological treatment of pain patients.

This adapted BPS exercise was used in a positive psychology intervention called 'Happy Despite Pain'. This intervention for chronic pain patients also included elements of gratefulness, savoring and self-compassion(Feige, Smeets, \& Peters, 2013). The positive psychology intervention proved to be as effective as a cognitive-behavioural treatment. Other positive psychology interventions or acceptance-based interventions such as mindfulness meditation (Kabat-Zinn, Lipworth, \& Burney, 1985)B, loving kindness meditation (Carson, et al., 2005) and acceptance and commitment therapy (McCracken, Vowles, \& Eccleston, 2005) have been found to be effective treatment for chronic pain patients. Currently other groups are implementing the BPS technique for prevention of the development of chronic post-operative pain after surgery and for improving quality of life in fibromyalgia patients.

Research on information processing related to resilience is rather scarce. Patients could however benefit from the refinement of effective cognitive training programs (MacLeod \& Mathews, 2012; Salemink, van den Hout, \& Kindt, 2007). New and interesting avenues to explore are for instance training programs including imaging positive events (Holmes, Lang, \& Shah, 2009) and perspective broadening (Schartau, Dalgleish, \& Dunn, 2009).

Last but not least, the fear-avoidance model proved to be very helpful in educating patients about the psychology of pain. More specifically, patients get more insight in how they get stuck in a downward spiral based on fear-avoidance. Increased understanding of the pathway of confrontation might not only provide researchers, but also pain patients more insight in how they can promote a qualitative and meaningful life despite pain. 


\section{CONCLUSION}

In the present dissertation, the causal status of optimism towards pain was demonstrated. No evidence was found for the role of pain-specific expectations as an underlying mechanism in the optimism-pain link. However, findings suggest that pain-related catastrophizing, interpretation patterns in general and motivational coping (flexible goal adjustment in particular) might be important underlying mechanisms in the relationship between dispositional optimism and pain. Replication of the studies in this dissertation in clinical samples would strengthen the conclusions in the context of pain.

The results in this dissertation contribute to a better understanding of what leads individuals to higher well-being despite pain. The systematic study of optimism in relation to pain and (pain-related) well-being may contribute to further disentangling the positive spiral of the fear-avoidance model of pain. Future research should integrate insights from the study of risk and resilience for pain to improve the well-being of individuals confronted with the tough reality of chronic pain. 


\section{REFERENCES}

Allison, P. J., Guichard, C., \& Gilain, L. (2000). A prospective investigation of dispositional optimism as a predictor of health-related quality of life in head and neck cancer patients. Quality of life research: an international journal of quality of life aspects of treatment, care and rehabilitation, 9, 951-960.

Armor, D. A., \& Taylor, S. E. (1998). Situated optimism: Specific outcome expectancies and self-regulation. In M. P. Zanna (Ed.), Advances in experimental social psychology (Vol. 30, pp. 309-379). New York: Academic Press.

Bandura, A. (1977). Self-efficacy: toward a unifying theory of behavioral change. Psychological review, 84, 191-215.

Bargiel-Matusiewicz, K., \& Krzyszkowska, A. (2009). Dispositional optimism and coping with pain. European journal of medical research, 14 Supp/4, 271-274.

Belanger, J. J., Lafreniere, M. A., Vallerand, R. J., \& Kruglanski, A. W. (2013). When passion makes the heart grow colder: the role of passion in alternative goal suppression. Journal of Personality and Social Psychology, 104, 126-147.

Benedetti, F., Pollo, A., Lopiano, L., Lanotte, M., Vighetti, S., \& Rainero, I. (2003). Conscious expectation and unconscious conditioning in analgesic, motor, and hormonal placebo/nocebo responses. The Journal of neuroscience: the official journal of the Society for Neuroscience, 23, 4315-4323.

Blackwell, S. E., Rius-Ottenheim, N., Schulte-van Maaren, Y. W., Carlier, I. V., Middelkoop, V. D., Zitman, F. G., Spinhoven, P., Holmes, E. A., \& Giltay, E. J. (2013). Optimism and mental imagery: a possible cognitive marker to promote well-being? Psychiatry research, 206, 56-61.

Boselie, J. J., Vancleef, L. M., Smeets, T., \& Peters, M. L. (2014). Increasing optimism abolishes pain-induced impairments in executive task performance. Pain, 155, 334-340.

Brenes, G. A., Rapp, S. R., Rejeski, W. J., \& Miller, M. E. (2002). Do optimism and pessimism predict physical functioning? Journal of Behavioral Medicine, 25, 219-231.

Brydon, L., Walker, C., Wawrzyniak, A. J., Chart, H., \& Steptoe, A. (2009). Dispositional optimism and stress-induced changes in immunity and negative mood. Brain, Behavior and Immunity, 23, 810-816.

Carson, J. W., Keefe, F. J., Lynch, T. R., Carson, K. M., Goli, V., Fras, A. M., \& Thorp, S. R. (2005). Loving-kindness meditation for chronic low back pain: results from a pilot trial. Journal of holistic nursing, 23, 287-304.

Carver, C. S., \& Scheier, M. (1998). On the Self-Regulation of Behavior. New York: Cambridge University Press.

Carver, C. S., \& Scheier, M. F. (2000). Scaling back goals and recalibration of the affect system are processes in normal adaptive self-regulation: understanding 'response shift' phenomena. Social Science \& Medicine, 50, 1715-1722.

Carver, C. S., \& Scheier, M. F. (2002). Optimism. In S. J. Lopez \& C. R. Snyder (Eds.), The handbook of positive psychology (pp. 231-243). New York: Oxford University Press.

Carver, C. S., Scheier, M. F., \& Segerstrom, S. C. (2010). Optimism. Clinical Psychological Review, 30.

Casey, L. M., Oei, T. P., \& Newcombe, P. A. (2004). An integrated cognitive model of panic disorder: the role of positive and negative cognitions. Clinical psychology review, 24, 529-555.

Casey, L. M., Oei, T. P., Newcombe, P. A., \& Kenardy, J. (2004). The role of catastrophic misinterpretation of bodily sensations and panic self-efficacy in predicting panic severity. Journal of anxiety disorders, 18, 325-340.

Clark, D. M., Salkovskis, P. M., Ost, L. G., Breitholtz, E., Koehler, K. A., Westling, B. E., Jeavons, A., \& Gelder, M. (1997). Misinterpretation of body sensations in panic disorder. Journal of consulting and clinical psychology, 65, 203-213.

Costello, N. L., Bragdon, E. E., Light, K. C., Sigurdsson, A., Bunting, S., Grewen, K., \& Maixner, W. (2002). Temporomandibular disorder and optimism: relationships to ischemic pain sensitivity and interleukin-6. Pain, 100, 99-110. 
Cozzarelli, C. (1993). Personality and self-efficacy as predictors of coping with abortion. Journal of Personality and Social Psychology, 65, 1224-1236.

Crombez, G., Eccleston, C., Van Damme, S., Vlaeyen, J. W., \& Karoly, P. (2012). Fear-avoidance model of chronic pain: the next generation. Clin J Pain, 28, 475-483.

Deci, E. L., \& Ryan, R. M. (1985). Intrinsic Motivation and Self-Determination in Human Behavior. New York and London: Plenum Press.

Eccleston, C., \& Crombez, G. (2007). Worry and chronic pain: a misdirected problem solving model. Pain, 132, 233-236.

Feige, M., Smeets, E., \& Peters, M. L. (2013). Happy despite pain - A randomized controlled trial - Guided internet-delivered positive psychology intervention reduces depressive symptoms and enhances well-being in patients suffering from chronic musculoskeletal pain. Unpublished thesis, Maastricht University.

Fosnaugh, J., Geers, A. L., \&Wellman, J. A. (2009). Giving off a rosy glow: the manipulation of an optimistic orientation. The Journal of social psychology, 149, 349-364.

Fredrickson, B. L. (2001). The role of positive emotions in positive psychology. The broaden-and-build theory of positive emotions. The American psychologist, 56, 218-226.

Fredrickson, B. L., \& Branigan, C. (2005). Positive emotions broaden the scope of attention and thought-action repertoires. Cogn Emot, 19, 313-332.

Fredrickson, B. L., \& Levenson, R. W. (1998). Positive Emotions Speed Recovery from the Cardiovascular Sequelae of Negative Emotions. Cogn Emot, 12, 191-220.

Fredrickson, B. L., Mancuso, R. A., Branigan, C., \& Tugade, M. M. (2000). The Undoing Effect of Positive Emotions. Motivation and emotion, 24, 237-258.

Garland, E. L., Fredrickson, B., Kring, A. M., Johnson, D. P., Meyer, P. S., \& Penn, D. L. (2010). Upward spirals of positive emotions counter downward spirals of negativity: insights from the broaden-and-build theory and affective neuroscience on the treatment of emotion dysfunctions and deficits in psychopathology. Clinical psychology review, 30, 849-864.

Geers, A. L., Helfer, S. G., Kosbab, K., Weiland, P. E., \& Landry, S. J. (2005). Reconsidering the role of personality in placebo effects: dispositional optimism, situational expectations, and the placebo response. Journal of psychosomatic research, 58, 121-127.

Geers, A. L., Kosbab, K., Helfer, S. G., Weiland, P. E., \& Wellman, J. A. (2007). Further evidence for individual differences in placebo responding: an interactionist perspective. Journal of psychosomatic research, 62, 563-570.

Geers, A. L., Rose, J. P., Fowler, S. L., Rasinski, H. M., Brown, J. A., \& Helfer, S. G. (2013). Why does choice enhance treatment effectiveness? Using placebo treatments to demonstrate the role of personal control. Journal of Personality and Social Psychology, 105, 549-566.

Geers, A. L., Wellman, J. A., Fowler, S. L., Helfer, S. G., \& France, C. R. (2010). Dispositional optimism predicts placebo analgesia. The journal of pain : official journal of the American Pain Society, 11, 1165-1171.

Geers, A. L., Wellman, J. A., Helfer, S. G., Fowler, S. L., \& France, C. R. (2008). Dispositional optimism and thoughts of wellbeing determine sensitivity to an experimental pain task. Annals of behavioral medicine 36, 304-313.

Goodin, B. R., \& Bulls, H. W. (2013). Optimism and the experience of pain: benefits of seeing the glass as half full. Current pain and headache reports, 17, 329 . 
Haanstra, T. M., van den Berg, T., Ostelo, R. W., Poolman, R. W., Jansma, E. P., Cuijpers, P., \& de Vet, H. C. (2012). Systematic review: do patient expectations influence treatment outcomes in total knee and total hip arthroplasty? Health and quality of life outcomes, 10, 152.

Higgins, E. T. (1987). Self-discrepancy: a theory relating self and affect. Psychological review, 94, 319-340.

Holmes, E. A., Lang, T. J., \& Shah, D. M. (2009). Developing interpretation bias modification as a "cognitive vaccine"for depressed mood: imagining positive events makes you feel better than thinking about them verbally. Journal of abnormal psychology, 118, 76-88.

Hood, A., Pulvers, K., Carrillo, J., Merchant, G., \& Thomas, M. (2012). Positive Traits Linked to Less Pain through Lower Pain Catastrophizing. Personality and Individual Differences, 52, 401-405.

In Den Bosch-Meevissen, Y. M. C., Hanssen, M. M., \& Peters, M. L. (in preparation). Optimism buffers against mental fatigue: How best possible self imagery leads to undiminished repeated self-control performance.

In Den Bosch-Meevissen, Y. M. C., Peters, M. L., \& Alberts, H. J. E. M. (in press). Dispositional optimism, optimism priming and prevention of egodepletion. European Journal of Social Psychology.

In Den Bosch-Meevissen, Y. M. C., Peters, M. L., \& Nicolson, N. A. (in preparation). Optimism and Stress Reactivity. Cultivating a positive view towards the future protects against stress.

Kabat-Zinn, J., Lipworth, L., \& Burney, R. (1985). The clinical use of mindfulness meditation for the self-regulation of chronic pain. Journal of Behavioral Medicine, 8, 163-190.

Karademas, E. C., Kafetsios, K., \& Sideridis, G. D. (2007). Optimism, self-efficacy and information processing of threatand well-being-related stimuli. Stress and Health, 23, 285-294.

Keefe, F. J., \& Wren, A. A. (2013). Optimism and pain: a positive move forward. Pain, 154, 7-8.

Kindermans, H. P., Huijnen, I. P., Goossens, M. E., Roelofs, J., Verbunt, J. A., \& Vlaeyen, J. W. (2011). "Being" in pain: the role of self-discrepancies in the emotional experience and activity patterns of patients with chronic low back pain. Pain, 152, 403-409.

King, L. A. (2001). The health benefits of writing about life goals. Personality \& social psychology bulletin, 27, 798-807.

Klein, W. P., \& Zajac, L. E. (2009). Imagining a rosy future: The psychology of optimism. In K. D. Markman, W. P. Klein, J. A. Suhr, K. D. Markman, W. P. Klein \& J. A. Surh (Eds.), Handbook of imagination and mental simulation. New York, NY: Psychology Press.

Lewin, K. (1948). Time perspective and morale. In G. W. Lewin (Ed.), Resolving social conflicts: Selected papers on group dynamics. New York: Harper.

Luger, T., Cotter, K. A., \& Sherman, A. M. (2009). It's all in how you view it: pessimism, social relations, and life satisfaction in older adults with osteoarthritis. Aging \& Mental Health, 13, 635-647.

MacLeod, C., \& Mathews, A. (2012). Cognitive bias modification approaches to anxiety. Annual review of clinical psychology, 8, 189-217.

Mahler, H. I. M., \& Kulik, J. Q. (2000). Optimism, pessimism and recovery from coronary bypass surgery: prediction of affect, pain and functional status. Psychology, Health \& Medicine, 5, 347-358.

Martijn, C., Tenbült, P., Merchkelbach, H., Dreezens, E., \& de Vries, N. K. (2002). Getting a grip on ourselves: challenging expectancies about loss of energy after self-control. Social Cognition, 20, 441-460.

Mathews, A., \& Mackintosh, B. (2000). Induced emotional interpretation bias and anxiety. Journal of abnormal psychology, 109, 602-615. 
Mathews, A., \& MacLeod, C. (1994). Cognitive approaches to emotion and emotional disorders. Annual review of psychology, 45, 25-50.

McCracken, L. M., Carson, J. W., Eccleston, C., \& Keefe, F. J. (2004). Acceptance and change in the context of chronic pain. Pain, 109, 4-7.

McCracken, L. M., Vowles, K. E., \& Eccleston, C. (2005). Acceptance-based treatment for persons with complex, long standing chronic pain: a preliminary analysis of treatment outcome in comparison to a waiting phase. Behaviour research and therapy, 43, 1335-1346.

Meevissen, Y. M., Peters, M. L., \& Alberts, H. J. (2011). Become more optimistic by imagining a best possible self: effects of a two week intervention. Journal of behavior therapy and experimental psychiatry, 42, 371-378.

Morley, S., Davies, C., \& Barton, S. (2005). Possible selves in chronic pain: self-pain enmeshment, adjustment and acceptance. Pain, 115, 84-94.

Muris, P., \& Field, A. P. (2008). Distorted cognition and pathological anxiety in children and adolescents. Cognition and Emotion, 22, 395-421.

Neff, L. A., \& Geers, A. L. (2013). Optimistic expectations in early marriage: a resource or vulnerability for adaptive relationship functioning? Journal of Personality and Social Psychology, 105, 38-60.

Nes, L. S., \& Segerstrom, S. C. (2006). Dispositional optimism and coping: a meta-analytic review. Personality and social psychology review, 10, 235-251.

Nissen, H. W. A. (1930). A study of exploratory behavior in the white rat by means of the obstruction method. Journal of genetic psychology, 37, 361-376.

Peters, M. L., Flink, I., Boersma, K., \& Linton, S. (2010). Manipulating optimism: Can imagining a best possible self be used to increase positive future expectancies? Journal of Positive Psychology, 5, 204-211.

Peters, M. L., Meevissen, Y. M., \& Hanssen, M. M. (2013). Specificity of the Best Possible Self intervention for increasing optimism: Comparison with a gratitude intervention. Terapia Psicologica, 31, 93-100.

Peters, M. L., Sommer, M., Rijke, J. M. d., Kessels, A. G. H., Heineman, E., Patijn, J., Marcus, M. A., Vlaeyen, J. W. S., \& Kleef, M. v. (2007). Somatic and psychological predictors of long-term unfavorable outcome after surgical intervention. annals of Surgery, 245, 487-494.

Peters, M. L., Vieler, J. S. E., \& Lautenbacher, S. (in preparation). Dispositional and induced optimism lead to attentional preference for faces displaying positive emotions: an eye-tracker study.

Pinto, P. R., Mclntyre, T., Ferrero, R., Almeida, A., \& Araujo-Soares, V. (2013). Predictors of acute postsurgical pain and anxiety following primary total hip and knee arthroplasty. The journal of pain, 14, 502-515.

Powell, R., Johnston, M., Smith, W. C., King, P. M., Chambers, W. A., Krukowski, Z., McKee, L., \& Bruce, J. (2012). Psychological risk factors for chronic post-surgical pain after inguinal hernia repair surgery: a prospective cohort study. European journal of pain, 16, 600-610.

Radcliffe, N. M., \& Klein, W. M. P. (2002). Dispositional, Unrealistic, and Comparative Optimism: Differential Relations with the Knowledge and Processing of Risk Information and Beliefs about Personal Risk. Personality and Social Psychology Bulletin, 28, 836-846.

Raikkonen, K., Matthews, K. A., Flory, J. D., Owens, J. F., \& Gump, B. B. (1999). Effects of optimism, pessimism, and trait anxiety on ambulatory blood pressure and mood during everyday life. Journal of Personality and Social Psychology, 76, 104-113. 
Ramirez-Maestre, C., \& Esteve, R. (2013). Disposition and adjustment to chronic pain. Current pain and headache reports, 17, 312 .

Ramirez-Maestre, C., Esteve, R., \& Lopez, A. E. (2012). The role of Optimism and Pessimism in Chronic Pain Patients Adjustment. The Spanish Journal of Psychology, 15, 286-294.

Renner, F., Schwarz, P., Peters, M. L., \& Huibers, M. J. (2014). Effects of a best-possible-self mental imagery exercise on mood and dysfunctional attitudes. Psychiatry research, 215, 105-110.

Rip, B., Fortin, S., \& Vallerand, R. J. (2006). The Relationship between Passion and Injury in Dance students. Journal of Dance Medicine, 10.

Robinson-Whelen, S., Kim, C., MacCallum, R. C., \& Kiecolt-Glaser, J. K. (1997). Distinguishing optimism from pessimism in older adults: is it more important to be optimistic or not to be pessimistic? Journal of Personality and Social Psychology, 73, 1345-1353.

Ryan, R. M., \& Deci, E. L. (2000). Intrinsic and Extrinsic Motivations: Classic Definitions and New Directions. Contemp Educ Psychol, 25, 54-67.

Salemink, E., van den Hout, M., \& Kindt, M. (2007). Trained interpretive bias and anxiety. Behaviour research and therapy, 45, 329-340.

Schartau, P. E., Dalgleish, T., \& Dunn, B. D. (2009). Seeing the bigger picture: training in perspective broadening reduces self-reported affect and psychophysiological response to distressing films and autobiographical memories. Journal of abnormal psychology, 118, 15-27.

Scheier, M. F., \& Carver, C. S. (1985). Optimism, coping, and health: assessment and implications of generalized outcome expectancies. Health Psychology, 4, 219-247.

Scheier, M. F., Carver, C. S., \& Bridges, M. W. (1994). Distinguishing optimism from neuroticism (and trait anxiety, selfmastery, and self-esteem): a reevaluation of the Life Orientation Test. Journal of Personality and Social Psychology, 67, 1063-1078.

Schrooten, M. G., Van Damme, S., Crombez, G., Peters, M. L., Vogt, J., \& Vlaeyen, J. W. (2012). Nonpain goal pursuit inhibits attentional bias to pain. Pain, 153, 1180-1186.

Segerstrom, S. C. (2001). Optimism, attentional bias for negative and positive stimuli. Personality \& social psychology bulletin, 27, 1334-1343.

Segerstrom, S. C. (2005). Optimism and immunity: do positive thoughts always lead to positive effects? Brain, Behavior and Immunity, 19, 195-200.

Segerstrom, S. C., Taylor, S. E., Kemeny, M. E., \& Fahey, J. L. (1998). Optimism is associated with mood, coping, and immune change in response to stress. Journal of Personality and Social Psychology, 74, 1646-1655.

Seligman, M. E. (1972). Learned helplessness. Annu Rev Med, 23, 407-412.

Sharot, T., Korn, C. W., \& Dolan, R. J. (2011). How unrealistic optimism is maintained in the face of reality. Nat Neurosci, $14,1475-1479$.

Sinclair, V. G. (2001). Predictors of pain catastrophizing in women with rheumatoid arthritis. Archives of psychiatric nursing, 15, 279-288

Sturgeon, J. A., \& Zautra, A. J. (2010). Resilience: A New Paradigm for Adaptation to Chronic Pain. Current pain and headache reports, 14, 105-112.

Thompson, A., \& Gaudreau, P. (2008). From optimism to pessimism to coping: The mediating role of academic motivation. International journal of stress management, 15, 269-288. 
Thornton, A. A., Perez, M. A., Oh, S., \& Crocitto, L. (2012). Optimism and prostate cancer-specific expectations predict better quality of life after robotic prostatectomy. Journal of clinical psychology in medical settings, 19, 165-176.

Vallerand, R. J. (2008). On the psychology of passion: In search of what makes people's lives most worth living. Canadian Psychology, 49, 1-13.

Vallerand, R. J., Blanchard, C., Mageau, G. A., Koestner, R., Ratelle, C., Leonard, M., Gagne, M., \& Marsolais, J. (2003). Les passions de l'ame: on obsessive and harmonious passion. Journal of Personality and Social Psychology, 85, 756767.

Vallerand, R. J., Paquet, Y., Philippe, F. L., \& Charest, J. (2010). On the role of passion for work in burnout: a process model. Journal of personality, 78, 289-312.

Van Damme, S., Crombez, G., \& Eccleston, C. (2008). Coping with pain: a motivational perspective. Pain, 139, 1-4.

Van Damme, S., \& Kindermans, H. (2014). A Self-Regulation Perspective on Avoidance and Persistence Behaviour in Chronic Pain: New Theories, New Challenges? The clinical journal of pain.

Van Damme, S., Legrain, V., Vogt, J., \& Crombez, G. (2010). Keeping pain in mind: a motivational account of attention to pain. Neuroscience \& Biobehavioral Reviews, 34, 204-213.

Vancleef, L. M., \& Peters, M. L. (2008). Examining content specificity of negative interpretation biases with the Body Sensations Interpretation Questionnaire (BSIQ). Journal of anxiety disorders, 22, 401-415.

Vanlessen, N., Rossi, V., De Raedt, R., \& Pourtois, G. (2013). Positive emotion broadens attention focus through decreased position-specific spatial encoding in early visual cortex: evidence from ERPs. Cogn Affect Behav Neurosci, 13, 60-79.

Vlaeyen, J. W., \& Linton, S. J. (2000). Fear-avoidance and its consequences in chronic musculoskeletal pain: a state of the art. Pain, 85, 317-332.

Vlaeyen, J. W., \& Linton, S. J. (2012). Fear-avoidance model of chronic musculoskeletal pain: 12 years on. Pain, 85, 317-332.

Wadlinger, H. A., \& Isaacowitz, D. M. (2006). Positive mood broadens visual attention to positive stimuli. Motivation and emotion, 30, 87-99.

Watson, D., Clark, L. A., \& Carey, G. (1988). Positive and negative affectivity and their relation to anxiety and depressive disorders. Journal of abnormal psychology, 97, 346-353.

Watson, D., Clark, L. A., \& Tellegen, A. (1988). Development and validation of brief measures of positive and negative affect: the PANAS scales. Journal of Personality and Social Psychology, 54, 1063-1070.

Wideman, T. H., Asmundson, G. G., Smeets, R. J., Zautra, A. J., Simmonds, M. J., Sullivan, M. J., Haythornthwaite, J. A., \& Edwards, R. R. (2013). Rethinking the fear avoidance model: toward a multidimensional framework of painrelated disability. Pain, 154, 2262-2265

Wright, L. J., Zautra, A. J., \& Going, S. (2008). Adaptation to early knee osteoarthritis: the role of risk, resilience, and disease severity on pain and physical functioning. Annals of behavioral medicine: a publication of the Society of Behavioral Medicine, 36, 70-80.

Zautra, A., Smith, B., Affleck, G., \& Tennen, H. (2001). Examinations of chronic pain and affect relationships: applications of a dynamic model of affect. Journal of consulting and clinical psychology, 69, 786-795.

Zimbardo, P. G., \& Boyd, J. N. (1999). Putting time in perspective: A valid, reliable individual-differences metric. Journal of Personality and Social Psychology, 77, 1271-1288. 


\section{Valorisation Addendum}



Scientific research aims at observing and explaining the world around us. Even more important than the aim of observing or answering the 'what' question seems to be the aim of explaining 'why' things happen. If we apply this to pain, only a deeper understanding of the experience of pain might contribute to creating a significant change. The specific aim of this dissertation is to contribute to a deeper understanding of the link between optimism and pain. In line with pain research in general, the higher goal of this dissertation lies in changing the tough reality of chronic pain. Although the probability of reaching this goal is uncertain, its value is clearly illustrated by the individual, social and societal impact of (chronic) pain. In this valorisation addendum, a discussion of the additional scientific and practical value of this dissertation is provided.

\section{RELEVANCE OF THIS DISSERTATION: THE IMPACT OF CHRONIC PAIN}

Chronic pain is an important health problem. A large scale European survey (Breivik, Collett, Ventafridda, Cohen, \& Gallacher, 2006) indicated that approximately one in five Europeans suffer from chronic pain. This study showed that most of the pain patients experience pain during consecutive years. One of the factors that undoubtedly impacts on the experience of pain is the fact that not always a clear medical diagnosis can be provided for the presenting symptoms. Moreover, regardless of the origin of the pain, medical treatments insufficiently reduce the pain in a subset of pain patients. The European survey also pointed out that in addition to daily limitations due to the pain, one in five pain patients experiences work-related disability. Moreover, one in four pain patients receives the diagnosis of depression at a given moment in time. This survey clearly shows that chronic pain has a great impact on peoples'lives.

Hence, the individual and social impact of chronic pain complaints is enormous. The economic consequences are even so impressive. The total price tag for direct and indirect costs of chronic pain in The Netherlands raises as high as 20 billion euro per year (Boonen, et al., 2005). With more than 2 million individuals who suffer from pain on a daily basis, chronic pain is one of the most prevalent chronic diseases (Dutch Pain Society, 2011). Considering the extent and the costs of chronic pain, it becomes clear that it places a heavy economic burden on society.

\section{TO WHOM MIGHT THIS DISSERTATION BE RELEVANT?}

The knowledge gained from this dissertation might eventually contribute to the reduction of individual, social and societal costs of chronic pain. The results of the performed studies might be of relevance to the following target groups. First, this dissertation is relevant for researchers in the field of pain. The results and the methodology that was used can be described as innovative in respect to the existing knowledge on optimism and pain. Second, the gained knowledge might provide therapists and health managers with new leads to provide effective health care for chronic pain patients. Third, the studies in this dissertation might be useful to chronic pain 
patients and their direct environment as the results might contribute to the refinement of pain treatments. Fourth, the results might be useful to society through their contribution to the reduction of the economic costs of chronic pain. Fifth, this dissertation might impact on the well-being of the general population through its share in the advancements in health psychology.

Considering how these target groups might benefit from the research that was performed, it seems that we can distinguish two ways in which this dissertation might contribute. First, the results and methodology that was used in this dissertation hold scientific value that is primarily of interest to researchers. Second, the clinical implications of this dissertation might be useful to health care workers/managers, pain patients and their environment and - in a broader sense - to the general population and society. The scientific and the societal/economic value of this dissertation will be addressed subsequently.

\section{THE SCIENTIFIC VALUE OF THIS DISSERTATION}

There is nothing so practical as a good theory

(Kurt Lewin, 1945)

Following Kurt Lewin's conviction (Lewin, 1945), the ultimate value of this dissertation might lie in its theoretical and scientific implications. Before making knowledge available for individual, social and economic use, it needs to be suitable. In other words, it is important to build a good theory first.

Until a few years ago, research on optimism and pain was mainly observational in nature. The robust association between optimism and pain/well-being was well-documented in the literature. However, the correlational nature of the concerning studies failed to provide a satisfactory explanation of why optimism is related to lower levels of pain or higher levels of pain-related well-being. When the studies in this dissertation were conducted, two issues remained largely unclear in the current state of science. The two research questions that needed to be addressed were the following: 'Is optimism causally related to pain?' and 'What are the underlying mechanisms in the relation between optimism and pain/(pain-related) well-being?'. Answering the causality issue held promise for understanding the nature of the optimism-pain link. Moreover, it would provide an indication for the usefulness of intervening on optimism in 
the treatment of pain. Answering the why question by gaining more information about underlying mechanisms of the protective influence of optimism on pain, would offer the deeper understanding needed to create a significant change based on this research topic.

The data gathered for the purpose of this dissertation yielded several conclusions that contribute to the scientific knowledge in the field of optimism and pain. First, the causal status of optimism towards pain was experimentally confirmed. Second, the role of specific expectations as an underlying mechanism in the relation between optimism and pain was disconfirmed. The importance of both optimism as a generalized positive outcome expectancy and specific expectations in the experience of pain was however stressed. Third, it was concluded that interpretation might be an important mechanism through which optimism leads to beneficial outcomes. In relation to pain, pain catastrophizing, as a negative set of pain-related cognitions, proved to be an important factor explaining the optimism-pain link. Fourth, motivational coping, particularly flexible goal adjustment, seems to be an important underlying mechanism of the association between optimism and well-being. These findings contribute to the refinement of the Fear Avoidance model (Vlaeyen \& Linton, 2000). This dissertation provides new leads to research the 'healthy upwards' cycle to functional recovery of this leading psychological theory in the field of pain.

The previous tentative conclusions contribute to the knowledge about the optimismpain/well-being link. In addition, the methodology used in this dissertation may be regarded as scientifically innovative. Chapter 2 describes an adapted version of the Body Sensations Interpretations Questionnaire. This adapted BSIQ enables the measurement of positive interpretations of ambiguity and it might therefore be a useful tool for future research. Not only the adapted $\mathrm{BSIQ}$, but especially the experimental confirmation of the causal status of optimism towards pain is of scientific value. The study that was described in chapter 4 and that was published in Pain as Hanssen, Peters, Vlaeyen, Meevissen and Vancleef (2013) has been praised for its innovative methodological procedure. In a commentary by Keefe and Wren (2013), the study has been called a positive move forward for research on optimism and pain, since this field of research to this date was mainly correlational in nature. The commentary encouraged the use of the methodology presented in this dissertation to further advance the field of resilience and pain. The experimental study of optimism was recommended to gain useful information for improving novel but promising positive psychology interventions in the treatment of pain.

After publication of the mentioned study, that was conducted for the purpose of this dissertation, the advice of Keefe and Wren (2013) has been picked up. Other researchers sought contact with our research group in Maastricht because they were inspired to use the optimism manipulation in the context of fundamental research or to test clinical applications. This second aim (the development of clinical applications) will be further explained in the following paragraph. 


\section{THE SOCIETAL AND ECONOMICAL VALUE OF THIS DISSERTATION}

As mentioned before, the 'pure pleasure of knowing' was not the only reason for this dissertation. The following project lines illustrate its societal and economical value.

First, the finding that induced optimism and positive expectations lead to a diminished pain experience is currently being addressed scientifically for direct clinical purposes. The Best Possible Self intervention and similar interventions based on this procedure are being used to introduce generalized or specific positive expectations in clinical practice. One important application that is now being tested is for instance whether inducing specific positive expectations with regard to the recovery after a medical procedure leads to a faster recovery. This approach that includes inducing positive expectations reminds of the broader idea that one could take advantage of the placebo effect that has been convincingly demonstrated in psychology, in clinical practice. Further research and debate on this matter is very desirable, since this approach definitely might hold clinical and economical value. This dissertation can give a further impetus to this debate.

Second, the results of this dissertation contribute to the field of positive psychology. In the last decennia, interest in the value of this science discipline for clinical practice slowly emerged. Positive Psychology Interventions for chronic pain are currently being investigated in our research group and in other research labs. First results indicate that positive psychology interventions might be a useful alternative for cognitive-behavioural pain treatments. Positive psychology interventions can easily be administered as self-help exercises, at low costs and with the potential to have a wide dissemination. Further developing positive psychology interventions for chronic pain might not only contribute to the well-being of pain patients and their direct social context, but indirectly this might hold benefits for society in reducing the costs of chronic pain.

Third, the message of this dissertation that higher levels of optimism lead to lower levels of pain emphasizes the importance of psychological factors in the experience of pain. Although the psychology of pain has been studied extensively, the findings have not yet found firm ground in the way society thinks about pain and health in general. The dominance of the biomedical framework becomes obvious when you consider difficulties such as excessive medication use and doctor-shopping in case of unexplained physical complaints. Educating people on a bio-psychosocial way of thinking and offering them information on how they can take care of their psychological health in addition to their physical health might definitely hold value for society. Projects aimed at teaching kids in school might prevent costly problems in later life. In this indirect way, the results of this dissertation might also contribute to well-being in the general population, based on their contribution to the advancement of health psychology in general. 


\section{REFERENCES}

Boonen, A., van den Heuvel, R., van Tubergen, A., Goossens, M., Severens, J. L., van der Heijde, D., \& van der Linden, S. (2005). Large differences in cost of illness and wellbeing between patients with fibromyalgia, chronic low back pain, or ankylosing spondylitis. Annals of the Rheumatic Diseases, 64, 396-402.

Breivik, H., Collett, B., Ventafridda, V., Cohen, R., \& Gallacher, D. (2006). Survey of chronic pain in Europe: prevalence, impact on daily life, and treatment. European Journal of Pain, 10, 287-333.

Dutch Pain Society. (2011). 2,2 miljoen Nederlanders lijden aan chronische pijn en kosten de maatschappij miljarden per jaar. Den Haag: Dutch Pain Society.

Hanssen, M. M., Peters, M. L., Vlaeyen, J. W., Meevissen, Y. M., \& Vancleef, L. M. (2013). Optimism lowers pain: evidence of the causal status and underlying mechanisms. Pain, 154, 53-58.

Keefe, F. J., \& Wren, A. A. (2013). Optimism and pain: a positive move forward. Pain, 154, 7-8.

Lewin, K. (1945). The research center for group dynamics at Massachusetts Institute of Technology. Sociometry, 8.

Vlaeyen, J. W., \& Linton, S. J. (2000). Fear-avoidance and its consequences in chronic musculoskeletal pain: a state of the art. Pain, 85, 317-332. 

Summary 

Chronic pain places a heavy burden on people's lives. Over the years, psychological research has tried to provide a positive contribution to the everyday reality of chronic pain patients. The fearavoidance model, as the leading theoretical model in psychological pain research, depicts several risk factors (i.e. pain catastrophizing and fear of pain) for pain-related disability. This led to the development of exposure treatment for chronic pain patients. Although cognitive-behavioural pain treatments including exposure techniques proved to be successful, effect sizes are relatively small.

In the last decades, research on resilience gained more interest for its attempt to disentangle what leads people to higher well-being despite challenging circumstances. Dispositional optimism has been proposed as a resilience factor related to diminished pain-sensitivity and higher well-being despite pain. This dissertation focusses on optimism as a natural placebo for pain, hereby focussing on two important aspects: First, the causal status of the optimism-pain link; Second, the role of several underlying mechanisms in the relationship between optimism and pain/well-being (despite pain). Main findings that were reported in the chapters of this dissertation will be summarized.

Chapter 1 presents a general overview of the theoretical background to the subject of this dissertation. First, a definition and conceptualisation of the construct dispositional optimism is provided. Second, an overview of the evidence for the association between optimism and pain/ well-being is given. Third, theories on risk and resilience for pain are clarified. Fourth, selected working mechanisms based on the described theories are presented. The selected mechanisms are: pain specific expectations, pain-related catastrophizing, interpretation of ambiguity in general and motivational coping. At the end of this chapter, the outline of this dissertation is presented.

Chapter 2 shows the results of 3 studies in which negative and positive interpretation patterns of optimists were investigated. Based on information processing theories, interpretation of ambiguity has been selected as a mechanism that might underlie the protective influence of optimism towards experiencing distress in response to pain. Results of one prior study provided support for the tendency of optimists to make less negative interpretations of ambiguous situations. The conducted studies in chapter 2 aimed at replicating and extending this finding by investigating whether optimists also make more positive interpretations in addition to less negative. The Body Sensations Interpretations Questionnaire (BSIQ), in which participants have to rate the probability of neutral and catastrophic solutions of ambiguous situations was adapted for the purpose of this study by adding positive solutions. All three studies showed optimism to be related to less negative and (to a lesser degree) more positive interpretations of ambiguity. The last study used an open-ended version of the adapted BSIQ. The valence of participants' self-generated responses to this open ended version of the BSIQwas rated/coded by independent coders and by participants themselves. Optimism was found to be associated with participants' ratings of their own responses. Significance was reached for only one correlation between optimism and coders' ratings of these responses. In the discussion of chapter 2 the importance of other cognitions (coping/self-efficacy) and reappraisals are considered. In general, it is concluded that interpretations patterns might be an important mechanism in the relation between optimism and pain/pain-related well-being. 
Chapter $\mathbf{3}$ describes two lab studies with healthy participants that focus on the role of pain-specific expectations as an underlying mechanism in the association between optimism and pain. It has been suggested that optimism as a generalized positive outcome expectancy might guide specific expectations in new and uncertain situations. The first lab study that is described in this chapter tested whether optimists expect less pain in the lab and therefore are less sensitive to a cold pressor task (mediation hypothesis). In placebo research, it was found that optimism interacts with induced expectations in determining pain sensitivity. A second study tested whether optimists are more inclined to follow positive expectations about the pain task, leading to lower pain sensitivity when exposed to experimentally induced cold pain (moderation hypothesis). Based on the results of these studies, both the mediation and moderation model with optimism, pain-specific expectations and pain-sensitivity are disconfirmed. It is concluded however that both sets of expectations are related to pain-sensitivity. The link between generalized and specific expectations is further discussed in this chapter. The content of specific optimistic expectations and the conditions under which specific positive expectations are expressed by optimists are considered interesting objects for future study.

In chapter $\mathbf{4}$ an experimental test of the causal status of optimism towards cold pressor pain is presented. In this study, two possible underlying mechanisms in the optimism-pain link were also studied. Expected pain was measured as a first mechanism to check whether findings of chapter 3 could be confirmed. Second, based on the fear-avoidance model of pain, situational pain catastrophizing was depicted to explain the optimism effect on pain. Healthy participants participated in this experiment with the cold pressor test. Half of the participants wrote and visualised about their 'best possible self' in the future (optimism induction), while the other participants conducted a comparable exercise focussing on 'a typical day'. The optimism induction proved to be successful in inducing a temporary optimistic state. Moreover, inducing optimism led to lower pain intensity ratings during the cold pressor task. Not expected pain, but situational catastrophizing significantly mediated the relationship between induced optimism and lower cold pressor pain. The study described in this chapter is the first study to find experimental evidence for the causal role of optimism towards pain. In addition, the finding of chapter 3 on specific expectations (independent relation with pain only) is replicated. The mediation model with situational pain catastrophizing is supported.

Chapter $\mathbf{5}$ describes a questionnaire study in healthy participants in which motivational coping is investigated as another possible underlying mechanism. In this study, optimism was related to several indices of well-being (anxiety, depression, general well-being and physical complaints). Motivational coping was confirmed as a mediator in the relationship between optimism and wellbeing. Flexible goal adjustment emerged as a particularly important factor to consider in protecting optimists from psychological and physical complaints and promoting general well-being.

In chapter $\mathbf{6}$, an overview of the main findings of this dissertation is presented and the findings are discussed in the light of recent literature. Methodological limitations are addressed. Based on the findings in this dissertation, recommendations are made to further investigate the pathway of confrontation in the fear-avoidance model. Suggestions are made on how positive 
psychology (i. e. broaden-and-build theory, self-determination theory, passion theory) can contribute to further unravelling the positive upward spiral to functional recovery. Last but not least, this chapter includes ideas on how the findings of this dissertation might be translated to promote well-being in pain patients. 

Samenvatting 

Chronische pijn heeft een grote impact op iemands leven. Onderzoek naar de psychologie van pijn tracht een positieve bijdrage te leveren aan de dagelijkse realiteit van chronische pijn patienten. Het vrees-vermijdingsmodel van pijn, het leidende theoretische model in psychologisch pijnonderzoek, beschrijft verschillende factoren (bv. pijngerelateerd catastroferen en vrees voor pijn) die het risico op het ervaren van pijngerelateerde beperkingen vergroten. Het identificeren van deze risicofactoren leidde tot de ontwikkeling van psychologische behandelingen voor chronische pijn patiënten. Hoewel deze pijnbehandelingen, die gebruik maken cognitief-gedragsmatige technieken (o. a. exposure), succesvol bleken, zijn de effecten relatief klein.

In de laatste decennia groeide de interesse voor onderzoek naar beschermende factoren in het onderzoek naar pijn. Dispositioneel optimisme wordt beschouwd als een beschermende factor die samenhangt met lagere pijngevoeligheid en beter welzijn ondanks pijn. Deze dissertatie richt zich op de rol van optimisme als een 'natuurlijk placebo'ten aanzien van pijn. De focus ligt hierbij op twee belangrijke aspecten, namelijk de causale status van optimisme ten aanzien van pijn en de potentiële onderliggende mechanismen in de relatie tussen optimisme en pijn/ welzijn ondanks pijn. De bevindingen van de studies die in functie van deze dissertatie werden uitgevoerd, worden in de verschillende hoofdstukken gerapporteerd.

Hoofdstuk 1 schetst een algemeen beeld van de theoretische achtergrond van het onderwerp van deze dissertatie. Ten eerste wordt het construct dispositioneel optimisme gedefinieerd en geconceptualiseerd. Ten tweede wordt een overzicht van de aanwezige evidentie voor de associatie tussen optimisme en pijn/welzijn gepresenteerd. Ten derde worden psychologische theorieën aangaande risico- en beschermende factoren in de context van pijn uitgelegd. Ten vierde worden mogelijke werkingsmechanismen voorgesteld die doorheen deze dissertatie nader onderzocht werden ter verklaring van de relatie tussen optimisme en pijn, namelijk: pijnspecifieke verwachtingen, pijngerelateerd catastroferen, interpretatie van ambiguïteit in het algemeen en motivationele coping. Dit hoofdstuk eindigt met een beschrijving van de inhoudelijke structuur van deze dissertatie.

Hoofdstuk 2 toont de resultaten van drie studies waarin negatieve en positieve interpretatiepatronen van optimisten werden onderzocht. Gebaseerd op de principes van de informatieverwerkingstheorieën werd interpretatie van ambiguïteit geselecteerd als een mogelijk verklarend mechanisme voor de beschermende invloed van optimisme ten aanzien van de pijnervaring. Een eerdere studie toonde aan dat optimisten minder negatieve interpretaties maken van ambiguïteit. De drie studies die worden voorgesteld in dit hoofdstuk hadden tot doel om deze bevinding te repliceren. Daarenboven werd onderzocht of optimisten niet alleen minder negatieve, maar ook meer positieve interpretaties maken. Een aangepaste versie van de Body Sensations Interpretation Questionnaire (BSIQ) werd gebruikt om positieve en negatieve interpretatiepatronen te meten. In deze aangepaste BSIQ geven proefpersonen aan in welke mate ze negatieve, neutrale en ook positieve verklaringen voor ambigue situaties als waarschijnlijk achten. De resultaten van de studies in dit hoofdstuk toonden aan dat optimisme gerelateerd is aan minder negatieve en (in mindere mate) meer positieve interpretaties van ambiguïteit. In de laatste studie van dit hoofdstuk werd een open versie van de aangepaste BSIQ gebruikt en kon- 
den deelnemers zelf een verklaring voor de ambigue situatie formuleren. Vervolgens werd de valentie van deze zelf gegenereerde verklaringen door de deelnemers zelf en door onafhankelijke beoordelaars gescoord. Het verband tussen optimisme en interpretatiepatronen kwam vooral naar voren in de valentiescores van proefpersonen zelf. In de discussie van dit tweede hoofdstuk wordt het mogelijke belang van andere cognities (coping/self-efficacy) en van herinterpretatie bediscussieerd. Samenvattend wordt geconcludeerd dat interpretatie van ambiguïteit mogelijk een belangrijk mechanisme is in de relatie tussen optimisme en pijn/pijngerelateerd welzijn.

Hoofdstuk 3 beschrijft twee labstudies met gezonde proefpersonen waarin de rol van pijnspecifieke verwachtingen in de relatie tussen optimisme en pijn werd onderzocht. In de literatuur wordt gesuggereerd dat optimisme als een globale positieve uitkomstverwachting specifieke verwachtingen stuurt in nieuwe en onzekere situaties. In lijn hiermee werd in de eerste studie van dit hoofdstuk getoetst of optimisten minder pijn verwachten in het lab en daardoor ook een verminderde pijngevoeligheid tonen tijdens een koudwatertaak (mediatiehypothese). In eerder placebo onderzoek werd gevonden dat de interactie tussen optimisme (globale uitkomstverwachting) en specifieke verwachtingen bepalend is voor pijnsensitiviteit. In de tweede studie van dit hoofdstuk werd onderzocht of optimisten meer geneigd zijn om geïnduceerde positieve verwachtingen over een pijntaak te volgen waardoor ze vervolgens minder pijnsensitiviteit tonen tijdens deze pijntaak (moderatiehypothese). De resultaten van beide studies lieten zien dat zowel het mediatie- als het moderatiemodel met optimisme, pijnspecifieke verwachtingen en pijnsensitiviteit verworpen dient te worden. Optimisme en pijnspecifieke verwachtingen bleken echter wel onafhankelijk van elkaar samen te hangen met pijnsensitiviteit. De link tussen gegeneraliseerde en specifieke verwachtingen is verder bediscussieerd in dit hoofdstuk. Het belang van het verder onderzoeken van de inhoud van specifieke verwachtingen en de condities waarin specifieke positieve verwachtingen tot uitdrukking komen bij optimisten wordt benadrukt.

Hoofdstuk 4 stelt een experimentele studie voor waarin de causale status van optimisme ten aanzien van experimentele pijn werd onderzocht. Niet enkel causaliteit, maar ook onderliggende mechanismen in de optimisme-pijn relatie werden bestudeerd. Om na te gaan of de bevindingen van hoofdstuk 3 gerepliceerd konden worden, werden pijnspecifieke verwachtingen gemeten als een eerste potentieel mechanisme in de relatie tussen optimisme en pijn. Gebaseerd op de assumpties van het vrees-vermijdingsmodel werd situationeel pijngerelateerd catastroferen onderzocht als tweede mogelijk onderliggend werkingsmechanisme. Gezonde proefpersonen namen deel in een experiment met de koudwatertaak. De helft van de deelnemers in de studie schreef en visualiseerde over 'hun best mogelijke zelf' in de toekomst (optimisme inductie), terwijl de andere helft van de deelnemers een vergelijkbare oefening uitvoerde over 'een typische dag' (controle conditie). Met behulp van de optimisme manipulatie werd op succesvolle wijze een tijdelijke optimistische staat opgewekt. Het induceren van optimisme leidde tot lagere rapportage van pijnintensiteit tijdens de koudwatertaak in vergelijking met de controlegroep. Pijngerelateerde verwachtingen bleken wederom niet de relatie tussen optimisme en pijn te verklaren, maar de mediërende rol van pijngerelateerd catastroferen werd wel bevestigd. De studie die beschreven is in dit hoofdstuk is de eerste studie die experimenteel 
bewijs levert voor de causale status van optimisme ten aanzien van pijn. Bijkomend betekent deze studie een replicatie van de bevinding in hoofdstuk 3 ten aanzien van specifieke verwachtingen (enkel een onafhankelijke relatie met pijn) en een bevestiging van het mediatiemodel met situationeel pijngerelateerd catastroferen.

Hoofdstuk 5 beschrijft een vragenlijststudie in gezonde proefpersonen waarin motivationele coping wordt onderzocht als mogelijk onderliggend mechanisme in de relatie tussen optimisme en welzijn (ondanks pijn). In deze studie wordt optimisme gerelateerd aan verschillende indices van welzijn (angst, depressie, algemeen welzijn en fysieke klachten). De resultaten van deze studie tonen aan dat motivationele coping de relatie tussen optimisme en welzijn medieert. Het flexibel aanpassen van doelen blijkt daarbij een belangrijke factor te zijn die optimisten kan beschermen voor psychologische en fysieke klachten en ter promotie van welzijn (ondanks pijn).

Hoofdstuk 6 presenteert de belangrijkste bevindingen van deze dissertatie en bediscussieerd deze in het licht van de recente literatuur. Methodologische beperkingen worden eveneens geadresseerd. Gebaseerd op de conclusies in deze dissertatie worden er aanbevelingen gedaan om het pad van de confrontatie in het vreesvermijdingsmodel verder te onderzoeken. Er worden suggesties gedaan ten aanzien van de manier waarop positieve psychologie (bv. broaden-and-build model, zelfdeterminatietheorie en passietheorie) kunnen bijdragen in het verder ontrafelen van de positieve opwaartse spiraal naar functioneel herstel. Tenslotte wordt in dit hoofdstuk ook ingegaan op de wijze waarop de bevindingen in deze dissertatie vertaald kunnen naar en bij kunnen dragen aan het welzijn van chronische pijnpatiënten. 

Dankwoord 

Het is zover! Mijn 'seemingly never ending story' is klaar voor de boekenkast. Ik prijs mezelf gelukkig dat ik in de afgelopen jaren zoveel inspiratie, vriendschap, steun, collegialiteit, deskundigheid en (soms noodgedwongen) humor heb mogen ontdekken op dit pad. Een welgemeende dankjewel aan iedereen die op zijn/haar unieke wijze heeft bijgedragen!

Om te beginnen dank ik graag mijn (co-)promotorenteam, want dit boekje is toch ook van hun: Madelon, als promotor gaf je me de kans om te promoveren op een erg interessant en innovatief project. Ik ben er erg dankbaar voor dat je me jouw kindje - het optimisme project - volledig toevertrouwde. Je hielp me knopen doorhakken waar nodig, maar liet me vrij als je zag dat het goed was. Je was altijd (lees: in het weekend, in de avonduren, in Frankrijk en zelfs in de verhuiswagen) bereikbaar en bereid om me bij te staan met raad en daad. Dat - en jouw verregaande optimisme uiteraard - brachten voor mij veel rust en vertrouwen in dit project. Madelon, je bent een bescheiden, maar groot onderzoeker en ik vind het een voorrecht zoveel van jou te hebben mogen leren in de afgelopen jaren. Daarnaast heb ik ook jouw persoonlijke betrokkenheid steeds als bijzonder aangenaam ervaren. Er zijn veel promotoren, maar er is slecht 1 Madelon... dankjewel!

Linda, niet kort na de start van mijn project werd jij - aanvankelijk vooral vanuit inhoudelijke overwegingen - mijn co-promotor. Ik vond het heel interessant om samen nieuwe studies op te zetten en hierbij te leren van jouw expertise in informatieverwerking. Gaandeweg heb jij je ontpopt tot manusje-van-alles in mijn promotietraject en het was geruststellend te weten dat jouw deur steeds wagenwijd open stond voor vragen van allerlei aard. De manier waarop jij aan de kar van dit project alsook van de BM-groep trok/trekt, vind ik bewonderenswaardig. Daarnaast ben ik ook erg dankbaar te mogen leren van jouw doortastendheid en nauwgezetheid in het uitvoeren van wetenschappelijk onderzoek. Voor alle steun en inspiratie... dankjewel Linda!

Ik prees mezelf gelukkig met de tandem Peters-Vancleef, die mijn manuscripten steeds razendsnel van feedback voorzag met een interbeoordelaarsbetrouwbaarheid waarvan Krippendorff onder de indruk zou zijn (-). Bedankt voor jullie harde werk, jullie eeuwige geloof in mij, de kansen die jullie blijven creëren, de inspirerende brainstormsessies en de gezelligheid!

Graag wil ik mijn dank uitdrukken aan de onderzoekers die me inspireerden om een duik te nemen in het wetenschappelijke bad en die ervoor zorgden dat ik na wat gespartel steeds boven water kwam:

Johan, ik had het geluk om als Master student bij een deskundige pijnonderzoeker als jou terecht te komen. In de loop van mijn onderzoeksstage raakte ik steeds meer gebeten door wetenschappelijk onderzoek. Jouw aandeel hierin schat ik hoog in en mijn omaatjes - nog steeds onder de indruk van jouw afstudeerpraatje voor mij - zijn het daar ongetwijfeld volmondig mee eens. Dankjewel voor de intrigerende introductie in het onderzoek en voor de (buiten)kans om onderzoekservaring op te doen in Maastricht en Montreal. Hierdoor ging er letterlijk en figuurlijk een nieuwe wereld voor me open. Ik ben blij dat je - zowel persoonlijk als wetenschappelijk betrokken bleef bij mijn promotietraject. Dankjewel voor dit alles Johan! 
Michael and Heather, thank you very much for welcoming me in the research lab in Montreal. I learned a lot from this special experience and I will always be very grateful for this opportunity. Stephen, I lively remember being very impressed after our brainstorm session about the design of my Master project and I thank you for this moment and for all of the following warm encounters. Geert, jouw expertise in de motivationele context van pijn en jouw voorliefde voor analytisch denken blijven me uitdagen. Dankjewel voor de prettige samenwerking. Robert, thank you for inspiring me with your work and for the shared efforts to bridge the gap between passion research and the motivational context of pain. Andrea, bedankt voor de interessante brainstormsessies en voor jouw bijdrage in mijn poging om mijn wetenschappelijke ambities te kunnen waarmaken. Dankjewel ook aan alle onderzoekers vanuit Leuven en Gent (in het bijzonder Tine, Liesbet, Emelien en Ann) voor fijne samenwerkingen, vruchtbare overlegmomenten of leuke gesprekken.

Een welgemeende dankjewel aan alle BM'ers voor de tweewekelijkse bron van inspiratie in de vorm van een mix aan unieke onderzoeksonderwerpen en unieke onderzoekers! Een portie 'happy clapping' voor positivo's zoals Elke, Yvo, Jantine en Hugo die niet enkel met hun onderzoek, maar ook via interessante gesprekken hun indruk nalieten op hoe ik denk over onderzoek (en... vooruit dan maar... het leven). Bedankt aan alle CPS'ers om van CPS een club te maken die gonst van creativiteit, ambitie en collegialiteit. Bijzondere dank aan Peter voor alle geboden kansen en voor zijn hart voor deze mooie club.

Bedankt aan alle leden van de beoordelingscommissie van mijn proefschrift en alle coronaleden voor hun onmisbare bijdrage aan mijn promotie.

Dank aan alle participanten en de vele studenten die aan de studies meewerkten. Fab and Inge, special thanks to you for your intrinsic motivation and for the pleasant cooperation.

Omdat niet enkel wetenschappelijke, maar ook praktische ondersteuning onontbeerlijk is voor een promotietraject, dank ik Angela (voor alle eerste hulp bij administratief geklungel en voor de gezelligheid), Lindy (voor de eeuwige glimlach bij de meest onmogelijke vragen), Michiel en Charlie (voor programmeerwerk en amusante besprekingen), Astrid en Sita (voor het nauwgezette codeerwerk en alle ondersteuning), de Annies, Emmy, Truus, Marionne, Chantal, Rosanne, Ruud, de mannen van de technische ondersteuning en de ICT'ers, Ermo, Rense en iedereen die een onmisbare bijdrage levert aan een prettige samenwerking op de universiteit. Ook een welgemeende dankjewel aan Natalja, Pauline, Cor en Marisol, die me veel geleerd hebben over het onderwijs en over hoe je met ver doorgedreven idealisme overal een feestje van kan maken (:)!

Omdat je een aanzienlijk deel van je tijd doorbrengt op je werk en ik daar bijzonder veel persoonlijke interesse, collegialiteit en vriendschap heb mogen ervaren, dank ik:

Mijn lieve paranimfen, dankjewel om letterlijk achter me te willen staan op de promotiedag, zoals jullie dat figuurlijk ook hebben gedaan tijdens het promotietraject. Bammie (aka Lotte Bamelis), een idealer eerste kamergenootje kon ik me niet wensen. Zorgzaam en attent ben je als geen een en ik mis je nog steeds als Gangela op de 4de. Dankjewel voor jouw betrokkenheid, voor de eer jouw paranimf te mogen zijn en voor jouw geweldige en blijvend verrassende gevoel voor humor. Lemmie (aka Lotte Lemmens), wat is het zalig om gelijkgestemde 
zieltjes te ontdekken en zeker op een zonnige zaterdag op UNS40. Ik heb genoten van de sociale nerd (snerd) schrijfsessies op de uni of in een bungalowtje in het bos. Een betere steun in de afrondingsfase kan ik me niet voorstellen. Dankjewel voor de perfecte mix tussen productiviteit, warme betrokkenheid en gezelligheid.

Hanne, een heel speciaal woordje van dank voor jou. Weinig mensen kennen me zo goed als jij en hebben zo'n mooie bijdrage geleverd aan mijn manier van in het leven staan. Dankjewel hiervoor en voor alle 'sprankeltjes' voor, tijdens en na mijn promotietijd! Pim, over jou als collega kan ik kort zijn: 'pure gold' (behalve tijdens het WK dan ;))! Dankjewel voor jouw oprechte betrokkenheid! Andreaatje, wat heb ik ervan genoten jou beter te leren kennen in de aanloop naar jouw promotie. Ik kijk op naar jouw manier van werken en ben erg blij met een lieve collega als jij. Wiki-Ken, voor alle leuke, interessante en grappige momenten: dankjewel! Saskia en Rilana, bedankt voor gezellige en af en toe hilarische tijden. Zutphie en Lorraine, bedankt voor alle gezellige lunchkes en babbeltjes! Jullie zijn topcollega's. Martinique, heaven didn't seem far from Vancouver Island, right? :) Dankjewel voor gedeelde avonturen en inzichten! Marlies, ik heb respect voor jouw deskundigheid die je netjes onder een laagje bescheidenheid weet te verstoppen. Dank voor alle collegialiteit en kunstig advies. Nicolette, je bent een zalig kamergenootje: dankjewel. Aan alle (ex-)collegaatjes van de eerste verdieping, dankjewel voor de supergezellige tijden! Ik ben erg blij nog steeds in contact te zijn met sommigen onder jullie. Dankjewel Johanna, voor de vriendschap en voor mijn steun en toeverlaat in de afrondingsfase: jouw mooie boekje! Dankjewel Sjoert, voor jouw volharding in warme betrokkenheid. Dankjewel Ellintje, voor het delen van lief en lied als kamergenootjes. Dankjewel Jan, voor de eerder zeldzame maar leuke zonnige lunchkes! Aan alle lieve en leuke collega's van de vierde, dankjewel voor de gezelligheid, zoete honing, straffe verhalen, het delen van weekendwerk en onderwijsperikelen, (nicotinevrije) sigi-breakjes en zoveel meer.

Graag dank ik iedereen die aan de zijlijn stond te supporteren en er mede voor zorgde dat ik steeds over voldoende energie en eigen optimisme beschikte om me in het project te blijven smijten:

Riet, hoe bijzonder om al sinds de kleuterklas vriendinnetjes te zijn. We zijn zelf gelukkig gestopt met groeien (+- 1.80 is wel genoeg), maar dat geldt voor onze vriendschap absoluut niet. Ik ben trots dat ik tijdens dit traject meter mocht worden van jullie geweldige dochter Fenna. Dankjewel dat ik tijdens de vrije momenten steeds even welkom was bij jullie drietjes. Anne, ook wij zijn al heel wat jaartjes vriendinnetjes van elkaar! Het is zalig dat ik zoveel mooie Anne(Manu) momenten van zo dichtbij mocht meemaken. Dankjewel voor alle gezelligheid. Lieve en Mietie, wat zijn jullie mooie mensjes! Dankjewel voor jullie bijzondere vriendschap en de onvoorwaardelijke steun, de deugddoende herkenbaarheid, Lieve, en de - soms kordate - heerlijke eerlijkheid, juf Miet. Talia, dankjewel voor mooie en leerrijke momenten in Canada, Melkvoet- en Jongmansstraat. Annemarie, mijn allereerste onderzoeksmaatje, dank voor de warme samenwerking en voor jouw goede voorbeeld als wereldreizigster. It was exactly what i needed to get this party started ;)! Kas and Adam, I never knew the words 'loft style appartment, climbing wall, sound proof booth, good people' would lead to finding a home in Montreal. That was special: thank 
you! An, mijn welgemeende dank voor de oase van rust, warmte en inzicht temidden van de occasionele chaos. Dankjewel aan de '(single) ladies'voor de vele gezellige avondjes, feestjes, gesprekken en tripjes! Aan de vrienden die eindeloos luisterden naar 'nee, ik heb geen tijd' en 'nog 4 maanden' (;), dankjewel voor jullie geduld, jullie interesse en de vele leuke momenten in Hasselt. Dankjewel aan enkele bijzondere fans vanuit Godsheide :-)! Bedankt ook aan mijn vrienden van de muziek (in het bijzonder het Blue Monday combo) voor de wekelijkse verstrooiing. Voor de wekelijke big smile op mijn gezicht, bedankt Samina en lieve flamencas. Els, een extra dikke merci voor jouw grenzeloze geduld en deskundigheid bij het werken aan mijn cover. Wat was ik blij met je. Dankjewel ook voor jouw mooie bijdrage hieraan, Eric.

Tenslotte ben ik aanbeland bij een groepje mensen die in de afgelopen jaren enorm met me hebben meegeleefd en die nu ook erg trots zijn dat ik dit proefschrift heb afgerond, namelijk mijn lieve familie:

Mama en papa, ik ben erg dankbaar voor het feit dat we thuis altijd alle kansen hebben gekregen. Jullie hebben ons altijd gesteund in al onze ondernemingen (of toch de meeste;) en nog steeds staan jullie altijd klaar met raad en daad, verse maaltijden, vervangwagens, attente berichtjes/mailtjes,... Geen moeite is ooit teveel! Ik besef steeds meer dat dit eigenlijk heel bijzonder is. Ik heb van jullie geleerd dat je afmaakt waar je aan begint, dus bij deze (-)! Dankjewel voor alle interessante levenslessen, het inspirerende academische voorbeeld, jullie onvoorwaardelijke liefde en jullie grenzeloze steun tijdens deze uitdaging.

Aan mijn zus en broer, dankjewel dat ik de nerd mocht zijn van de club (-)! Evi, ik ben trots op de manier waarop je je latere educatieve aspiraties zo mooi combineert met een gezin. Het is bijzonder dat je daarnaast - samen met Frank - nog steeds altijd voor iedereen klaar staat. Dankjewel dat ik meter mocht worden van jullie zalige kapoen Juul,'tante' van lieve Neal en voor jullie grote betrokkenheid! Jan, ik ben blij met een lieve broer als jij en ik ben je dankbaar voor de leuke familiemomenten. Casper is een zalig kereltje en ik geniet ervan zijn tante te zijn en oneindig UNO met hem te mogen spelen. Ook aan jullie drietjes dank voor alle steun!

Mammie en Tanteke, woorden schieten me te kort om uit te drukken hoe trots ik op jullie ben! Dankjewel voor jullie inspirerende voorbeeld en voor jullie grenzeloze liefde! Bompa, bedankt voor de mooie herinneringen! Moeke, dankjewel voor de onlosmakelijke speciale band!

Neal, Casper, Juul en Fenna, dankjewel voor jullie zalig ongecompliceerde en ontwapenende aanwezigheid in mijn leven! 
Curriculum Vitae 

Marjolein Marie-Paule Hanssen was born on May 4th, 1979 in Genk, Belgium. In 1997, she graduated from secondary school at Sint-Jozefsinstituut, Genk, Belgium. In 2001, she obtained a bachelor degree in Social Readaptation Sciences at HIRL Institute for Higher Education, Leuven, Belgium. In 2002, she finished a Post-Graduate Creative Therapy at PHL University College, Hasselt, Belgium. After this, she went to Maastricht University to obtain her Bachelor and Master Degree Mental Health at the Faculty of Health, Medicine and Life Sciences in 2007. In 2007 and 2008, she worked as a research assistant of Prof. Dr. Johannes W. S. Vlaeyen at the Department of Clinical Psychological Science at Maastricht University. During this appointment as a research assistant, she stayed at the research lab of Prof. Dr. Michael J. L. Sullivan for a period of 5 months to study the social context of pain. From 2008 until 2014, she worked on her PhD dissertation at the Department of Clinical Psychological Science at Maastricht University in the project group of Prof. Dr. Madelon L. Peters. Marjolein conducted her doctoral research as a member of the school for Experimental Psychopathology (EPP). At the end of 2012 and beginning of 2013, she worked as a lecturer at the Faculty of Health, Medicine and Life Sciences, Maastricht University. Since September 2013, she works as a lecturer and researcher at the Faculty of Psychology and Neuroscience of Maastricht University. 


\section{PeER ReVIEWEd PUblications}

Hanssen, M. M., Peters, M. L., Vlaeyen, J. W. S., Hayes, A. F., Schouten, E. \& Vancleef, L. M. G. (in press). Optimism, motivational coping and well-being: Evidence supporting the importance of flexible goal adjustment. Journal of Happiness Studies.

Hanssen, M. M., Vancleef, L. M. G., Vlaeyen, J. W. S. \& Peters, M. L. (2014). More optimism, less pain! The influence of generalized and pain-specific expectations on experienced cold-pressor pain. Journal of Behavioral Medicine, 37(1), 47-58.

Hanssen, M. M., Peters, M. L, Vlaeyen, J. W. S, Meevissen, Y. \& Vancleef, L. M. G. (2013). Optimism lowers pain: evidence of the causal status and underlying mechanism(s). Pain, 154(1), 53-58.

Peters, M. L., Meevissen, Y. M. C. \& Hanssen, M. M. (2013). Specificity of the Best Possible Self intervention for increasing optimism: Comparison with a gratitude intervention. Terapia Psicologica, 31(1), 93-100.

Hanssen, M. M. \& Peters, M. L. (2009). Is optimisme gezond en pessimisme ongezond? Over de uniek voorspellende waarde van de Levensoriëntatietest ten aanzien van stressgerelateerde klachten. Psychologie en gezondheid, 37(5), 298-307.

Vlaeyen, J. W., Hanssen, M., Goubert, L., Vervoort, T., Peters, M., van Breukelen, G., Sullivan, M. J. \& Morley, S. (2009). Threat of pain influences social context effects on verbal pain report and facial expression. Behaviour Research and Therapy, 47(9), 774-782.

\section{OTHER PUBLICATIONS}

Vancleef, L. M. G., Hanssen, M. M. \& Peters, M. L. (2011). S409 Examining implicit interpretation bias in relation with pain-related anxiety and pain responsiveness. European Journal of Pain, 5(1), S254.

Hanssen, M. M. (2011). Dispositional optimism predicts placebo analgesia. Referaat Nederlands Tijdschrift Pijnbestrijding, 30(46), 30-31.

Hanssen, M. M., Vancleef, L. M. G. \& Peters, M. L. (2009). 951 Dispositional optimism protects against a negative health-threatening interpretation bias. European Journal of Pain, 13, S268.

Vancleef, L. M. G., Hanssen, M. M. \& Peters, M. L. (2009). 964 Pain-directed interpretation bias in function of pain anxiety. European Journal of Pain, 13, S272. 


\section{SUBMITTED MANUSCRIPTS}

Hanssen, M. M., Peters, M. L. \& Vancleef, L. M. G. (submitted). What does it mean to be an optimist in an ambiguous world? Investigating negative versus positive interpretation patterns of optimists.

Vancleef, L. M. G., Hanssen, M. M. \& Peters, M. L. (submitted). Are individual levels of pain anxiety related to negative interpretation bias? An examination using an ambiguous word priming task.

\section{Presentations}

Hanssen, M. M., Vancleef, L. M. G. \& Peters, M. L. (2014). Dispositional optimism and well-being despite pain: A motivational perspective. Poster presentation at Fifteenth World Congress on pain of the International Association for the Study of Pain; 2014 oct 6-11; Buenos Aires, Argentina.

Hanssen, M. M., Vancleef, L. M. G. \& Peters, M. L. (2014). Optimism as a resiliency for chronic pain: cognitive-behavioural and motivational pathways of resilience. Oral presentation at Colloquium Department of Clinical Psychological Science, Utrecht University; 2014 jun 12, Utrecht, The Netherlands.

Hanssen, M. M., Vancleef, L. M. G. \& Peters, M. L. (2013). Investigating positive versus negative interpretation patterns of optimists. Poster presentation at: IPPA 2013. Third world congress on positive psychology of the International Positive Psychology Association; 2013 jun 27-30; Los Angeles, CA, USA.

Hanssen, M. M., Peters, M. L. G. \& Vancleef, L. M. (2012). Optimism as a resiliency for chronic pain: A motivational perspective. Oral presentation at International Pain Meeting; 2012 oct 10-12; Philips-Universität, Marburg, Germany.

Hanssen, M. M., Peters, M. L., Vlaeyen, J.W.S., Meevissen, Y. \& Vancleef, L. M. (2012). Optimism lowers pain: Evidence for the causal status and underlying mechanism(s). Poster presented at: IASP 2012. Forteenth World Congress on pain of the International Association for the Study of Pain; 2012 aug 27-31; Milan, Italy.

Hanssen, M. M., Peters, M. L., Vlaeyen, J. W. S., Schouten, E. \& Vancleef, L. M. G. (2011). Goaldirected coping as a mediator between optimism and well-being. Poster presented at: IPPA 2011. Second world congress on positive psychology of the International Positive Psychology Association; 2011 jul 23-26; Philadelphia, PA, USA. 
Hanssen, M. M., Peters, M. L., Vlaeyen, J. W. S. \& Vancleef, L. M. (2011). Optimism as a resiliency for chronic pain: Cognitive and behavioral pathways of resilience. Oral presentation at symposium in the context of the Francqui Chair 2010-2011 awarded to Prof. Dr. Geert Crombez; 2011 may 13; Leuven, Belgium.

Hanssen, M. M., Peters, M. L., Vancleef, L. M. \& Vlaeyen (2010). The influence of general and specific expectancies towards pain. Poster presented at: IASP 2010. Thirteenth World congress on pain of the International Association for the Study of Pain; 2010 sep 2-5; Montreal, Québec, Canada.

Hanssen, M. M., Meevissen, Y. \& Peters, M. L. (2009). Superior predictive value of the Life Orientation Test in comparison to other positive psychological constructs. Poster presented at: IPPA 2009. First world congress on positive psychology of the International Positive Psychology Association; 2009 jun 18-21; Philadelphia, PA, USA.

Hanssen, M. M., Vancleef, L. M. G. \& Peters, M. (2009). Dispositional optimism protects against a negative health-threatening interpretation bias. Poster presented at: EFIC 2009. Sixth congress of the European Federation of the International Association for the Study of Pain; 2009 sep 9-12; Lisbon, Portugal. 